\title{
Forager Mobility in Constructed Environments
}

\author{
by Randall Haas and Steven L. Kuhn
}

Online enhancements: data file

\begin{abstract}
As obligate tool users, humans habitually reconfigure resource distributions on landscapes. Such resource restructuring would have played a nontrivial role in shaping hunter-gatherer mobility decisions and emergent land-use patterns. This paper presents a model of hunter-gatherer mobility in which the habitual deposition of material resources at places on landscapes biases the future mobility decisions of energy-optimizing foragers. Thus foragers effectively construct the environments to which they adapt. With the aid of an agent-based model, this simple niche-construction model is used to deduce four predictions for emergent structure in hunter-gatherer settlement patterns. The predictions are tested against archaeological data from a hunter-gatherer settlement system in the Lake Titicaca Basin, Peru, 7,000-5,000 cal BP. Good agreement is found between the predicted and empirical patterns, demonstrating the model's efficacy and suggesting a behavioral explanation for structural properties of hunter-gatherer settlement systems. The nicheconstruction behavior and its self-organized properties may have been key components in the emergence of socioeconomic complexity in human societies.
\end{abstract}

Places. . . are as much a part of us as we are part of them, and senses of place-yours, mine, and everyone else's-partake complexly of both. (Basso 1996:xiv)

We shape our tools and thereafter they shape us. (Culkin 1967:70, summarizing the work of Marshall McLuhan)

Human mobility ranging from immobility to hypermobility is fundamental to the human experience. Mobility affects individual health, resource access, and social interaction across a continuum of spatial, temporal, demographic, and cultural scales (Kuhn, Raichlen, and Clark 2016; Salazar and Smart 2011). As important and pervasive a theme as it has become, studies of prehistoric mobility have a seemingly paradoxical element. Archaeologists cannot observe movement per se. Rather, they make inferences about mobility based on the spatial locations of materials that people carried and discarded, intentionally or unintentionally. Conclusions about movement are therefore typically grounded in more or less static distributions of debris on contemporary landscapes. This paper is specifically concerned with the decisions that mobile foragers, or hunter-gatherers, make about where to move on landscapes and how we can broadly recognize such mobility decisions in fragmentary records of cultural materials that were deposited by humans as they moved across ancient landscapes.

Randall Haas is an Assistant Professor in the Department of Anthropology at the University of California, Davis (1 Shields Avenue, Davis, California 95616, USA [wrhaas@ucdavis.edu]). Steven L. Kuhn is a Professor in the School of Anthropology at the University of Arizona (Building 30, Tucson, Arizona 85721, USA). This paper was submitted 22 V 17, accepted 27 IV 18, and electronically published 19 VII 19.
Anthropological studies of forager mobility based on archaeological and ethnographic information have largely emphasized external drivers of mobility decisions. They have shown that natural resource structure accounts for many dimensions of forager mobility and land-use patterns. Environmental proxies such as biomass productivity, precipitation, temperature, and latitude are demonstrably successful in predicting population size, residential move frequency, residential move distances, territory size, group size, and technology across broad environmental gradients (e.g., Binford 1990, 2001; Elston, Zeanah, and Codding 2014; Grove 2009, 2010; Hamilton et al. 2007; Jochim 1976; Kelly 2013; Kelly et al. 2013; Morgan 2009a; E. A. Smith 1981; Thomas 1972, 1973; Zeanah 2002, 2004). The patch choice model offers a particularly elegant example (Bettinger, Garvey, and Tushingham 2015; Bird and O'Connell 2006; Kelly 2013). It posits that individuals tend to exploit the most calorically productive resource patch until return rates drop below that of the next most productive patch (accounting for travel between patches), at which time individuals should move. Another related example is the ideal free distribution model, which generally posits that human populations will occupy the richest ecological territories first and iteratively fill less desirable territories as populations grow (Winterhalder et al. 2010).

Despite their explanatory successes, environmentally based models of human movement are incomplete predictors of the archaeological record. In particular, the sizes, locations, and occupation spans of archaeological sites often exhibit much greater variation within environmental contexts than conventional models might lead us to expect. Previous studies show that hunter-gatherer settlement size is extremely variable. Hamilton et al.'s (2007) review of 339 ethnographic hunter-gatherer groups 
observes group-size variation over six orders of magnitude. Haas et al. (2015) similarly observed extreme site size variation in the settlement systems of prehistoric hunter-gatherers in the New World. They showed that such variation is consistent with power law statistical structure, wherein the largest sites are extremely large but extremely rare and the smallest sites extremely common. Although localized natural resources such as springs, rockshelters, or raw material localities likely account for at least some of the largest settlements, there are often scalar mismatches between settlement size and resource availability. Seemingly identical environments can exhibit wildly different occupational intensities.

A number of empirical observations on large, open-air hunter-gatherer sites support this general pattern. Among ubiquitous small sites are rare sites exhibiting extreme occupation intensity. Hunter-gatherers occupied the coastal site of La Paloma for more than 3 millennia from 7,800 to 4,700 cal BP (Benfer 1999). The highlands site of Asana was occupied for more than 7 millennia from 10,500 to 3,500 cal BP (Aldenderfer 1998). North American hunter-gatherers also appear to have reoccupied open-air sites over long time spans. The Tenderfoot site in the Gunnison Basin of Colorado was reoccupied many times, with feature dates spanning more than 7 millennia from 8,600 to $1,400 \mathrm{cal}$ BP (Stiger 2001:157). The Paleo-Indian site of Hell Gap was used for at least 3,000 years between 11,000 and 8,000 years ago (Larson, Kornfeld, and Frison 2009). Artifact distribution and site size analyses of Paleo-Indian sites in the Rocky Mountains and Great Plains suggest long-term reoccupation of some open-air sites (Andrews, LaBelle, and Seebach 2008; LaBelle 2010). In the US southeast, the Poverty Point site was used for at least 3 millennia from approximately 6,000 to $3,000 \mathrm{cal} \mathrm{BP}$ (Ortmann 2010). The nearby Watson Brake site was used for at least 500 years from 5,500 to $5,000 \mathrm{cal} \mathrm{BP}$ (Saunders et al. 1997, 2005). In southern Africa, evidence suggests that the hunter-gatherer site of Likoaeng was in use for more than 2 millennia from 3,300 to $1,200 \mathrm{cal}$ BP (Mitchell et al. 2011). Archaeologists can usually point to natural resources that drew occupants to the general area, but rarely is it possible to explain why some particular location within broader environmental constraints was intensively used while seemingly identical locations nearby were virtually ignored.

An array of systemic and postdepositional processes - including group size, occupation span, erosion and burial, collection bias, looting, and localized resource patches - are often evoked to account for such variation (Grøn 2012; Schiffer 1987). Yet such interpretations are often post hoc and thus offer limited predictive power. One potential response would be to construct extremely complicated models of site formation that integrate the wide array of endogenous and exogenous variables that conceivably affect site formation with the hope of arriving at a satisfactory level of predictive utility. Alternatively, we might concede that many of the social and environmental contingencies that go into settlement location and occupation intensity are largely beyond archaeological detection and satisfactory explanation. This paper examines a possibility between those extremes by modeling the structure of variation among forager site sizes within a given environmental context. While we do not attempt to explain the size of any particular archaeological site, we attempt to explain the distribution of site sizes within a given hunter-gatherer settlement system within a given environment. What we will show is that forager site size variation can be surprisingly structured and entails mobility decisions with preferential attachment to culturally constructed places on landscapes.

We begin with the premise that knowing a prehistoric forager's motivation for initially occupying a novel point within some environmental context is partially, if not wholly, unknowable. The contingencies that go into specific site selection may be quite complicated, historically contingent, and ephemeral. Nonetheless, subsequent site selection may be relatively predictable if we consider that foragers tend to reoccupy previously occupied locations. John Yellen (1977) observed that !Kung logistic-foraging groups habitually reused previous camps to take advantage of existing brush structures. Similar observations have been made among Australian foragers (Tindale 1972; Wandsnider 1992). A more explicit treatment of this type of site reoccupation behavior is found in Lewis Binford's Archaeology of Place. Binford (1982) stated that, "aside from certain 'absolute' characteristics of biogeography within the region, there is always a 'cultural geography'" (emphasis in original; 6). The difficulty of defining archaeological site types led Binford to propose that mixed assemblages could be understood as the reuse of places for varied purposes during different times of year. He observed that Nunamiut sites once used as logistical camps could become residential camps at later times, and vice versa (see also Schiffer 1975:260).

Putting such theoretical observations to work may seem problematic for two major reasons. First, cultural geographies tend to be assumed rather than explicitly grounded in higherlevel theory. Binford, for example, does not specify why foragers should reuse previous site locations, though the underlying logic is ostensibly pragmatic reuse of artifacts and features. Second, testing for relationships between human behavior and environmental structure that is created by that very human behavior presents a seemingly circular analytical challenge. More conventional analyses do not suffer from such a problem because forager behavior and natural environments are considered independent phenomena. What is required to put the concept of cultural geographies to work in archaeological research is (1) an explicit theoretical umbrella that makes sense of why mobile foragers should ever reoccupy specific locations on landscapes and (2) a formal model and analytical tools to generate archaeologically testable predictions for mobility in cultural geographies.

\section{A Niche-Construction Model of Forager Mobility}

Anatomically modern humans are obligate tool users. We use the term tool broadly here to include the range of extrasomatic materials that humans modify and rely on to maintain physical 
homeostasis. Implements and constructions of stone, fiber, shell, bone, skin, and earth are used to regulate body temperature, obtain calories, court, parent, and otherwise interact with environments and other individuals. Given the constant requirement of tools, search-and-handling costs involved in obtaining the requisite materials and modifying them into useful objects fundamentally affect human fitness. Individuals who can minimize such costs can put the time savings to work in more direct fitness pursuits. One way that foragers can minimize the costs of tool use is through the organization of mobility (Kuhn 1995). Foragers may make logistical trips for the expressed purpose of obtaining raw materials - a relatively expensive means of procuring materials. Or they may offset acquisition costs by embedding raw material procurement in mobility routines centered on more direct fitness pursuits (Brantingham 2003).

Another mode of material procurement entails the reuse of places where cultural materials were previously deposited. Kuhn (1995) argued that when residential moves are infrequent and occupation durations long, foragers should "provision places" with materials in anticipation of returning to those locations. When residential mobility is high, in contrast, emphasis should be placed on "provisioning people" with transportable and reliable materials. This model assumes an element of planning. To provision places, foragers must know they are likely to return to those places.

Here we consider the possibility that some basic level of site reoccupation ought to occur even in the absence of explicit planning. The habitual use of tools necessarily results in the rearrangement of resources across landscapes. Assuming that at least some of the materials retain utility after use and deposition, the locations of deposition can become de facto resource patches. Subsequent foragers can reduce material search-andhandling costs by recycling those locations and their associated concentrations of abandoned artifacts and features (Barkai, Lemorini, and Vaquero 2015; Camilli and Ebert 1992; Holdaway, Wandsnider, and Rhodes 2008; Schlanger 1992; Wandsnider 1992). In other words, simply by moving, modifying, and depositing materials on landscapes, people actively construct the ecological niches to which they adapt. This basic rationale is consistent with the concept of ecological niche construction, which encourages us to consider not only how exogenous environmental factors influence the adaptive responses of organisms but also how they adapt to the very environments that they themselves create (Broughton, Cannon, and Bartelink 2010; Kendal, Tehrani, and Odling-Smee 2011; Laland and O’Brien 2010).

This notion of site reuse may seem trivial, but as we will show, it generates surprising macroscale structure, with implications for archaeological settlement patterns and emergent complexity in human societies. Such macroscale properties self-organize from recursive mobility patterns. If a brush hut, grinding slab, storage pit, and flaked stone are present at some location within a foraging patch at year one and those features and materials retain some utility, then a future forager exploiting the same ecological patch in subsequent years could gain some benefit by reusing that location. In doing so, the forager is likely to further improve the location by investing additional energy into infrastructure and abandoning more materials with residual utility. These improvements would further enhance the draw of the location, subsidizing additional use of the location, and so on and so forth in recursive fashion. Foragers can thus become locked into using otherwise unexceptional locations on landscapes generating remarkable accumulations of person-hours of occupation and material deposition. Meanwhile, other seemingly equivalent locations may experience little or no occupation.

Such feedback loops in site reuse could be quite persistent as well. Culturally deposited materials may lose utility by natural decay, consumption, or economic obsolescence, but serial deposition of materials or the deposition of relatively durable materials could be expected to continually draw individuals to a specific location as long as those materials remain relevant to the socioeconomic system, which in many cases could extend for hundreds or thousands of years, if the lengths of archaeological periods offer any indication. Accordingly, this conceptual model offers a working hypothesis for why the intrinsic environmental properties of a given location alone may not be able to account for an observed intensity of human occupation. The hypothesis suggests instead that it may be a locality's constructed properties that largely determine occupation intensity and thus artifact density.

Of course, it is logically impossible that all mobility decisions are constrained by the landscape alterations of previous foragers. Initial occupations of locations are necessary. Natural resource opportunities, resource depletion, and competition encourage the abandonment of some locations and occupation of novel locations on landscapes. Historical contingenciessuch as point of entry into a resource patch or encounters with mobile prey - are expected to condition where initial occupations fall. But though the initial occupation may begin as a quirk of history, humans may add to the attraction of the place through subsequent alterations that increase its future attractiveness and elevate its prominence over other seemingly equivalent locations. Thus small differences in the initial conditions of site use and reuse can lead to radically different outcomes in overall occupation intensity of particular places on landscapes.

This working model of forager mobility is nondeterministic in the sense that it does not predict absolute locations or sizes of particular settlements - properties that are instead expected to be highly sensitive to initial conditions (sensu Bentley and Maschner 2008; Brown, Witschey, and Liebovitch 2005; Lansing 2003; Lansing and Downey 2011). The recursive behavior of the model explicitly acknowledges path dependence and shifts emphasis away from absolutes toward structural variation or relational patterns among entities. The model is thus a neutral model (Bell 2001; Hahn and Bentley 2003; Kimura 1985), suggesting that aspects of settlement size variation can be understood as a stochastic process under the fundamental 
behavioral constraints of tool use, mobility, and energetic optimization. The model is conceptually consistent with Binford's (1982) cultural geographies but departs by suggesting an evolutionary underpinning for site reoccupation. It is also theoretically consistent with Kuhn's (1995) provisioning of places model but offers a generalized form that suspends the assumption of planning. The current model considers how three basic behaviors - obligate tool use, mobility, and energy optimizationinteract to give rise to extreme variation in the use of particular places on landscapes. The task at hand, then, is translating this simple conceptual model of forager mobility in constructed environments into archaeologically testable predictions.

\section{Generating Model Predictions}

Some of the test implications for the working model of forager mobility in constructed environments are readily deduced from simple logical arguments as identified by Binford (1982). Multiple occupations and functionally mixed artifact assemblages should be expected. Other expectations may not be so readily apparent given the conceptually intractable nature of recursive processes. The emergent properties of recursive behaviors can be quite surprising and nonintuitive. Nonetheless, the recursive nature of the model can be expected to produce distinct structural properties that may be observable in the archaeological record. Such properties can be deduced with the help of agentbased models (ABM). ABM is a computational method specifically designed to explore how iterated microlevel behaviors give rise to macrolevel structure, or emergent properties (Bankes 2002; Premo 2006).

We present an ABM that operationalizes the conceptual model described in the previous section by predicting quantitative patterns in the spatial distributions of cultural materials deposited by foragers whose mobility decisions are biased toward previously deposited materials. In the $\mathrm{ABM}$, a single virtual forager initially occupies a random location on a pristine landscape (fig. 1). At each time step, the forager ( $a$ ) deposits a unit of material culture on the landscape and $(b)$ makes a decision about where to reside next. With probability $m$, the forager decides to reside at the position of a previously deposited material. Higher values of $m$ reflect greater probability that a given occupation decision will be determined by the location of a previously deposited material. For example, if $m$ equals 0.95 , there is a $95 \%$ chance at any given time step that the virtual forager will occupy the location of a culturally deposited material.

To keep the model simple, the target material is selected at random from the population of previously deposited materials. This is not to suggest that a forager's material choices are actually random. To the contrary, the use of a random model behavior suggests that an individual's material choice may be so

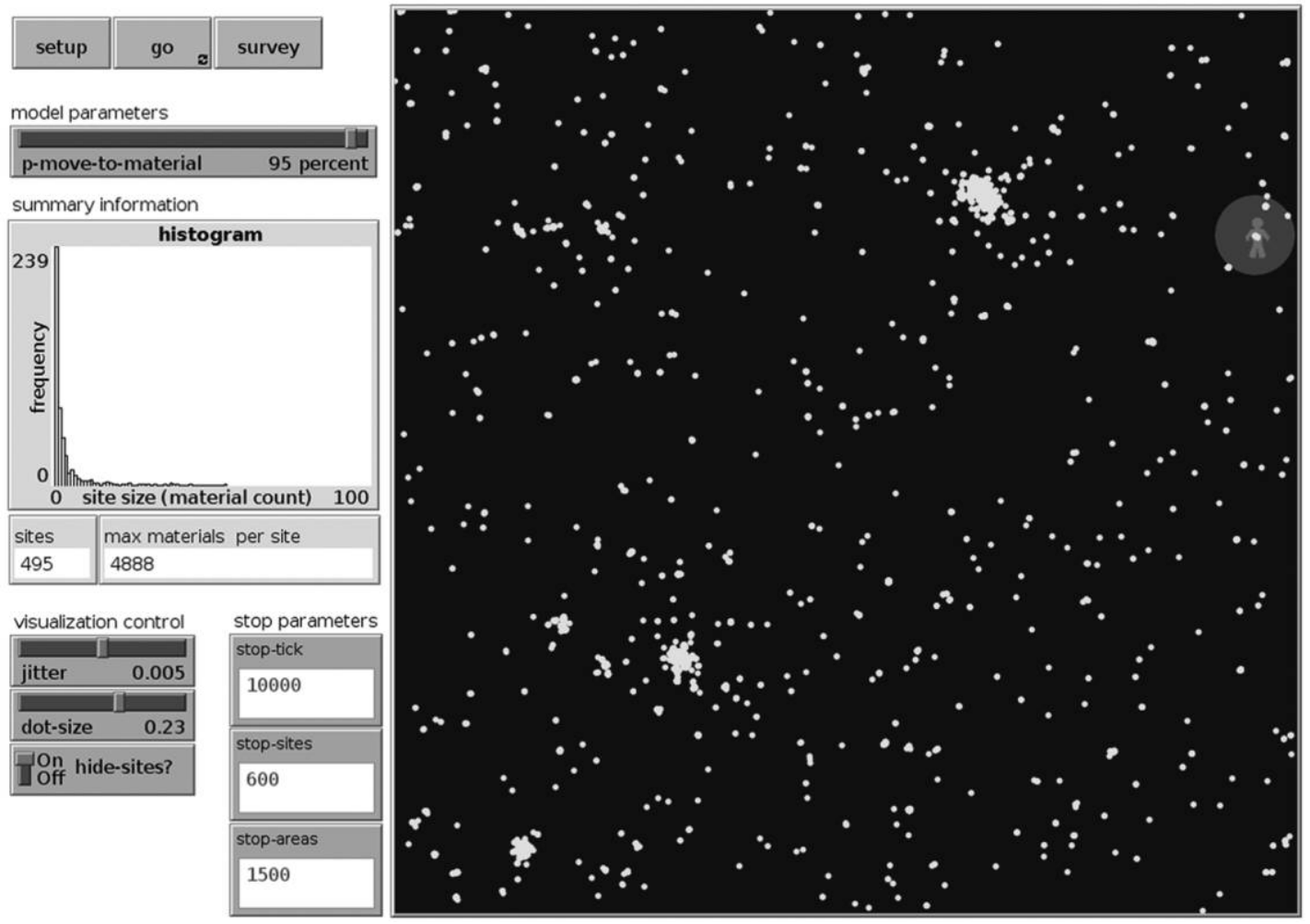

Figure 1. Graphical user interface for agent-based model implementation of the working niche-construction model of forager mobility. Each small yellow circle in the model world (right) represents forager-deposited material. This example shows a model run after the deposition of 495 sites in 10,000 time steps, or ticks. All agent-based models are created using the NetLogo programming language (Wilensky 1999). A color version of this figure is available online. 
complicated and contingent as to be appropriately modeled as a random process. In some instances, the material that the virtual forager selects is at the forager's current residential site, in which case, the forager simply continues to occupy the same location. In other instances, the targeted material is located elsewhere in the model space, requiring a residential move.

The probability that an occupation decision is not determined by the location of a previously deposited material is simply $1-m$. In such instances, the virtual forager moves their residence to a previously unoccupied location on the virtual landscape. For example, if $m=0.95$, then there is a $5 \%$ chance that the virtual forager will occupy a novel location at any given time step. To simulate a single ecological zone and isolate the effects of the niche-construction behavior, exogenous natural resources within an environmental context are assumed to be randomly distributed on the virtual landscape. Again, this is not to suggest that real-world natural resource distributions are necessarily random. Rather, it is assumed that within-patch resource locations, their interception and the foragers' decision to pursue them may be so complicated and contingent as to be appropriately modeled as random.

It is difficult to know a priori what range of biases, $m$, are plausible. We can readily imagine that a forager's bias toward previously deposited cultural materials would depend on a number of factors. In environments where resource availability is limited, foragers could be expected to rely more heavily on previously deposited resources, thus requiring a model with a relatively high value of $m$. In resource-rich environments, we might expect that forager land use is less influenced by previously deposited cultural materials, thus requiring a model with a relatively low value of $m$. We therefore explore a range of $m$ values, including a strong case $(m=0.95)$, a moderate case ( $m=0.50)$, and a weak case $(m=0.05)$ of niche-construction behavior. Higher values indicate a stronger pull to previously deposited materials, while lower values indicate a stronger pull to novel locations.

As virtual materials are deposited on the model landscape, their positions are altered slightly to model the physical reality that materials are unlikely to occupy the exact same horizontal space. The direction of the displacement is drawn at random from a uniform distribution. Following from the ethnoarchaeological findings of Surovell and O'Brien (2016), the distance of artifact displacement follows an inverse distance function, such that the probability of an object being deposited at a given distance from the center of occupation is proportionate to $1 /$ distance. Thus it is extremely common for materials to be deposited near the previously abandoned objects and rare for materials to be deposited at extreme distances. The model world is a torus, so that material displacements that extend beyond the model boundary simply cross into the opposite boundary. This modeling strategy mitigates boundary effects. Time steps, or ticks, are in arbitrary units. Table 1 presents the fundamental elements of the NetLogo (Wilensky 1999) programming code with explanations, and the full code is presented as a supplement to this paper. Figure 2 illustrates spatial outcomes under the three degrees of mobility bias, $m$.

It should be noted that the model's use of a single forager serves to provide interpretive tractability. Additional foragers or forager groups could be included, but such added complexity would produce the same result given the model behaviors. This analysis wishes to hold such complexities aside in order to explore niche-construction behavior without the interpretive ambiguities that can arise with increased model complexity.

In sum, the simple working ABM for forager mobility posits that a forager continually decides where to reside on a virtual landscape, and that decision is biased to varying degrees by the location of previously deposited cultural materials. While the forager moves through the virtual landscape, it deposits cultural materials at a constant rate. The resultant distribution of those materials are then evaluated and used to predict structural properties of occupation intensity distributions.

\section{Archaeological Predictions}

In this section, we use the working niche-construction model of forager mobility and the associated $\mathrm{ABM}$ to deduce four predictions for structural properties of archaeological site occupation intensities. For the ABM, simulations are run until

Table 1. Basic NetLogo (Wilensky 1999) code for the agent-based model used to operationalize the working niche-construction model

\begin{tabular}{|c|c|c|}
\hline Line & NetLogo code & Description \\
\hline 1 & to go & Initiates sequence \\
\hline 2 & ask foragers [ & Calls foragers (in this case, one forager) \\
\hline 3 & ifelse p-move-to-material $>=$ random 101 & $\begin{array}{l}\text { If probability, } m \text {, of moving to a material is greater than or equal to random } \\
\text { number between } 1 \text { and } 100 \text {, execute following }\end{array}$ \\
\hline 4 & [set target [who] of one-of materials & Set target destination to previously deposited randomly selected material \\
\hline 5 & move-to material target] & Move to location of target material \\
\hline 6 & [setxy random-xcor random-ycor] & $\begin{array}{l}\text { Otherwise, if probability of moving to a material is less than random number } \\
\text { generated above, move to random location }\end{array}$ \\
\hline 7 & hatch-materials 1[ & Forager deposits unit of material culture at current location \\
\hline 8 & rt random $360 \mathrm{fd}(1 /$ random-float 1$) *$ jitter] & $\begin{array}{l}\text { Material is moved in random direction to distance that is randomly selected } \\
\text { from inverse distance function scaled by jitter constant }\end{array}$ \\
\hline 9 & end & Ends sequence \\
\hline
\end{tabular}



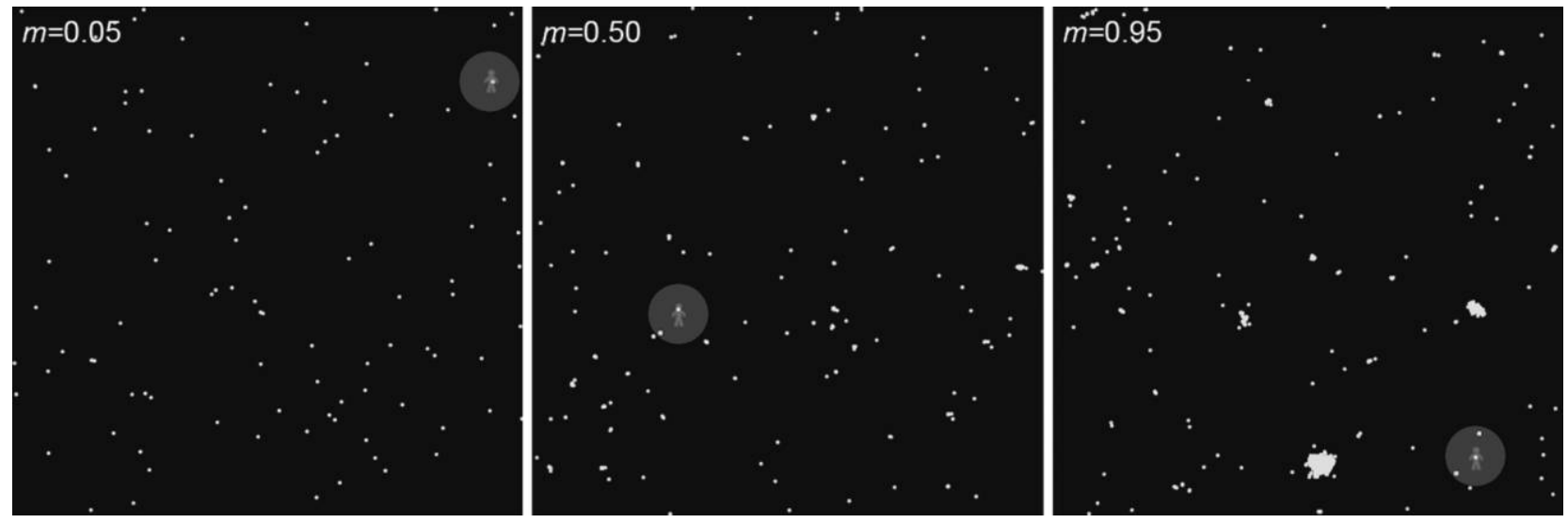

Figure 2. Environment of the agent-based model and the effect of the material culture bias, $m$, on artifact dispersion. Note that higher values of $m$ generate higher degrees of material clustering. A color version of this figure is available online.

1,000 archaeological sites are produced, and this is repeated for each of the three values of $m$. For each simulated archaeological site, material counts, occupation spans, and site areas are recorded as metrics of site occupation intensity. The variations in the simulated archaeological records thus serve as predictions for the variations in archaeological records.

\section{Prediction 1: Artifact-Per-Site Counts Approximate a Power Law Distribution}

The recursive behavior intrinsic to the working nicheconstruction model anticipates a highly skewed distribution of person-hours among sites, such that most sites experience low use, while few sites experience extremely high use. The basic reason for this expectation is that once a site is used early in a simulation, it will tend to attract subsequent use. Meanwhile, foragers continually create new sites in the pursuit of opportunities elsewhere. Newer sites are less likely to experience reoccupation due to the simple fact that they have not had the time to accumulate the material resources that attract reoccupation. Thus the attractiveness of a location is not due to its intrinsic value. The virtual forager is simply selecting artifacts at random from the total pool of artifacts in the system. The attractiveness of a place instead emerges from the low-level decisions of a forager who is optimizing their use of a socionatural landscape.

The generic process just described is well known in statistical physics and goes by terms including preferential attachment, the Matthew effect, the Pareto process, and the rich-get-richer process (Mitzenmacher 2001; Newman 2005). Preferential attachment is known to give rise to highly right-skewed distributions termed power law distributions, in which the smallest observations are most frequent and the largest observations are extremely large and rare. The probability distribution of a power law function takes the form $f(x) \propto x^{-\alpha}$, where $x$ is some variable and $\alpha$ is a scaling parameter. We use the ABM to demonstrate the link between the working niche-construction behavior and power law structure in the distribution of artifacts across geographic space.

Figure 3 illustrates the statistical shape of the expected distribution of artifacts among sites created by foragers moving through constructed environments. Three degrees of material bias $(m=0.95,0.5$, and 0.05$)$ are used to generate quantitative predictions, each producing 1,000 virtual archaeological sites with material counts. Sample sizes of 70 sites are drawn from each simulated settlement pattern to facilitate comparison with the archaeological case study of the same sample size, which will be described below, and this is repeated 1,000 times. Three data visualization techniques are presented - a standard histogram, a histogram of log-transformed values, and a cumulative mass function (CMF) plot with logarithmic axes.

The modeled distributions all share several key features. The standard histograms are highly right skewed (i.e., heavy tailed), the histograms of the log-transformed values are moderately right skewed, and the CMF plots reveal log-linear structure. These qualitative features are commonly used to detect power law structure (Bentley, Hahn, and Shennan 2004; Newman 2005). Accordingly, if the archaeological artifact distributions result from the posited niche-construction behavior, we should expect to observe the same qualitative features in artifact-persite counts.

While such qualitative properties are useful for initial assessment of statistical structure, they are insufficient to confidently identify the presence or absence of power law structure. Small sample sizes, for example, can result in the erroneous identification of plausible power law fits if not checked against more rigorous procedures. We therefore use the methods described by Clauset, Shalizi, and Newman (2009) and Edwards et. al. (2007) to determine whether a power law model is statistically plausible and parsimonious relative to alternative statistical models of comparable simplicity (i.e., those that have few free parameters). The method proceeds as follows: First, we decide on a set of candidate statistical models that could conceivably describe the data. The choice of models follows from 
$\operatorname{ABM}(\mathrm{m}=0.95, \mathrm{n}=70)$
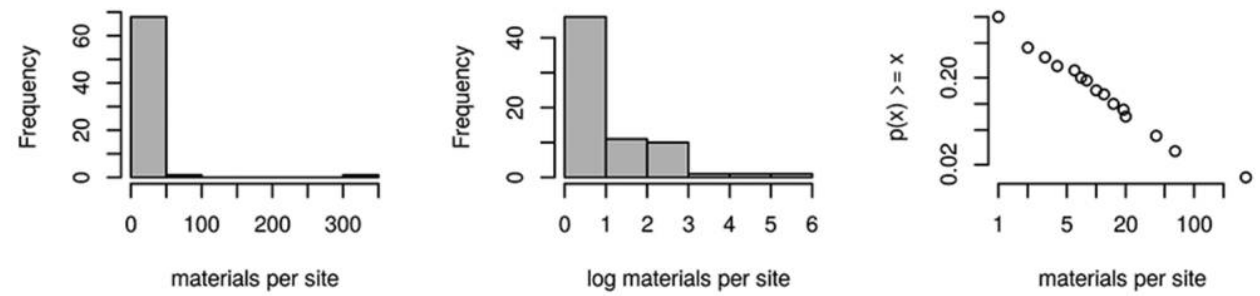

$\operatorname{ABM}(m=0.50, n=70)$
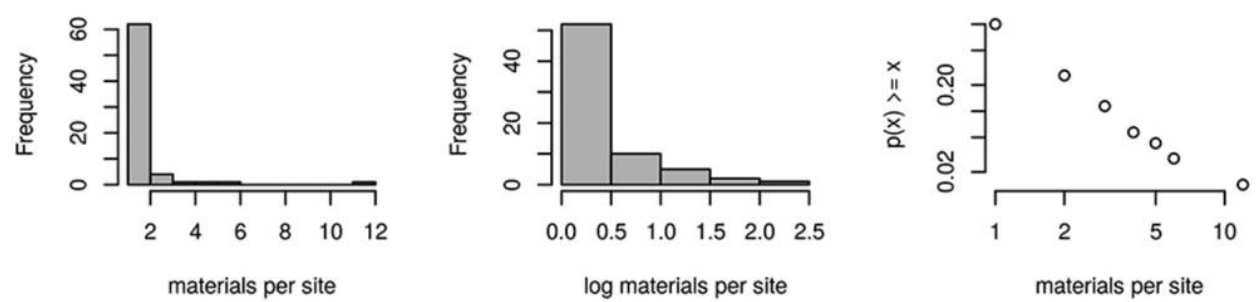

$\operatorname{ABM}(m=0.05, n=70)$
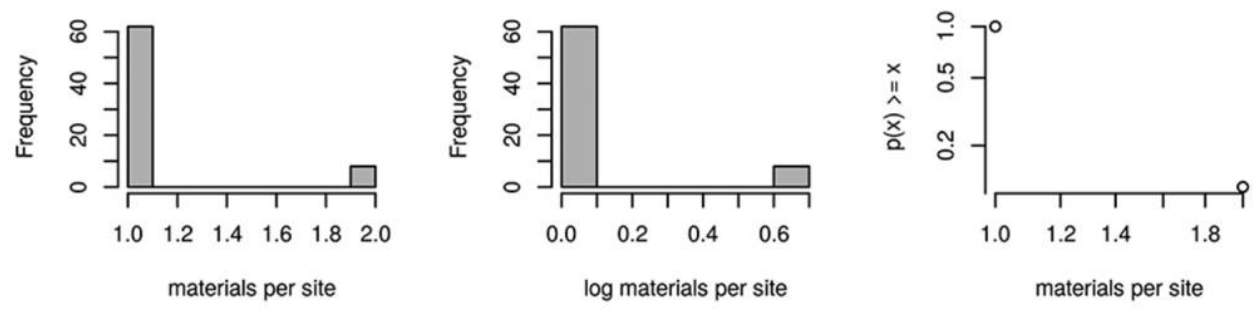

Figure 3. Predicted distributions for material count variation among sites in hunter-gatherer settlement systems. Each column presents a different graphical summary, including a standard histogram (left), histogram of log-transformed data (center), and cumulative mass plot with logarithmic axes (right). Each row represents a different degree of niche-construction bias, $m$. All three cases share the same qualitative properties. The standard histograms are highly right skewed. The histograms of log-transformed data are moderately right skewed. The cumulative mass function plots are approximately log linear. These qualitative properties are all consistent with power law structure. $\mathrm{ABM}=$ agent-based model.

subjective assessment of statistical shape, theoretical reasoning, or the suggestions of previous research. Here we consider Poisson, geometric, and zeta power law models because each pertains to discrete data, and previous research has either explicitly or implicitly suggested that they could characterize variation in human settlement size variation or in phenomena that have similar underlying mechanics (Brown, Liebovitch, and Glendon 2006; Brown and Witschey 2003; Clauset, Shalizi, and Newman 2009; Hahn and Bentley 2003).

Second, we solve for best-fit parameters for each of the candidate models using maximum likelihood estimation (MLE). Third, we determine whether the observed data could have plausibly come from each of the best-fit statistical models. The method of determining statistical plausibility uses KolmogorovSmirnov (KS) D statistic and Monte Carlo simulation of synthetic data sets as described by Clauset, Shalizi, and Newman (2009). A given model is rejected if there is a $10 \%$ chance or less $(p \leq .10)$ of deriving the ABM data from a given best-fit sta- tistical model. Fourth, if two or more models are statistically plausible, we use Akaike information criteria (AIC) weights to decide whether any are more parsimonious than the others. Those that generate high AIC weights $(w>0.10)$ are considered parsimonious relative to the alternatives. Models that generate low AIC weights $(w \leq 0.10)$ are rejected. All calculations were performed in the $\mathrm{R}$ statistical computing language ( $\mathrm{R}$ Core Team 2013), and all code can be found in Haas et al. (2015).

The statistical structure of each of the three sets of ABM results was characterized using the methods just described. For a given case of 1,000 ABM-generated sites, the tests were bootstrapped 1,000 times, each time drawing a sample of 70 sites (the sample size of the archaeological case study below) to explore the range of potential outcomes due to statistical chance. The results indicate that power law models offer plausible and parsimonious fits to the simulated data in the majority of tests for the cases of high $(m=0.95)$ and medium $(m=0.50)$ degrees of niche construction. When $m=0.95,80 \%$ of the results are 
consistent with power law models, $1 \%$ are consistent with Poisson models, none are consistent with geometric models, and $19 \%$ fail to identify a plausible model. When $m=0.50,84 \%$ of the results are consistent with power law structure, $1 \%$ are consistent with Poisson models, none are consistent with geometric models, and $15 \%$ fail to identify a plausible model. When $m=0.05$, none of the statistical models fit the simulated data.

The posited niche-construction behavior therefore predicts that artifact-per-site distributions should be statistically consistent with power law statistical models and inconsistent with Poisson and geometric statistical models when nicheconstruction behavior is moderate or high. In other words, if we find that archaeological site-based artifact counts are consistent with a power law statistical model and more parsimonious than the alternatives, the prediction is supported. Conversely, if we find that Poisson or geometric models are plausible and more parsimonious, then the current prediction is rejected. If a given empirical case is inconsistent with all three statistical models, conclusion is indeterminate.

\section{Prediction 2: Site Size Varies Independently of Localized Natural Resources}

Although localized natural resources such as springs, raw material quarries, and rockshelters certainly attract highoccupation intensity, the niche-construction model explored here adds that we should also expect site size variation holding such environmental variables constant and even in the absence of such localized resources. In other words, we should expect large and small sites in the presence of localized natural resources, and we should expect large and small sites in the absence of localized natural resources. This follows from the premise that within a natural resource patch, hunter-gatherers effectively construct subpatches with site improvements and the deposition of usable materials. Conversely, the null prediction is that larger sites should tend to be associated with localized natural resources, while smaller sites should not be (Jochim 1981:155-159).

\section{Prediction 3: Artifact Quantity Covaries Partially with Occupation Span}

As a result of the feedback behavior posited for the working niche-construction model, foragers are expected to become locked into reusing places on the landscape. Meanwhile, the model posits that new sites are continually created as foragers occupy novel locations to exploit natural resources independently of culturally deposited materials. As a result, the most material-rich sites should always exhibit long occupation spans that approach the full temporal range of a settlement system's existence, while those of small sites should vary widely, such that some small sites exhibit short occupation spans while others exhibit long occupation spans. To be clear, occupation span simply refers to the difference between the first and last occupations. It does not speak to how occupation is distributed within that span - that is, whether the occupation is continuous or discontinuous.

The ABM can be used to illustrate this expectation. The simulation shown in figure 1 , with $m=0.95$, serves as the example. For this test, the model was run until 1,000 sites were deposited. Figure 4 shows occupation spans for each simulated site plotted as a function of material count. As reasoned above, the sites with fewer artifacts - those toward the left side of the plot-tend to exhibit more variation in occupation span than sites with many artifacts, which tend to exhibit longer occupation spans that approach the full duration of the simulation.

An ideal archaeological test of prediction 3 would involve comparison of site occupation spans and artifact counts for many sites in a given settlement system. Such robust archaeological inventories are difficult to muster. However, it may be possible to partially test the prediction by examining the occupation spans of the most artifact-rich sites in a given settlement system. Without ecological inheritance or highly localized natural resources, such as with a fission-fusion model of mobility, there would be little reason for hunter-gatherers to return to a specific location after abandonment. Given the assumption that mobile foragers move at least once per year and often more frequently (Kelly 2013), any such site should represent only a single occupation lasting no more than a year. For sites that are not clearly attached to some localized resource such as a spring or rockshelter, chronometric analysis of archaeological sites should tend to reveal short occupation spans in which the error terms of all chronometric data overlap one another. Conversely, the working model predicts that the occupation spans of rare sites, particularly the most artifact-rich sites, should cover multiple human generations up to the full duration of a settlement

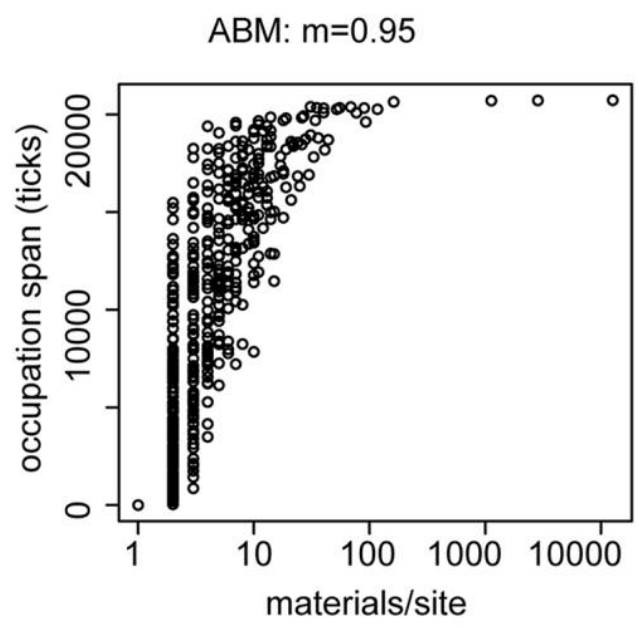

Figure 4. Hypothesized partial relationship between site occupation span and material quantity. Material-rich sites are expected to have long occupation spans that approach the full duration of the settlement system's existence, while material-poor sites have variable occupation spans. The graphic was generated from an agentbased model (ABM) trial that produced 1,000 sites and used a material bias, $m$, of 0.95 . 
system's existence. This pattern could be expected to occur in both exceptional and unexceptional natural resource locations.

\section{Prediction 4: Site Area Variation Follows a Lognormal Distribution}

The working niche-construction model holds implications for site area variation in hunter-gatherer settlement systems as well. Again, the recursive nature of the niche-construction model makes it difficult to use simple logic to predict the expected size distribution. ABM is therefore used to deduce expected structure. Site area distributions are simulated for strong, moderate, and weak values of $m$, using inverse-distance-weighted artifactdisplacement functions. All results reveal qualitatively similar structure. Figure 5 summarizes the simulation results with histograms. The qualitative structure is consistent with lognormal and power law distributions - the standard histogram is highly right skewed, the histogram of log-transformed values is ap- proximately normal, and the cumulative distribution function (CDF) plot with logarithmic axes is generally straight with slight upward convexity.

The more rigorous quantitative methods reveal that lognormal distributions are favored. When $m$ is .95 , lognormal site area distributions are favored in $50 \%$ of the simulated site samples and power law models in $3 \%$. Forty-seven percent of simulations did not produce a plausible fit to any of the statistical models considered. When $m$ is .50 , lognormal site area distributions are favored in 55\% of the simulated site samples and power law models in $4 \%$. Forty-one percent of simulations did not produce a plausible fit to any of the statistical models considered. When $m$ is .05 , none of the statistical models were found to offer plausible fits to the data. Normal and exponential models were never found to offer plausible fits to the data. Accordingly, given the working niche-construction model, we should expect archaeological site area distributions in huntergatherer settlement systems to be consistent with lognormal
ABM $(m=0.95, n=70)$
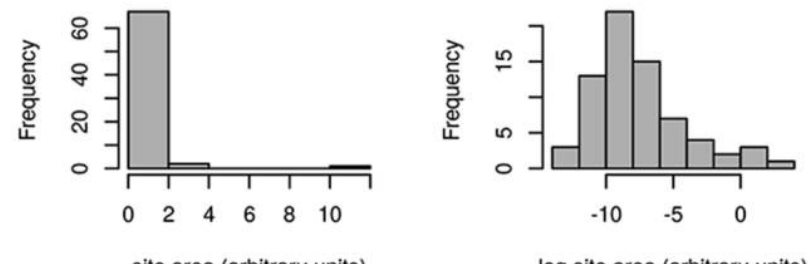

$\log$ site area (arbitrary units)

$\operatorname{ABM}(m=0.50, n=70)$
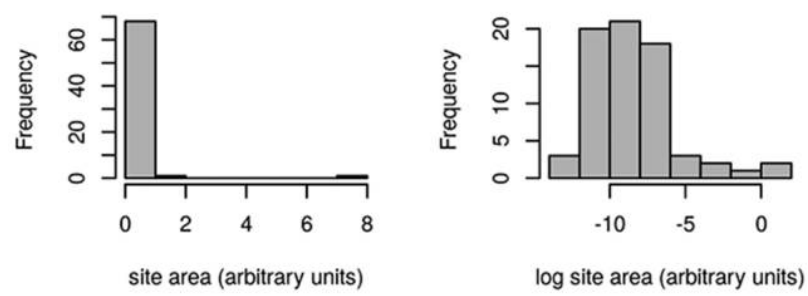

$\operatorname{ABM}(m=0.05, n=70)$

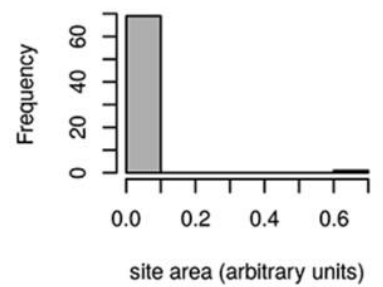

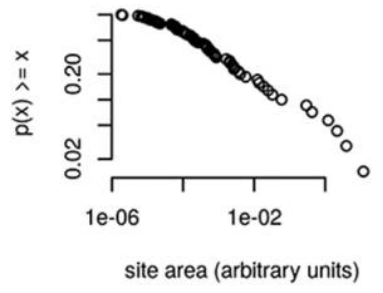
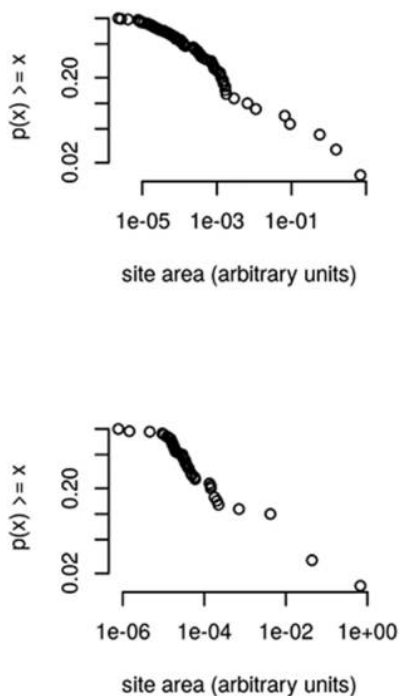

Figure 5. Distributions generated by an agent-based model (ABM) for site area variation in hunter-gatherer settlement systems using an exponential artifact displacement function. Each column presents a different graphical summary, including a standard histogram (left), histogram of log-transformed data (center), and cumulative density function (CDF) plot on logarithmic axes (right). Each row represents different degrees of niche-construction bias, $m$. The standard histograms are highly right skewed. The histograms of logtransformed data are approximately normal with a slight left skew. The CDF plots are upwardly convex. These qualitative features are therefore predicted features of the archaeological site area distributions. 
distributions. If the archaeological distribution is consistent with normal, exponential, or none of the candidate models, then the prediction is rejected.

\section{Case Study: A Late Archaic Period Hunter-Gatherer} Settlement System in the Lake Titicaca Basin, Peru

An ideal case study should (a) occur in a relatively homogeneous resource environment where localized resources cannot readily explain site size variation and $(b)$ offer a degree of temporal control. The Lake Titicaca Basin Late Archaic Period settlement system generally meets these criteria and is used as the test case here. The Late Archaic Period (ca. 7,000-5,000 cal BP) precedes the Terminal Archaic Period (5,000-35,000 cal BP), a period of low-level food production (Bruno 2006; Craig et al. 2010). The Late Archaic subsistence economy is characterized by mobile hunting and gathering based on exploitation of vicuna (Vicugna vicugna), taruca (Hippocamelus antisensis), tubers, and small seeds (Aldenderfer 1998).

Flaked stone technology is the most archaeologically visible cultural material of Titicaca Basin Archaic Period assemblages. The technology emphasizes bifacial projectile points and scrapers. Late Archaic projectile points are distinct in size and form (Klink and Aldenderfer 2005). In the western Titicaca Basin, there are two general forms - a stemmed form (type 4D) and a concave-base form (type $3 \mathrm{~F}$ ) - that were presumably used with spears or atlatl darts. The abundance of flaked stone, groundstone, and faunal remains along with an absence of permanent architecture or ceramics indicates a relatively high degree of residential mobility (Cipolla 2005; Craig 2011; Haas and Viviano Llave 2015; Klink 2005).
The specific archaeological case used here draws on a systematic settlement survey covering $41 \mathrm{~km}^{2}$ in the lower Ilave River drainage centered at $\mathrm{S} 16^{\circ} 13^{\prime}, \mathrm{W} 69^{\circ} 45^{\prime}, 3,860 \mathrm{~m}$ asl (World Geodetic System 1984), west of Lake Titicaca (Aldenderfer, De la Vega, and Klink 1996; Craig 2011). The survey was specifically focused on locating Archaic Period sites, and therefore the research design targeted geologic settings conducive to Archaic Period site preservation such as relict alluvial terraces that have been relatively stable throughout the Holocene Epoch (Rigsby, Baker, and Aldenderfer 2003). Within these geologic settings, systematic pedestrian transects at $15-\mathrm{m}$ spacing were used to locate archaeological materials. The positions of all encountered sites and isolated artifacts were recorded by global navigation satellite system, and temporally diagnostic materials were systematically collected. Site areas were estimated by pin flagging the boundaries of sites and estimating their north-south and east-west dimensions by compass and pace. The survey resulted in the collection of 247 Late Archaic projectile points from 58 sites.

All sites are located near the margins of relict alluvial terraces. All share easy access to perennial rivers within $2 \mathrm{~km}$ or less and are situated in Altiplano habitat (fig. 6). The Altiplano environment is characterized by expansive, rolling-hill grasslands dissected by perennial rivers and flanked by mountains (Winterhalder and Thomas 1978). Elevations range between 3,800 and 4,000 $\mathrm{m}$ asl, for a total elevation change of $200 \mathrm{~m}$. This relatively low gradient does not traverse any major ecological zones and translates to a locally homogeneous environmental structure, with plant communities dominated by ichu grass (Stipa ichu). Bofedales are perhaps the most economically important source of environmental diversity in the

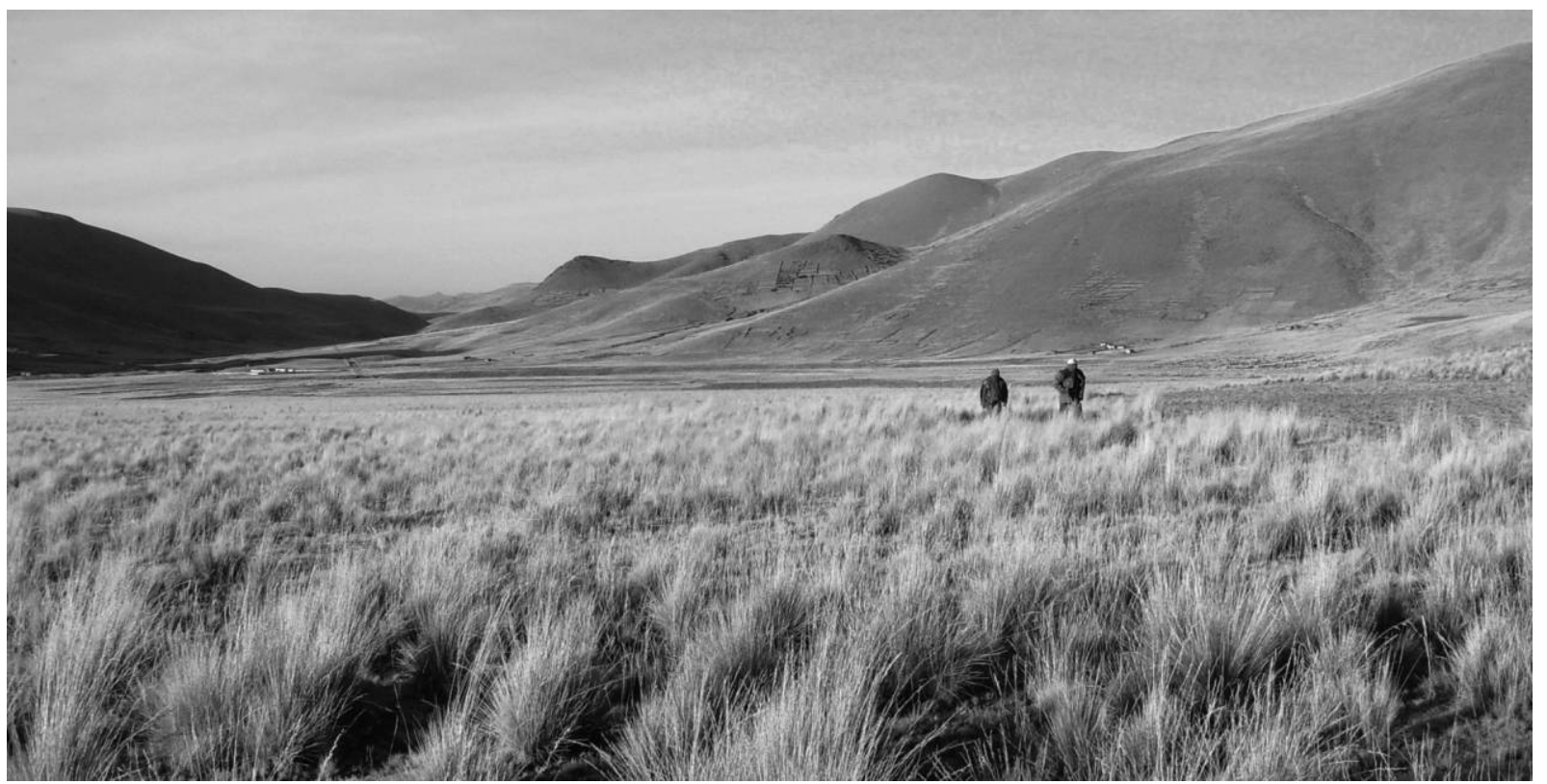

Figure 6. Ilave Basin study area in the relatively homogeneous Altiplano environment. A color version of this figure is available online. 
Altiplano (Aldenderfer 1998). Bofedales are localized wetlands with relatively high forage productivity that is important for wild camelid subsistence. Although bofedales were economically important to Archaic foragers in other parts of the southcentral Andes, they are rare in the study area and are therefore unlikely to have directly influenced land use in the subregion under investigation.

Data previously collected by Mark Aldenderfer and Nathan Craig (2011) serve as the foundation for testing the predictions derived from the working model. To mitigate against the possibility of biased surface collections, the first author of this paper revisited all sites that were recorded as having two or more Archaic projectile points to systematically collect projectile points (fig. 7). Although the previous surface collection necessarily decreased the artifact densities at those sites, 18 years had elapsed between collections, and it seemed reasonable to expect that a sufficient number of points would have surfaced in the meantime and thus minimized that source of sampling bias (Stiger 2001). Indeed, the recollection effort generated 117 Late Archaic Period projectile points from 25 sites.

Testing prediction 3 requires knowledge of site occupation spans. The first author therefore conducted limited excavations at the site of Soro Mik'aya Patjxa (SMP; Ilave 95-259; Haas and Viviano Llave 2015). SMP is the third-largest Late Archaic Period site in the sample, covering 0.3 ha and producing 25 Late
Archaic projectile points in Aldenderfer's survey and an additional 13 in Haas's surface collections. The excavation effort examined $50 \mathrm{~m}^{2}$ of surface area and $21 \mathrm{~m}^{3}$ of sediment. Abundant carbon was recovered from secure feature contexts, including human burials and shallow pits. Seventeen plant charcoal samples were submitted to the University of Arizona's Accelerator Mass Spectrometry Laboratory for radiocarbon dating.

\section{Prediction 1 Test Results: Power Law Structure in Artifact-Per-Site Counts}

Prediction 1 suggested that artifact counts among sites should exhibit power law structure. To test for power law structure, systematic, $100 \%$ surface collections of temporally diagnostic projectile points were made in the Ilave study area. Artifact counts are limited to Late Archaic projectile points in order to control for time. Figure 8 summarizes the data using histograms. The observed counts are highly variable, ranging from 1 to 80 artifacts per site. Qualitatively, the histograms show all of the characteristics of power law structure, including extreme right skew in the standard histogram, moderate right skew in the histogram of log-transformed values, and log linearity in the CMF plot (cf. fig. 3). More rigorous quantitative analysis using MLE, KS tests on Monte Carlo simulations, and AIC weights

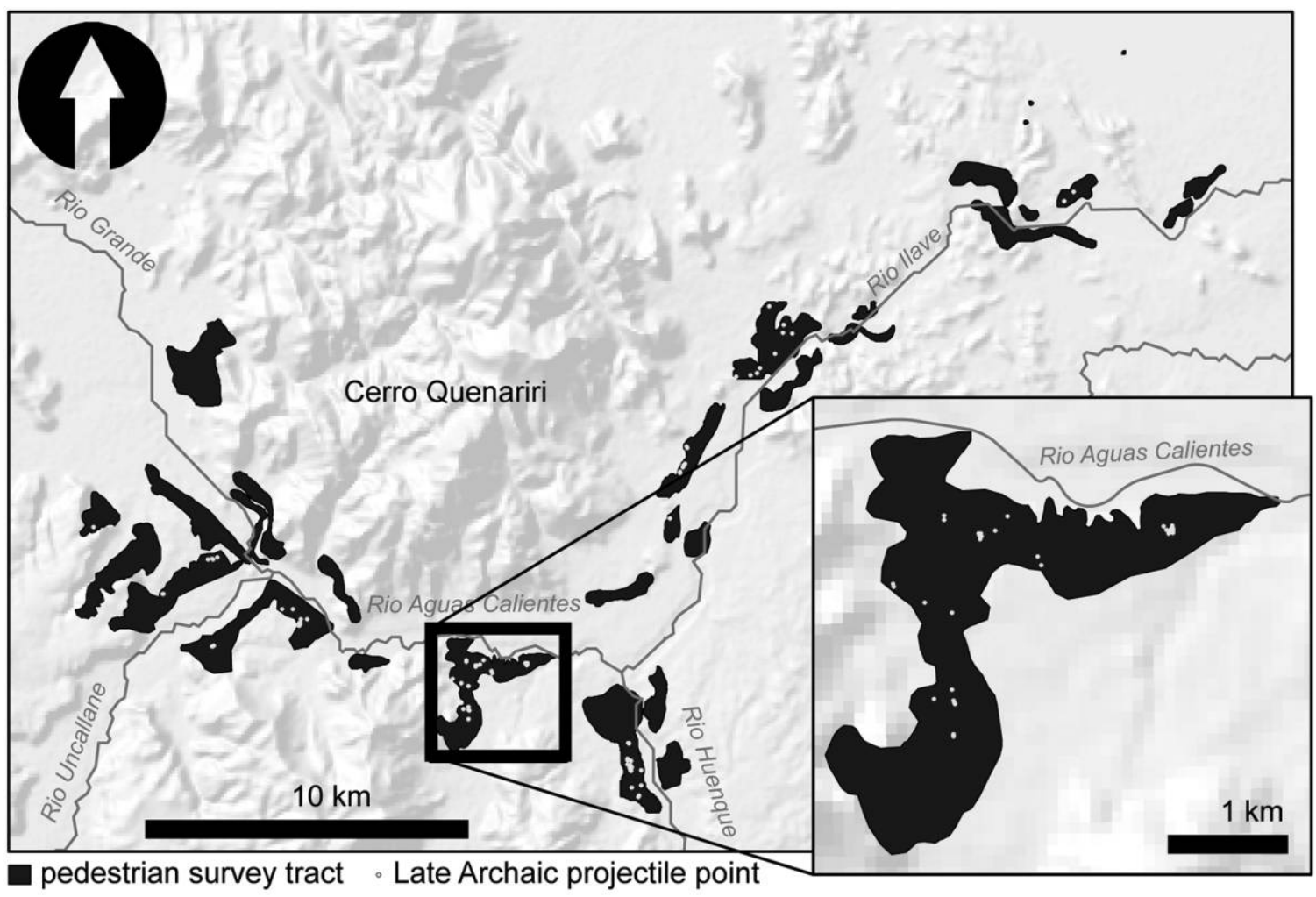

Figure 7. Late Archaic projectile point locations in the Ilave Basin study area. The inset shows a close-up of one area to give a sense of the spatial patterning. A color version of this figure is available online. 


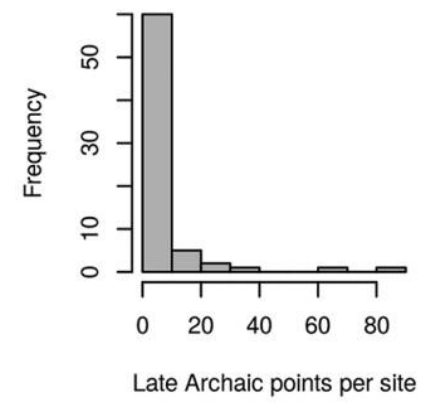

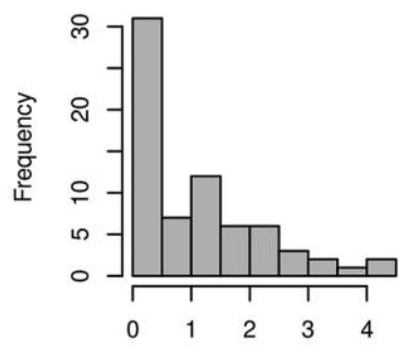

$\log$ Late Archaic points per site

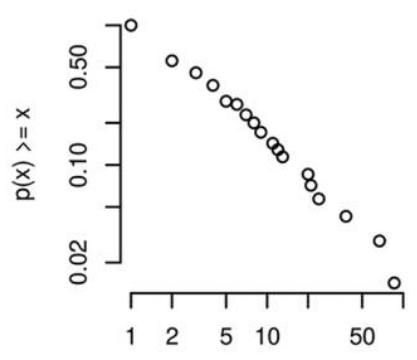

Late Archaic points per site

Figure 8. Late Archaic projectile point counts per site in the Ilave study area. The structural properties of the distributions are qualitatively similar to those predicted by the agent-based model (see fig. 3). Quantitative model-fitting tests described in the text add quantitative support.

reveals that the distribution is most consistent with a power law function. Only a best-fit power law model generated a statistically plausible result $(D=0.08, p=.11)$. Poisson and geometric distributions were determined to be statistically implausible ( $D=0.52, p=.00$ and $D=0.25, p=.00$, respectively). It is noteworthy that the best-fit power law scaling parameter, $\alpha$, as determined by MLE, is 1.6 , which is comparable to the alpha value produced for the ABM-simulated strong case of niche construction $(\alpha=1.8 \pm 0.1)$. This would seem to indicate a high propensity for site reuse in the empirical case. Thus the archaeological data support prediction 1 .

\section{Prediction 2 Test Results: Site Size Varies Independently of Localized Natural Resources}

Prediction 2 suggested a lack of association between the size of a site and the presence or absence of localized natural resources such as springs, raw materials, or other resource patches. The null prediction is that large sites ought to occur near localized natural resources, while small sites ought to occur in locations without localized natural resources. As described above, the high-elevation environmental structure of the Altiplano case study is relatively homogeneous (see fig. 6). No particular locations within the study area stand out in terms of having unusual natural resources. Water is abundant throughout the region, and perennial rivers are accessible within $2 \mathrm{~km}$ of all points in the study area. Localized lithic quarries were not observed in the study area, though river-gravel sources of low-quality materials are readily accessible from all locations in the study area. Although some rockshelters are present in the Uncallane River portion (see fig. 7), Archaic Period occupation was not observed in any of them (Aldenderfer, De la Vega, and Klink 1996).

Despite the extreme site size variation observed among Late Archaic sites (see prediction 1 test results), we were unable to identify any localized natural resources in spatial association with the largest sites. Indeed, we were unable to identify any clear, spatially localized natural resources in this relatively homogeneous study area. While the paleoenvironment of the Late
Archaic Period certainly differed from the modern environment (Baker et al. 2001; Rigsby, Baker, and Aldenderfer 2003), it seems unlikely that the differences would have significantly altered the types and structure of natural resources available to Late Archaic foragers in ways that would affect the patterns of interest here. It therefore appears that the Altiplano environmental structure cannot readily account for the observed archaeological variation.

\section{Prediction 3 Test Results: Partial Covariation between Site Size and Occupation Span}

Prediction 3 suggested that rare artifact-rich sites should exhibit multiannual occupation spans and potentially multigenerational occupation spans that could approach the entirety of the settlement system's existence. The current cultural chronology of the Lake Titicaca Basin suggests that the Late Archaic Period persisted for approximately 2,000 years (Klink and Aldenderfer 2005), which gives a sense of an upper end of what we could expect in this particular case.

The site of Soro Mik'aya Patjxa (SMP) was selected for excavation to test this prediction (Haas and Viviano Llave 2015). SMP is located on the edge of an alluvial terrace near the center of the vast Ilave Basin pampa, or grassland. The site was among the most extensively occupied Late Archaic sites in the study area. Excavations produced an abundance of carbon from secure pit-feature contexts that are used to test the current prediction. Table 2 presents the results of $17{ }^{14} \mathrm{C}$ assays. Calibrated median dates range from 8,000 to $6,500 \mathrm{cal} \mathrm{BP}$, suggesting a minimum occupation span of 1,500 years. Considering the apparently mundane nature of the environmental context coupled with the high residential mobility of the site's hunter-gatherer occupants, the occupation span of more than a millennium is surprising. However, it is consistent with the expectations of the working niche-construction model, which suggests that the exceptional attraction of the site derives from the constructed properties of that location. The temporal span of SMP is therefore consistent with prediction 3 of the working model. 
Table 2. Radiocarbon Age Determinations for the Site of Soro Mik'aya Patjxa $(n=17)$

\begin{tabular}{|c|c|c|c|c|c|c|c|c|c|c|}
\hline \multirow[b]{2}{*}{ Lab ID } & \multirow[b]{2}{*}{ Material $^{\mathrm{a}}$} & \multicolumn{4}{|c|}{ Provenience } & \multicolumn{2}{|c|}{ Radiocarbon BP } & \multicolumn{3}{|c|}{ 95\% Calendar $\mathrm{BP}^{\mathrm{b}}$} \\
\hline & & Area & Unit & Level & Feature & Age & Error & Max & Median & Min \\
\hline AA102848 & Wood & 1 & 61 & 2 & 10 & 5,891 & 49 & 6,850 & 6,713 & 6,566 \\
\hline AA102854 & Wood & 7 & 19 & 1 & 14 & 5,914 & 35 & 6,843 & 6,733 & 6,660 \\
\hline AA102843 & Wood & 1 & 55 & 1 & 16 & 5,924 & 48 & 6,883 & 6,748 & 6,656 \\
\hline AA102828 & Wood & 1 & 25 & 1 & 3 & 5,940 & 49 & 6,891 & 6,768 & 6,664 \\
\hline AA102851 & Bark? & 7 & 11 & 1 & 9 & 5,957 & 48 & 6,904 & 6,788 & 6,670 \\
\hline AA102859 & Wood & 7 & 26 & 1 & 18 & 5,983 & 47 & 6,945 & 6,822 & 6,679 \\
\hline AA102858 & Wood & 7 & 23 & 1 & 15 & 5,996 & 51 & 6,966 & 6,836 & 6,693 \\
\hline AA102834 & Parenchyma & 1 & 33 & 2 & 6 & 6,002 & 48 & 6,972 & 6,842 & 6,729 \\
\hline AA102855 & Parenchyma & 7 & 19 & 1 & 14 & 6,003 & 50 & 6,981 & 6,843 & 6,725 \\
\hline AA102837 & Parenchyma & 1 & 48 & 1 & 13 & 6,089 & 49 & 7,157 & 6,959 & 6,800 \\
\hline AA102829 & Parenchyma & 1 & 25 & 1 & 3 & 6,103 & 48 & 7,159 & 6,980 & 6,808 \\
\hline AA102835 & Twig & 1 & 33 & 2 & 6 & 6,148 & 50 & 7,170 & 7,053 & 6,896 \\
\hline AA102842 & Twig & 1 & 52 & 1 & 13 & 6,157 & 49 & 7,175 & 7,063 & 6,903 \\
\hline AA102827 & Grass stem & 1 & 22 & 1 & 2 & 6,401 & 50 & 7,425 & 7,338 & 7,255 \\
\hline AA102831 & Grass stem & 1 & 27 & 1 & 5 & 6,458 & 71 & 7,499 & 7,369 & 7,255 \\
\hline AA102826 & Parenchyma & 1 & 22 & 1 & 2 & 6,631 & 50 & 7,580 & 7,517 & 7,435 \\
\hline AA102838 & Twig & 1 & 48 & 1 & 13 & 7,090 & 59 & 8,013 & 7,914 & 7,794 \\
\hline
\end{tabular}

${ }^{a}$ All dates generated using accelerator mass spectrometry on charred materials from lower levels of feature contexts.

b OxCal, version 4.2.3 (Bronk Ramsey 2013); r:5 IntCal13 atmospheric curve (Reimer 2013).

\section{Prediction 4 Test Results: Lognormal Site Area Variation}

Prediction 4 suggested that site area variation should be most consistent with a lognormal statistical model over normal, exponential, and power law alternatives. Fifty-one Late Archaic Period sites were analyzed for statistical structure in site area variation. To avoid overestimation of site areas due to inflation from non-Late Archaic occupations, the analysis includes only sites for which $50 \%$ or more of the temporally diagnostic projectile points could be assigned to the Late Archaic Period. Figure 9 summarizes the results using three types of histograms. Qualitatively, the results appear to be consistent with the simulation results (compare fig. 9 with fig. 5). The histogram of empirical data is extremely right skewed, and the histogram of log-transformed data is approximately normal. A notable departure from expectations is that the CDF plot is upwardly convex, while the predicted CDF plot is more linear. Moreover, the more rigorous quantitative tests support exponential structure in the empirical data. We therefore reject the prediction of lognormal structure in site area variation.

It is currently unclear what factors drive this slight deviation from expectation, but the deviation does indicate either a model shortcoming or data bias. That an exponential distribution offers a better fit to the empirical data than does the predicted lognormal structure suggests that the bias is systematic, with larger sites disproportionately affected. This is because lognormal distributions can have heavier statistical tails than exponential distributions. In other words, exponential distributions tend to be more attenuated in their variation. This is somewhat surprising because it suggests that the archaeological variation is

llave Late Archaic Sites $(n=51)$

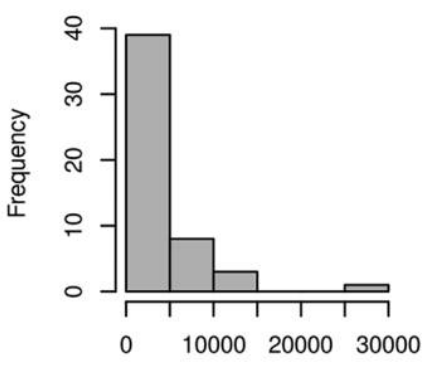

Late Archaic site area (sq. m)

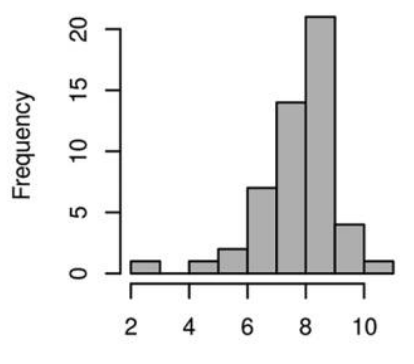

log Late Archaic site area (sq.m)

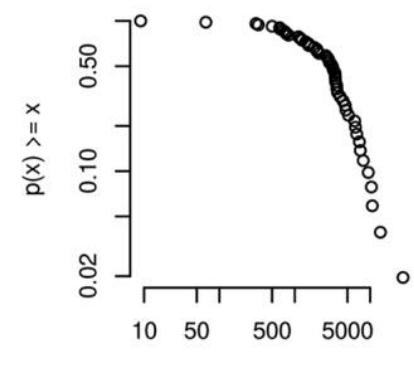

Late Archaic site area (sq. m)

Figure 9. Late Archaic site area variation in the Ilave study area. The structural properties of the distributions are qualitatively similar to those predicted by the agent-based model (see fig. 6). However, more objective tests indicate the distributions are inconsistent with the predicted distributions. 
more constrained than the predicted variation. One possible explanation is systematic bias in how site areas were recorded. Establishing site boundaries is fraught with subjectivity, and it is possible that the boundaries of larger sites are systematically underestimated due to lower thresholds in artifact density for defining the boundary's cutoff point. Alternatively, it may be that the temporal control method used to exclude extraneous occupation from site area estimation systematically biases the sample insofar as the largest sites are the most likely to be excluded because they are the most likely to contain other temporal components. Statistical vagary is yet another potential problem. Meta-analysis of the statistical model-fitting procedures used here have shown that while type-I errors (i.e., rejecting a lognormal model given lognormally distributed data) are rare, they can occur, especially when trying to discriminate between exponential and lognormal models (Haas et al. 2015). Theoretical and empirical analyses of artifact dispersion and methodological bias or consideration of alternative models may ultimately be required to answer these questions. For now, we simply acknowledge the shortcoming for this particular test case and leave the problem to future research.

\section{Summary and Conclusion}

Humans inevitably expand the spatiotemporal distributions of cultural materials on the landscapes they occupy. In doing so, they potentially reduce future costs of raw material acquisition and the production costs of tools and structures. Inheritors of the landscape therefore benefit from previous activities even without trying to do so. The presence of a brush structure, grinding slab, storage pit, and flaked stone tools deposited at a site should be expected to bias future residential choices toward use of that location. Because such material subsidies potentially free up time and energy for reproductive pursuits, evolutionary theory predicts that the culturally deposited materials should be incorporated into the mobility strategies of foragers, thus biasing occupations to previously occupied locations. In turn, when foragers reoccupy locations to take advantage of previously deposited materials, they probabilistically deposit additional materials, which attracts future use of the location, resulting in more deposition, and so on. Subtle variations in initial conditions - that is, point of entry, weather conditions, and chance resource encounters - that are often beyond empirical detection probabilistically cause certain locations to be occupied or passed up. But once a particular location is occupied for the first time, foragers may be predisposed to use it again. Repeated reuse over the long term may make a location so attractive as to lock it into annual cycles of movement. This positive-feedback niche-construction behavior predicts distinctive structural properties in land-use patterns and corresponding archaeological site size distributions.

$\mathrm{ABM}$ was used to derive logically valid predictions from the model of recursive mobility behavior. Drawing insight from the elegant mechanics of the neutral theory (Bell 2001; Hahn and Bentley 2003; Kimura 1985), the virtual forager simply decides at each time step to use the location of some previously deposited material with probability $m$ or a novel location on the landscape with probability $1-m$. This simple decision process effectively models the posited niche-construction behavior by biasing land use to the locations of previously deposited cultural materials.

The ABM and simple logical arguments were used to make four predictions for artifact distribution patterns. The Late Archaic Period hunter-gatherer settlement system of the Lake Titicaca Basin served as the test case. The analysis found empirical support for three of four predictions: (1) power law structure in site-based artifact counts, (2) there exists spatial independence between site size and localized natural resources, and (3) partial correlation between site size and occupation span can be deduced from the working niche-construction model. Only the prediction of lognormally distributed site area variation found a lack of empirical support, though it remains unclear as to whether this is a limitation of the model or the data. Given the preponderance of support for the model predictions, we conclude that the working niche-construction model offers a plausible and parsimonious understanding of mobility among foragers.

\section{Discussion}

The niche-construction model of forager mobility explored here accounts for several previously unexplained patterns of archaeological variation. In this section, we briefly consider potential alternative explanations for those patterns, discuss the boundaries of the analysis with additional predictions of the model, and explore some implications of the model for human behavior.

\section{Alternative Explanations for the Observed Patterns}

Archaeology perennially faces the problem of equifinality when attempting to explain empirical observations (Lyman 2004). The working model considers only a one-parameter systemic behavior to the exclusion of many other potential processes, including taphonomic processes, observer bias, and systemic behaviors, all of which can affect archaeological variation (Grøn 2012; Schiffer 1987). Nonetheless, some processes are more likely than others, and we will briefly consider what we perceive to be two of the most likely competing models here.

At first glance, fission-fusion dynamics would seem to offer a viable alternative for generating the archaeological patterns of interest. Fission-fusion refers to the periodic splitting and merging of human groups over time. To operationalize a fissionfusion dynamic, we might simply imagine a model universe with many foragers whose mobility is biased by the locations of other individuals as opposed to previously deposited artifacts. Under such assumptions, we should expect preferential attachment to places to emerge, as in the material-based model. Thus a fission-fusion model is likely to account for extreme variation in artifact accumulation among sites (prediction 1) 
without recourse to environmental structure (prediction 2). However, it cannot explain why some rare locations experience accumulation over extremely long time frames (prediction 3). Once individuals abandon a given location, fissionfusion offers no intrinsic mechanism to attract reoccupation of that location. This is not to suggest that hunter-gatherers do not engage in fission-fusion dynamics. Aggregation and dispersion are and were undeniably important to many if not all hunter-gatherer societies (Hamilton et al. 2007; Turnbull 1968; Woodburn 1968). However, such a mechanism does not explain why otherwise unremarkable places on the landscape are reoccupied repeatedly. We note that adding fission-fusion dynamics to the model described here would probably amplify the sorts of patterns observed.

A second potential explanation for the empirical patterns examined here might posit that functional site types (sensu Binford 1980) account for the observed variation. However, for theoretical and empirical reasons, we believe this is unlikely. Functional classification of hunter-gatherer sites is perennially difficult precisely because the ways places are used can vary over time (Binford 1982). Moreover, the Late Archaic Period lithic assemblages that we are working with are notably uniform. Sites of different sizes show no readily apparent differentiation in tool or raw material types. Smaller sites seem to be random subsets of the larger sites. Thus strict functional variation seems unlikely to explain the patterns of interest here.

We are currently unaware of any other alternative models with clear theoretical predictions for the structural properties of hunter-gatherer land-use patterns explored here. We suggest that the niche-construction model serves as a parsimonious starting point that accounts for a suite of archaeologically testable hypotheses and does so with few behavioral parameters. Any alternative models going forward should be formalized and put to work in predicting hunter-gatherer behavior and the macroscale properties of the associated archaeological record.

\section{Analytical Boundaries and Additional Predictions}

In addition to considering alternative models, it is important to briefly consider the boundaries of the current model and analysis in order to highlight areas in need of additional work. First, we emphasize that the analysis pertains to a geographic scale that falls within the typical foraging radius for hunter-gatherers (Kelly 2013). The areal extent of the case study is just $49 \mathrm{~km}^{2}$ and spans a maximal distance of less than $40 \mathrm{~km}$. The elevational gradient spans just $200 \mathrm{~m}$, lending to a relatively homogeneous environmental structure. Thus the analysis does not speak to large geographic areas that traverse multiple ecological zones. At the other extreme, the model does not necessarily speak to variation over smaller geographic extents, such as within huntergatherer settlements or archaeological sites.

Despite these scalar boundaries, we should expect the model to scale up or down with minimal tuning. Economically rational foragers should structure their mobility patterns in similar ways across larger landscapes and within camps, biasing movement to previously used locations where infrastructure and materials accumulate. At larger geographic extents beyond a typical foraging radius, geographic distances become important. In the current model, the virtual forager does not factor the cost of mobility into their movement decisions. This is a reasonable simplification given the small spatial and large temporal scales of analysis here. However, over long geographic distances beyond the foraging radius, mobility costs matter. A scaled-up version of the working niche-construction model would therefore need to be spatially explicit. The combined effects of preferential attachment to places and travel costs suggest that environmentally equivalent regions ought to experience different degrees of land use, with some rare regions experiencing particularly intensive use, and most regions experiencing comparatively low levels of use.

At the other extreme of small spatial extents within a settlement, we should expect the working model of preferential attachment to apply without modification. Spaces that foragers use early on within settlements ought to attract additional use and improvement, which ought to bias subsequent use. Todd Surovell and Matthew O'Brien (2016) qualitatively observed this site-level pattern in their recent ethnographic observations on intracamp mobility among residentially mobile reindeer herders of the Mongolian Taiga. The authors observed that "spatial attractors" created by the inhabitants themselves heavily biased intracamp mobility patterns. A potential exception would be debris that tends to exclude other activities because it is hazardous or noxious.

A second extension of the working niche-construction model might consider how different degrees of environmental heterogeneity might affect the strength of preferential attachment to places. In environments with scarce or very patchy lithic raw materials, returning to a previously occupied place to scavenge discarded artifacts could be more efficient than searching out fresh material. Where stone is essentially ubiquitous, the margin gained by recycling abandoned artifacts would be much reduced. Similar principles would apply to features related to shelter or even to firewood. Where protection from the sun, rain, or cold was a high priority, we would expect people to be more strongly attracted to existing infrastructure such as constructed shelters and firewood piles. Resource-poor environments ought to encourage stronger degrees of attraction to previously used places than comparatively rich environments. Thus the model predicts that the power law scaling parameter for site size variation ought to covary with environmental structure.

\section{Model Implications}

To the extent that the working niche-construction model offers a reasonable account of forager mobility, several key insights into forager behavior stand to be gained. First and foremost, it would appear that positive-feedback niche construction was not trivial to hunter-gatherer mobility. Previous hunter-gatherer research has tended to give primacy to external environmental structure in explaining mobility decisions. The results presented 
here do not undermine the undeniably important role that natural environments play in structuring forager mobility, especially at large, interpatch scales where forager behavior and the associated material record is well accounted for by environmental structure. However, niche-construction dynamics may also be central to hunter-gatherer mobility strategies.

A second key insight gained from the current study relates the emergence of socioeconomic complexity in human societies. This insight pertains to at least two areas of research-plant domestication and hierarchy. With regard to the former, domestication is known to result from long-term interactions with genetically plastic species (Langlie et al. 2014; Rindos 1983; B. D. Smith 2001). In the case of agriculture, the species are immobile, and thus it can be assumed that intensive interaction between species also involved intensive interaction with places. Given the proposition that infrastructure and materials consistently pulled mobile foragers to reoccupy specific locations on the landscape over decades or millennia, long-term interactions with certain plant populations may have been catalyzed. In turn, such coevolutionary processes with plants would have further fed into the attraction of places.

With regard to hierarchy, geographers and anthropologists have long observed that settlement size variation among sedentary societies is heavy tailed, with extremely small settlements extremely common and extremely large settlements extremely rare (Batty 2008; Drennan and Peterson 2004; Johnson 1980; Krugman 1996; Newman 2005; Zipf 1949). Most scholars seem to agree that settlement size variation among modern communities is consistent with power law or lognormal statistical models. Archaeologists have also found that the settlement systems of sedentary agricultural societies tend to exhibit heavytailed statistical structure. Following the lead of central-place economic theory (Christaller 1966), explanation of this statistical structure has tended to rely on complicated economic processes involving various combinations of agricultural production, specialized craft manufacturing, peer-polity competition, or warfare (Brown and Witschey 2003; Flannery 1998; Griffin 2011; Griffin and Stanish 2007; Inomata and Aoyama 1996; Johnson 1980; Krugman 1996; Paynter 1982). This has led some scholars to suggest that the heavy-tailed statistical structure of site size variation offers a line of evidence for hierarchical settlement organization (Ames 2008; Flannery 1998; Stanish 2003). The findings presented here suggest that the statistical signature of settlement size hierarchy can actually emerge among hunter-gatherer land-use systems whose populations were unequivocally mobile, independent of domesticated resources, without economic specialists, and without organized conflict. Caution is therefore warranted in using site size hierarchy as an indicator of complex social organization. The nicheconstruction model presented here suggests that forager mobility biased by culturally deposited materials is sufficient to generate an incipient form of settlement hierarchy.

Importantly, the sites that comprise hunter-gatherer land-use systems were likely occupied asynchronously in most cases. This is fundamentally different from situations in which settlements comprising the full range of size variation in a settlement hierarchy were or are generally occupied contemporaneously. In other words, the largest sites in the Lake Titicaca Basin Archaic samples may never have hosted great numbers of people at the same time, as did the sites in the settlement hierarchies of complex societies. Accordingly, high-ranking hunter-gatherer sites likely did not represent high-ranking political centers or concentrations of power. Nonetheless, the fundamental mobility processes that led to extreme site size variation in huntergatherer systems may have laid a foundation for the emergence of synchronous settlement size hierarchies and thus concentrations of power as populations became less mobile due to population growth, decreased resource productivity (i.e., circumscription), or increasing commitment to food production. The major difference for sedentary populations is that preferential mobility to places would lead to a heavy-tailed distribution of contemporaneously occupied settlements, with all of the resource and power imbalances that implies.

It was more than 30 years ago when Lewis Binford proposed that the structure of forager mobility varied as a function of environmental structure (Binford 1980), on one hand, and cultural geography (Binford 1982), on the other. The intellectual environment of that time, fueled by logical positivism and constrained by computational limitations, led subsequent scholarship to focus on deterministic relationships between forager mobility and environmental structure (e.g., Binford 2001). The niche-construction model of forager mobility presented here emphasizes the other end of the spectrum - the cultural and nonlinear dimensions of forager mobility. The working model is simple yet generates novel predictions for the structure of hunter-gatherer land-use systems. The archaeological test case supports the predictions, and it is hoped that future archaeological and ethnographic research will explore the boundaries of the model and compare the results with those derived from alternative models. For now, the analysis suggests that niche construction may have played a significant role in structuring the mobility of foragers and the spatial distributions of their material residues. Such microlevel behaviors and their macrolevel consequences hold potential relevance for models of human mobility generally and emergent complexity in human societies.

\section{Acknowledgments}

Mark Aldenderfer (University of California, Merced); Mary Stiner, Michael Schiffer, and David Raichlen (University of Arizona); Steven Lansing (Nanyang Technological University); Sean Downey (Ohio State University); and Janet Chernela (University of Maryland) provided helpful comments on drafts of the paper. Various members of the Collasuyo Archaeological Research Institute and members of the Ilave, Totorani, and Mulla Fasiri communities provided field and laboratory support. Mark Aldenderfer, Nathan Craig, Lauren Hayes, Virginia Incacoña, Mateo Incacoña Huaraya, Daniel Pilco Incacoña, Nestor Condori Flores, Albino Pilco Quispe, and Zoya Thomas 
provided logistical support in the field and laboratory. Financial support for this research was provided by a National Science Foundation Doctoral Dissertation Improvement Grant (BCS1311626), the American Philosophical Society's Lewis and Clark Fund for Exploration and Field Research, the School of Anthropology, the Graduate Professional and Student Council at the University of Arizona, and a Marshal Foundation dissertation writing fellowship.

\section{Comments}

\section{Robert L. Bettinger}

Department of Anthropology, University of California, Davis, California 95616, USA (rlbettinger@ucdavis.edu). 10 X 18

The paper by Haas and Kuhn is provocative in describing a major site formation force in which the occupation of a locality makes its subsequent occupation more likely than it would have otherwise been, generating a right-skewed (heavy-tailed) distribution of archaeological site sizes that closely matches the observed site size distribution in the Lake Titicaca Basin of Peru. The proximate explanation is that existing sites are favored as potential sources of useful raw material and site furniture left by previous occupants, making site choice a function of cultural rather than natural geography and site formation a form of niche construction. The fit between theory and data is convincing, but as is so often the case, there are other ways to think about the problem.

First, I do not see niche-construction theory adding much here. The niche-constructing aspects of this argument specifically-and of site formation theory more generally-are drawn mainly from simple economic principles and not nicheconstruction theory, which brings less to the table than widely imagined. Just about everything humans do has longitudinal feedback effects that can be construed as niche construction, but very little of what we have learned about these varied behaviors owes much to niche-construction theory.

Second, it is worth noting that, as Haas and Kuhn are no doubt aware, the Titicaca case is unusual in providing very few constraining natural features affecting choice of site location; this is in contrast to many cases where site location is highly constrained - for example, to water sources in desert environments - but in less extreme cases as well (e.g., Williams, Bettinger, and Thomas 1973). In such settings, visitors moving into existing sites will no doubt take advantage of raw materials and site furniture left from previous occupations, but raw material scavenging will be an effect of, not a cause for, choice of site location.

Finally, there is an alternative to Haas and Kuhn's "useful materials" explanation for the observed preference of Titicaca hunter-gatherers for occupying existing sites rather than establishing new ones. It derives from the well-developed body culture transmission theory (Boyd and Richerson 1985; Richerson and Boyd 2005) via something like what is termed guided variation, where individuals minimize the cost of learning by imitating the behavior of others when learning is costly or error prone and minimize the risks of imitating by experimenting with new behaviors (i.e., learning) when learning is cheap or changing conditions make existing behaviors potentially inappropriate (Bettinger, Garvey, and Tushingham 2015:244-246). Guided variation may entail observation of behaviors as they unfold but obviously extends to observed consequences of past behavior (one does not need to see a house being painted blue to know that it is painted blue). On this view, hunter-gatherers choosing where to spend a night, week, or month will chose a site that others have previously occupied on the premise that "the place worked for them and nothing much has changed, so it ought to work for us"-a quick, yet effective way of making decisions about settlement location that takes advantage of what others have learned so long as conditions remain roughly the same but encourages experimenting with alternative site locations when conditions change. Since hunter-gatherers, no less than archaeologists, are likely to be able to detect how recently a given site was occupied, a refinement would favor the use of sites more recently occupied.

Because the guided variation hypothesis predicts essentially the same right-skewed (heavy-tailed) distribution of archaeological site sizes predicted by Haas and Kuhn's utility hypothesis, deciding between the two requires additional testing. In theory, the utility criterion (occupy sites where raw materials are available) will apply more strongly where raw materials are scarce, where tool kits are neither intensively curated nor demanding to make, and to residential sites more than logistical sites. The guided variation criterion (occupy sites that others have occupied) will apply more strongly where foragers are less familiar with the environment and to sites occupied over intervals during which conditions have remained qualitatively much the same.

\section{Amy E. Clark}

Department of Anthropology, University of Oklahoma, 455 West Lindsey, Norman, Oklahoma 73019, USA (aeclark@ou.edu). 19 X 18

Archaeologists have long recognized that certain locations tend to invite reoccupation, even lacking the attraction of a natural resource. The accumulation of cultural materials itself is a draw (Barkai, Lemorini, and Vaquero 2015; Camilli and Ebert 1992), as is the cultural and spiritual attachment to place that is well documented among hunter-gatherers (Basso 1990, 1996). However, no one has explicitly asked the question in an environment devoid of spatially tethered resources, Why are some locations reoccupied repeatedly while others are occupied only once or twice? Haas and Kuhn present an intriguing model to address this question that will surely inspire subsequent testing in a variety of locations and at a variety of scales. 
Haas and Kuhn argue that simply by using a place on the landscape and depositing cultural material, humans are themselves building a resource that will attract reoccupation. With subsequent occupations, this phenomenon will only be accentuated by the accumulation of more and more cultural material. Haas and Kuhn approach this problem from an ecological perspective, arguing that foragers would only reoccupy a location if it was in their economic best interest to do so. However, foragers reoccupy locations for many reasons that are not economic in nature (Martínez-Tagüeña and Torres Cubillas 2018; Oetelaar and Oetelaar 2011). Certain places might have more cultural meaning than others, or there might be historic reasons why certain places over others are reoccupied. This would especially be the case with sites that contain burials. Indeed, the sole site excavated by Haas, Soro Mik'aya Patjxa, contained burials. This site is one of the largest sites in the sample (an "extremely rare" site near the top of a power law distribution) and therefore was likely a very important site in the Late Archaic settlement system. Haas and Kuhn argue that its importance was determined by the preferential attraction to a location already containing cultural features, such as ephemeral huts and, of course, lithic artifacts. Its importance was also likely conditioned by its prominence in the cultural beliefs and world views of its inhabitants. A cultural connection to the landscape would not necessarily alter the niche-construction model in a meaningful way; in many ways, they could go hand in hand. Just as cultural objects would accumulate upon repeated occupations, cultural meaning and repeated occupations would create a feedback loop in terms of cultural connections to the place that go beyond material artifacts. Therefore, the consideration of cultural landscape, attachment, and placemaking (Basso 1996) only adds depth to the model and does not necessarily negate it.

The most important contribution of this model will be its application in other locations. Even if it cannot be directly applied, its consideration could yield some interesting new perspectives on one's research area. The case study considered by Haas and Kuhn was as close to the idealized world of the agentbased forager as one could get, at least in the way it was presented. It would be more difficult to apply in areas with buried deposits or without temporally diagnostic artifacts. Buried openair Middle Paleolithic sites litter France, for example, but the sites found and excavated are likely heavily biased toward the largest sites in the settlement system. Furthermore, raw material sources, though ubiquitous, are nevertheless unevenly distributed across the landscape and would likely structure mobility — or at least make the site more visible in terms of volume of lithic material present.

Finally, Haas and Kuhn suggest that this model could easily be scaled up or down to be utilized in pan-regional analyses or at the scale of the site. It is an interesting model to consider at the intrasite spatial scale but becomes more difficult when one ponders the logistics of its implementation. Surovell and O’Brien's (2016) "spatial attractors" would indeed invite reuse of a particular location due to a human-made structure or resource. However, Surovell and O'Brien were discussing an eth- nographic account where certain features (such as doorways or where resources are stored) attract people, not artifacts. Of course, artifacts are more likely to be deposited in areas that people frequent, but this picture could get complicated with behaviors such as cleaning. The greatest obstacle, however, may be how to divide the intrasite spatial space into analytical units. Would one identify artifact clusters? Clusters, however, are defined based on having a high density of artifacts so they would most likely be equivalent to the "largest sites" on the landscape. It might work best if the site was simply divided evenly in space as a grid.

Nevertheless, though there may be some problems of application in other settings and scales, this model is an important contribution to our understanding of hunter-gatherer settlement systems. Many environments will have unevenly distributed resources that will tether human occupation, but that is not the only explanation nor is it necessarily the most important. Humans actively create their own tethered resource simply through their inclination to revisit a location with physical cultural artifacts - as well as metaphysical cultural meaning. Once this process begins, a few sites - usually those occupied earlier in the regional occupation sequence - create a feedback loop and become larger and larger, while most others remain small, and thus a power law relationship develops. Both agreement and exceptions to this model will certainly be fodder for the study of hunter-gatherer mobility for years to come.

\section{Nora Viviana Franco}

Instituto Multidisciplinario de Historia y Ciencias Humanas (IMHICIHU), Consejo Nacional de Investigaciones Científicas y Técnicas (CONICET), Saavedra 15, 5to piso (C1083ACA), Buenos Aires, Argentina; and University of Buenos Aires, Argentina (nvfranco2008@gmail.com).15 X 18

The utilization of theoretically based models can help us to get a better understanding of the behavioral reasons for patterns observed in the archaeological record. In their paper, Haas and Kuhn tackle the issue of the role of previously deposited materials in the choices made by hunter-gatherers, or "mobile foragers," as a way of reducing costs and emphasize the utility of niche-construction models to understand and predict the nature of the archaeological record.

Conscious or unconscious modification of the space by humans through time undoubtedly takes place (e.g., OdlingSmee et al. 2003). In addition, and contrary to what the authors mention, human utilization of sites can attract further occupations or limit them, as different examples related to the deposition of human remains indicate (Borrero et al. 2007; Franco et al. 2017; Mena et al. 2000). Due to changes in environment, detailed geomorphological and geoarchaeological studies are needed in order to understand them (Borrero 2011; Favier Dubois and Borrero 2005; Holdaway et al. 1998; Martínez and Martínez 2011). 
In this paper, the authors mention the existence of some basic level of site reoccupation without explicit planning. I believe that, although this can exceptionally happen, it is difficult to think that logistic hunter-gatherers, whose decisions are scheduled to cope with different resources (see, e.g., Binford 1977; Bousman 1993), do not anticipate their return to a place, as ethnoarchaeological information and the existence of seasonal gear show (Binford 1977). In the case of foragers, generic reoccupation of some areas - instead of the reoccupation of a specific place (Hietala and Stevens 1977) — can be expected. Depending on the strategy, as the authors mention, provisioning of places (Kuhn 1995) or provisioning people with transportable and reliable materials will take place. Although it is not central to the argument, I would like to mention that in the case of homogenous environments, materials do not necessarily need to be reliable (sensu Nelson 1991).

Haas and Kuhn do not use transport costs in the construction of the model because they believe that the lineal scale used $(40 \mathrm{~km})$ is too small for considering these costs. Although $40 \mathrm{~km}$ is within the range of distances that can be considered local (following ethnographical information in Meltzer 1989), it is difficult to believe that transport costs are not taken into account by pedestrian hunter-gatherers.

With reference to the testing of the model, the area chosen is small $\left(41 \mathrm{~km}^{2}\right)$, especially when taking into account published ethnoarchaeological information. Total area covered by ethnographic groups in latitudes below $15^{\circ}$ varies, according to Kelly (1995), between 25 and 2,860 $\mathrm{km}^{2}$, with only two cases with ranges of $41 \mathrm{~km}^{2}$ or less. Of course, variations related to the distribution and characteristics of resources can be expected (Binford 2001; Kelly 1995, 2013). In addition, the study area is too small to test the effect of fission-fusion movements.

I tend to think Haas and Kuhn's model will be more useful and easier to test in relatively homogenous environments. In heterogeneous environments, with a more discontinuous distribution of resources, the presence of highly valuable ones - for example, those necessary for subsistence-will probably be powerful "attractors" for human populations. Places where these resources are available will tend to be reused, with the same or a different function (see, e.g., Binford 1982). As huntergatherers expect to return to these sites, these are the places where people will probably purposely leave artifacts or structures for their anticipated return (seasonal gear, following Binford 1982). In these places, there will be an overlap between natural and cultural reasons to reoccupy them, although I believe the presence of highly valuable resources will be the main reason for return.

In addition, in patchy environments, places where natural lithic resources are available do not necessarily make good base camps. The strategy used and length of stay may vary, depending on the scarcity or abundance of selected lithic resources (e.g., Colombo and Flegenheimer 2013; Méndez et al. 2010). The degree of knowledge of the environment and/or the existence of neighbors should also generate variation (Borrero 1994-1995). In the case of the Great Lakes/northeastern area of North
America, for example, Ellis (2011) has postulated the existence of changes in the length of stay near raw material sources between Paleo-Indian and post-Paleo-Indian groups, which is in part related to the degree of knowledge of the environment.

Testing of the model requires careful chronological control. The utilization of sites that contain only projectile points, as this paper does, can bias the results. Projectile points are not discarded everywhere, and I believe that all the available variables should be used in order to test it. In general, technological as well as raw material information - in case variations exist through time - can contribute to the testing of the model. The presence of differential weathering as well as obsidian hydration studies, whenever it is possible to use them, would help to test the model.

As the authors mention, the role of previous archaeological remains with residual utility in shaping human decisions is worthy of understanding. It will probably not be easy to test due to the equifinality problems abundant in the archaeological record, and because of the stated reasons, I think it would be more useful in the case of homogeneous environments. In addition, I believe Haas and Kuhn's argument could be enriched by comparing the results obtained through the application of this model with other theoretically based ones (e.g., Smith 2015).

\section{Raven Garvey}

Department and Museum of Anthropology, University of Michigan, 3010 School of Education Building, 610 East University Avenue, Ann Arbor, Michigan 48109-1259, USA (garveyr@umich.edu). 16 X 18

There is a growing recognition among evolution-minded archaeologists that we humans do not simply adapt passively to our environments; we actively - if sometimes unwittinglymodify the very environments to which we adapt. Nicheconstruction theory rose to prominence in biology in the 1980s (Lewontin 1983; Odling-Smee 1988), and while archaeologists have a long history of studying feedback between humans and their environments, we have been relatively slow to incorporate formal models of niche construction among prehistoric foragers. As Haas and Kuhn show, though, emergent properties of recursive behaviors can structure archaeological records in ways that resemble distributions we routinely attribute to extrinsic factors (e.g., resource dispersions). Unless we can reliably distinguish the two, we risk misinterpreting foragers' mobility and, more fundamentally, humans' adaptive capacities.

"Forager Mobility in Constructed Environments" offers simulation-based standards to which archaeological records can be compared to identify power law or lognormal structure in regional-level site variation. Recognizing such structure, we may then be able to identify culturally modified environments and model their effects on optimizing foragers' mobility decisions. This is an exciting premise with broad implications, and I offer a few observations that might help us build on Haas and Kuhn's innovative approach. My comments relate to two topics: (1) potential confounding effects of historical research 
biases and (2) drivers and properties of $m$, the probability that a forager will preferentially return to (and thereby add further value to) sites where materials were deposited previously.

As Haas and Kuhn explain, foragers' preferential attachment to particular locations on a landscape produces a power law distribution of variously sized sites in which the largest are extremely rare and small sites are very common. In an unbiased regional study, then, most observations will derive from small sites. Historically, though, much archaeological research has centered on very large and/or frequently reoccupied sites, which are not only the rarest but also highly unlikely to reflect the full complement of prehistoric behaviors in a region (Garvey and Bettinger 2018). That is, preferential attachment can also concentrate archaeological effort and research dollars in localized, unrepresentative spots on landscapes, and the heavily skewed distributions - of observations, radiocarbon dates, publications, and paleoenvironmental analyses - generated by this approach are often the inverse of site size distributions produced by foragers' preferential attachment to places on the landscape. Accordingly, Haas and Kuhn's paper highlights the importance of systematic survey of any region where their approach might usefully be applied, not only to document the small sites but also to assess prehistoric resource availability. This is critical because, as the authors argue, recurrently visited places are ones that are either naturally rich (e.g., due to localized food abundance) or that become rich as a result of humans' "habitual deposition of material resources," so our ability to identify anthropic niche construction in a heterogeneous environment hinges on the presence of two or more equally rich patches with notably unequal prehistoric use intensities.

Understanding drivers and properties of $m$ will also help us identify appropriate contexts for application of the Haas-Kuhn model. One goal of their paper is to predict effects of passively constructed environments on energy-optimizing foragers' mobility, and while the authors name a variety of previously deposited items that might increase a site's attractiveness, among

stone-poor environment

reliance on stone (proportion of toolkit)

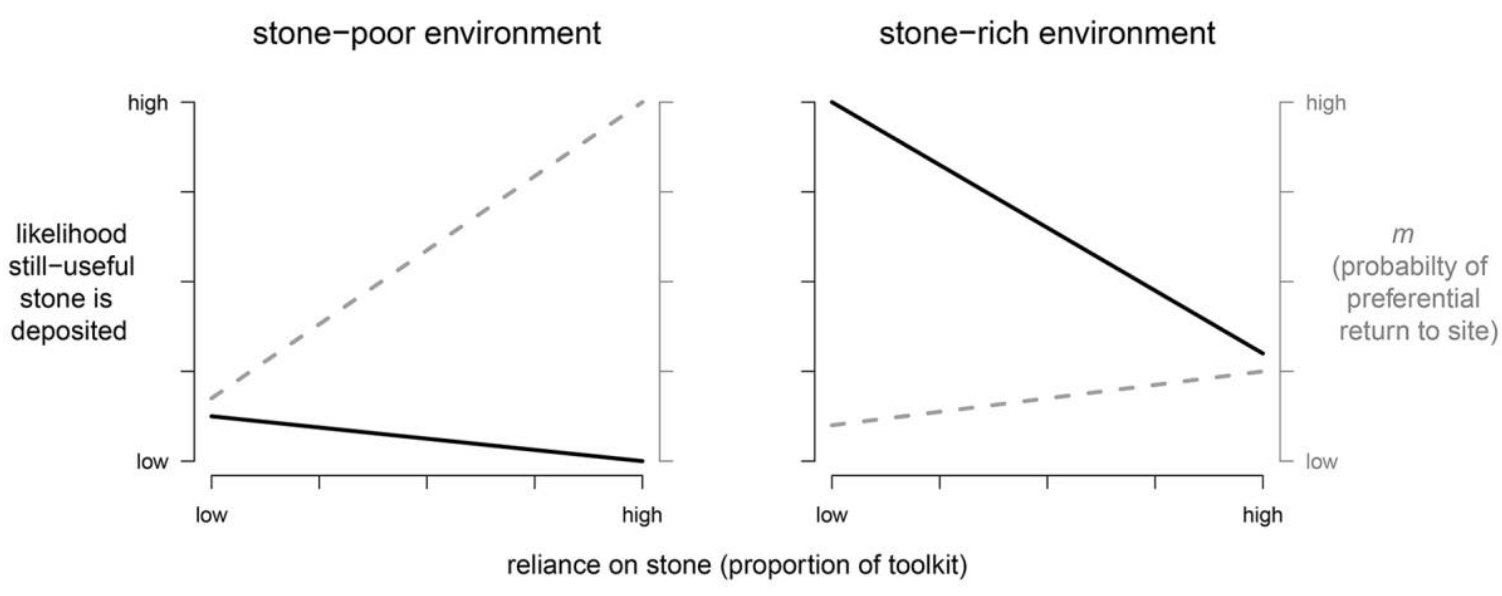

them, flaked stone artifacts are most common in many prehistoric contexts. I therefore center this comment on lithic resource optimization as a driver of $m$, though the probability that a forager will preferentially return to sites where materials were deposited previously could reflect any number of economic and cultural motivations.

When a forager is motivated by lithic resource optimization, $m$ will be a function of previously deposited items' utility, which is governed not only by the natural availability of lithic raw materials, as the authors note, but also by foragers' proportional reliance on stone and deposited items' remaining usability (uselife). As such, a salted site might be most attractive to ( $m$ highest among) foragers heavily reliant on stone in a stone-poor environment (fig. 10, left). However, these may be precisely the conditions under which previous occupants are least likely to have deposited still-useful stone. In the same (stone-poor) environment, foragers who do not rely heavily on stone might be more likely to deposit still-useful items, but this should have little effect on $m$ simply because stone is not an important part of the tool kit. In naturally stone-rich environments, the likelihood that still-useful items will be deposited should be higher, but deposited items have relatively less utility ( $m$ is low) because the probability of finding stone elsewhere is high (fig. 10, right). So the likelihood that still-useful stone items will be deposited is highest when foragers little reliant on stone live in stone-rich environments, but of course, $m$ is likely to be quite low in this situation. Going forward, it will be important to base our estimates of $m$ on our best understanding of the relevant technological (or other) systems - and to recalibrate our understanding of these systems in light of information from small sites if these were not previously part of our assessment.

Last, it may be worth exploring $m$ as a dynamic rather than a fixed variable. Depending on the natural distribution of lithic raw materials on a virgin landscape, change through time in $m$ might be logistic (S shaped): the effect of $m$ on mobility decisions being initially weak because the utility of a small number of

Figure 10. Graphical representation of the relationships between the degree of reliance on stone for tools and (1) the likelihood that still-useful stone will be deposited (solid black lines) and (2) $m$, the probability that a forager will preferentially return to a site where stone was deposited previously (dashed gray lines) in a stone-poor (left) versus a stone-rich (right) environment. 
deposited items at any given site may be insufficient to offset other costs, a site's attractiveness increasing ( $m$ accelerating) as useful items continue to accumulate to a point of diminishing returns, beyond which $m$ decelerates because foraging costs, waste accumulation, and/or costs of defending an increasingly attractive site grow concomitantly. Importantly, though, human population growth also tends to be logistic, so future applications of the Haas-Kuhn model should perhaps attempt to control for population growth, which is theoretically stimulated by preferential attachment because preferentially returning to salted sites simultaneously optimizes mobility and stone procurement, freeing up time and energy for other fitness-enhancing activities.

\section{Matt Grove}

Department of Archaeology, Classics and Egyptology, University of Liverpool, 12-14 Abercromby Square, Liverpool L69 7WZ, United Kingdom (matt.grove@liverpool.ac.uk). 14 X 18

\section{Preferential Attachment: To Agents and Artifacts}

Haas and Kuhn make a valuable contribution to the study of hunter-gatherer land use, postulating a simple generating mechanism for observed site size distributions. Above all, their conclusion that such distributions can emerge in populations that are "unequivocally mobile, independent of domesticated resources, without economic specialists, and without organized conflict" is of considerable importance. I have made similar arguments in the past (Grove 2011) but concentrated my attentions on multilevel social systems rather than prior artifact deposition as the potential generating mechanism. The main focus of this comment, therefore, is the relative merits of these two hypothesized mechanisms.

In brief, the model I developed to explain settlement size hierarchies of the kind Haas and Kuhn empirically observe assumes a "nested hierarchy" of group structures (Dunbar 1998) in which a given individual is a member of a nuclear family but also of a larger consanguineal kin group, a yet larger clan, and, ultimately, a community (these terms derive from Murdock 1949). In terms of size, each of these groupings is approximately a factor of three larger than the immediately smaller grouping (Hill and Dunbar 2003; Lehmann et al. 2014). There exists variation in the sizes of these groups, with greater variation occurring in larger groupings, as one would expect given that each larger grouping is composed of approximately three smaller groups. Finally, larger groupings occur proportionally less frequently, as is necessarily the case in a population of relatively constant size. Simulating site size distributions based on these assumptions provides a very close fit to the empirical data considered both by myself (Grove 2011) and by Haas and Kuhn.

Thus we arrive at two generating mechanisms that produce simulated distributions quantitatively similar to the archaeological data considered, and further theoretical development depends on both (1) finding situations in which they make opposing predictions and (2) modeling their joint effects and comparing the resulting simulation output to empirical data. Haas and Kuhn make an intriguing contribution to the first by noting that fission-fusion social systems (which are closely related to multilevel social systems) cannot account for the fact that some locations "experience accumulation over extremely long time frames." This issue may indeed raise problems for fission-fusion models, including my own. It is important, however, to examine the nature of the accumulation that occurs in Haas and Kuhn's model.

Since Haas and Kuhn model the actions of a single forager, their results are not well placed to falsify fission-fusion models; they make no claim to do so and note that adding fission-fusion to their model may amplify the observed patterns. More importantly, because their model concerns repeated visits over an extended period of time, it necessarily assumes that large accumulations of material are created by a high frequency of visits by a single forager rather than, for example, few visits by a large group. The two models make similar predictions concerning the time span over which a large site is used and the quantity of material that accumulates, but the Grove (2011) model suggests that distinct occupation phases created by large groups at sporadic intervals should be discernible, whereas the Haas and Kuhn model suggests that occupation should resemble a pseudocontinuous palimpsest. Examining a summed radiocarbon probability curve of the 17 dates provided for the site of Soro Mik'aya Patjxa (fig. 11) suggests that there may indeed be hiatuses in occupation, which would be more concordant with the Grove model. Alternatively, the generic profile of the dates - with a greater proportion occurring more recently in time-would tend to support the hypothesis of Haas and Kuhn that a site becomes more attractive as more material accumulates. This crude analysis lacks stratigraphic detail and cannot be used as a basis for firm conclusions, but analyses of this kind will be vital in determining the relative performance of

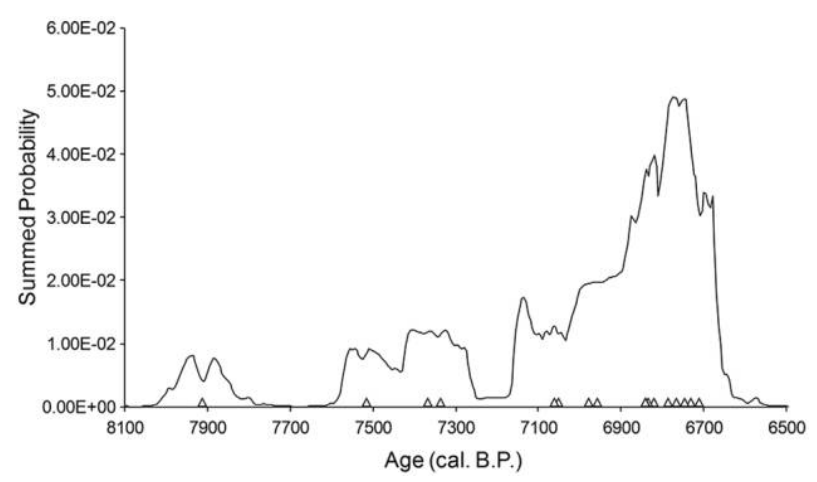

Figure 11. Summed radiocarbon probability curve of the 17 dates provided by Haas and Kuhn for the site of Soro Mik'aya Patjxa. Dates were calibrated using OxCal, version 4.3 (Bronk Ramsey 2009), via the IntCall3 calibration curve. Triangles indicate the medians of individual calibrated dates. Hiatuses can be observed at approximately 7,700 and $7,200 \mathrm{cal} \mathrm{BP}$. 
the two models in explaining archaeological data. Unfortunately, the finding that one large site was occupied over a long time period is not sufficient to prove covariation between site size and occupation span; to do this even minimally, one would also have to show that small sites were occupied only over short periods. Even if this were the case, it would not allow us to distinguish between the strengths of the two candidate models without detailed consideration of individual site stratigraphy.

I have no doubt that the mechanism identified by Haas and Kuhn would have had an important structuring effect on the formation of archaeological sites, and I would like to see this line of inquiry pursued further. I would also like to see it coupled with fission-fusion dynamics in a way that gives due weight to the social factors involved. The Haas and Kuhn model and the Grove (2011) model share a common foundation in the notion of preferential attachment, and it will be fascinating to disentangle the extent to which such attachment relates to artifacts (per the Haas and Kuhn model) as opposed to individuals (per the Grove model). That foragers could be attracted to artifacts even in the absence of their makers is an important insight that has not received sufficient attention. A further advance of the Haas and Kuhn model is that it explores how attachment to particular locations emerges even against a background of environmental homogeneity. Heterogeneity quickly emerges from this background, but it is a form of heterogeneity that is entirely the product of human agency; as Haas and Kuhn's title suggests, it is "constructed" by human foragers and subsequently structures their behavior.

Finally, it is my opinion that Haas and Kuhn use computer simulation exactly as it should be used in archaeology: to test whether simple, quantifiable hypotheses are capable of producing the patterning observed in the archaeological record. Used in this way, simulation is at least as valuable as more traditional techniques for developing middle-range theory such as ethnographic research and experimental archaeology. The simulation of synthetic data sets using quantitative implementations of multiple-candidate hypotheses allows for rapid falsification of many of those hypotheses and the retention of the few that have genuine value. The hypothesis developed by Haas and Kuhn has genuine value, and I look forward to the future development of this research.

\section{Marcus J. Hamilton}

Department of Anthropology, University of Texas, San Antonio, Texas 78249, USA (marcus.hamilton@utsa.edu). 15 X 18

This is an interesting paper that successfully combines aspects of hunter-gatherer ecology, niche-construction theory, and the empirical archaeological record through the application of agent-based modeling, providing much interesting food for thought. This in itself is a rare accomplishment. The combination of the words "agent-based models (ABMs)" and "archaeology" generally make me very nervous. Because ABMs are relatively easy to construct computationally, they are used widely in archaeology, but often uncritically, and are therefore overused and misunderstood. This is because there is an inherent danger of circular reasoning in the uncritical use of ABMs: by design, ABMs do (and can only do) exactly what you tell them to do. Often, someone will design an ABM, let it run, and examine the outcome probability distributions of events. They then observe that the statistics of the outcome are remarkably well predicted by the inputs of the model. Of course, this approach is akin to observing that given the expression $y=f(x)$, I find that my $y$ 's are remarkably well predicted by my function once applied to my $x$ variables; that is, if I have two $2 \mathrm{~s}$ and the interaction between them is additive, the predicted outcome of 4 is very often observed in the data. However, the most effective use of ABMs is as a tool to predict series of outcomes given a known set of internal dynamics that are allowed to interact in systematic ways. ABMs should be simulated experiments. This then has the benefit of producing a result that can be reverse engineered to understand how a particular pattern emerged from a set of known dynamics given specific rules of interaction. And this approach is most effective when the dynamics are simple (thus analytically knowable), but the interactions are complex and so require numerical simulation. This does not require complex models, as the outcome of even the simplest models can become analytically intractable given just a few interactions.

I am happy to report that Haas and Kuhn, in my estimation, navigate these potential pitfalls quite well. The set of known interactions are (1) hunter-gatherers are mobile, (2) they use tools to perform tasks, and (3) these tools are made from raw materials that are heterogeneously distributed in space. The experiment is, holding all else constant, if there are varying probabilities of reoccupying sites based on the frequency of prior use, what might the archaeological outcome look like along various axes of variation, such as occupation lengths, site size areas, or the distribution of site sizes? The rationale for reoccupation is niche construction; as hunter-gatherers make tools and use space, they alter the probability space of future behavior, as prior behavior entrains future possibilities (to varying degrees), thus the past feeds back into the future. The terminology I would use to describe this phenomenon in space is path dependence - a key feature of the "new economics" for which Paul Krugman would later receive a Nobel Prize. Here slight variation in initial conditions in space leads to large differences in future outcomes, as the marginal initial differences between locations build exponentially over time, leading to right-skewed distributions with fat tails of probability. Hence, even very simple random interactions can result in seemingly unlikely probability distributions.

The central finding of their model has interesting implications: you can get highly skewed distributions of site sizes (perhaps approximating something as fat tailed as a power law) even in entirely homogenous landscapes, with only a slight preference for reoccupying previously used sites. Of course, 
the question is (as is raised in the paper), what happens when this path dependence on reoccupation behavior is coupled with the external geological, cultural, and biological sources of heterogeneity we see in most real-world landscapes? Under what sets of conditions do these processes interact to increase skewness, and in what conditions do they counteract one another? At this point, I would also like to raise a second concern I have with ABMs, which is that (much like in machinelearning models) the interactions that led to their outcomes are ultimately black box and unknowable: that is why an ABM was employed in the first place rather than a simple mathematical expression. This means that while it is possible to predict that the outcome probability distributions must be right skewed and fat tailed as the mechanisms involved are multiplicative, there is no way of knowing whether the actual analytically predicted statistical distribution is a power law (senso stricto) or some other right-skewed, fat-tailed distribution, such as a lognormal or a more general family of stretched exponentials, for example. Thus while it is interesting to me that Haas and Kuhn find fat-tailed probability distributions of site sizes in homogenous landscapes (that are well approximated by power laws), much as predicted, the observation that the variation of site areas is better fit by an exponential than a lognormal distribution is less interesting, as at these scales these distributions will be quite similar, and there is no analytical prediction in the model to predicted one over the other.

The larger implication of the paper I find to be the most important: niche construction - or the general phenomena of feedbacks between internal and external processes that entrain future outcomes - has played a central role in the evolution of hunter-gatherer ecology. Hunter-gatherers are not, nor have they ever been, passive players responding to environmental constraints. To varying extents, hunter-gatherers both adapt to their landscapes and adapt their landscapes. And we can see this archaeologically.

\section{Christopher Morgan}

Department of Anthropology, University of Nevada, Reno, MS 0096, 1664 North Virginia Street, Reno, Nevada 89557-0096, USA

(ctmorgan@unr.edu). 15 X 18

In this article, Haas and Kuhn develop a robust, agent-based predictive model to generate very specific expectations for four very clear hypotheses derived from their basic idea that initial site use conditioned site reoccupations and occupational intensity. At this basic level, this is exactly the type of research I would like to see a lot more of: formal logic, mathematical models, and quantitative data all operating within a transparent hypothetico-deductive methodology. Their conclusion-that initial site use indeed played a major role in conditioning later settlement patterning - is an important one. It implies that site size variation and settlement choice result, essentially, from a kind of stochastic "founder effect" that affects future settlement decision-making.

To some degree, however, I think the authors overstate their case. Though they allude to the success of other types of predictive models, especially those based in some way on environmental parameters, they also claim that what conditions settlement choice is "partially, if not wholly, unknowable." I have to disagree. It is clear in many cases that phenomena like resource characteristics (Hevly 1983), central place foraging decisions (Morgan 2009b), and territoriality (Eerkens 1999), just to name a few, have considerable effects on settlement decision-making. It is also clear, however, that stochastic processes have robust predictive power with regard to the same (Brantingham 2006). In this context, I think Hass and Kuhn's real contribution consists of providing a good counterpoint to more traditional predictive modeling, one that if used in conjunction with appropriate ecologically based predictions, should result in both more accurate and precise prediction and explanation. As in Bayesian analysis, prior probabilities matter and often result in better models, only not in a contextual vacuum that disregards the fundamental human ecology of settlement decision-making.

I think the weakest part of this paper consists of the data used to address their hypothesis that "artifact quantity covaries partially with occupation span." A sample derived from "limited excavations" at one site that happened to be occupied for some 1,500 years provides no support either for or against their hypothesis. In my experience, many sites have similar occupational spans (and many, of course, have much longer ones). More importantly, we do not know what artifact assemblages look like at other single-use and recursively used sites in the area, so we cannot evaluate whether the data they report are of any consequence. Put simply, without comparison to other sites and site types, it is impossible to tell with any confidence how the data from Soro Mik'aya Patjxa relate to the occupational span hypothesis.

These criticisms aside, this paper makes a significant contribution to how we might use behavioral ecology to understand settlement patterns. As Hass and Kuhn hypothesize, this contribution hinges on the costs and benefits of recursive site use: materials, features, and artifacts left behind during previous occupations could be reused by later ones, thereby reducing the costs (and increasing the efficiency) of latter occupations. This is exactly the conclusion my coauthors and I reached in a recent experimental study we undertook to assess the costs of investing in common hunter-gatherer residential features (e.g., wickiups, housepits, storage pits, lean-tos; Morgan et al. 2018). We found that though the initial costs of building such facilities were relatively low (less than a day's work for a family of four and about 2,500 kcal/person), not paying these costs in repeated successive occupations could conceivably result in substantially more efficient occupations, especially when compounded over 1,500 years or more.

More importantly, I think that Haas and Kuhn's work elicits some profound thinking about fundamental cultural 
evolutionary processes that might be revealed by settlement pattern analysis. This thinking hinges on the underlying explanation that Hass and Kuhn elide: what really determines why people reuse sites if not for nearby resources? I speculate that this type of decision-making relates as much to the costs and benefits of tool and feature reuse as to the costs and benefits of different types of culture transmission. There are, of course, many ways people learn and pass on knowledge (frequency-dependent bias, direct bias, indirect bias, etc.), but of all of them, individual trial-and-error learning is almost always the costliest way of deriving a new skill or set of knowledge (Richerson and Boyd 1992). Finding the optimal site location that balances the benefits of proximity to resources with the demands of differential foraging goals (sensu Zeanah 2004) would rely on exactly this type of individual learning: one really would not know if one spot was better than another without testing all similar locations against one another. Rather, finding a place that works well enough (especially in the context of frequent residential moves) and then returning to that place time and again would reduce search time for new (and perhaps better) campsites, which in turn would reduce opportunity costs affiliated with site selection. Biased and recursive site occupation might thus not necessarily result in fitness maximization with regard to settlement choice, but it could result in other adaptively advantageous behaviors paid for by the reduced costs of learning where to camp. Of course, the probability of meeting up with other people, including those of the opposite sex, might be another benefit of returning to predefined locations, one with much more obvious evolutionary ramifications (but one that has been little explored with regard to modeling settlement patterns). One way to do so might be to apply Allee's principle to the ideal free distribution (Fretwell and Lucas 1969), something also as yet absent in the increasingly prevalent use of this model in the archaeological literature (e.g., Codding and Jones 2013).

\section{Calogero M. Santoro, Cristobal Quiñinao,} and Daniela Valenzuela

Instituto de Alta Investigación, Universidad de Tarapacá, Antofagasta 1520, Arica, Chile (calogero_santoro@yahoo.com)/ Instituto de Ciencias de la Ingeniería, Universidad de O'Higgins, Avenida Libertador Bernardo O’Higgins 611, Rancagua, Chile/ Departamento de Antropología, Universidad de Tarapacá, Cardenal Caro \#348, Arica 1010068, Chile. 24 X 18

Haas and Kuhn present a provocative archaeological agentbased model $(\mathrm{ABM})$ to "predict structural properties of occupation intensity distributions" among hunter-gatherers within homogenous landscape. They apply this "simple nicheconstruction model . . . to deduce four predictions for emergent structure." These predictions were then verified with a hunter-gatherer settlement system constructed with archaeological data from the Lake Titicaca Basin in southeastern Peru (ca. 7,000-5,000 cal BP). This is an original and powerful contribution that integrates mathematics, archaeology, and computational science with standard model techniques to deal with the complex reality of hunter-gatherer mobility, opening promising multidisciplinary research.

The model assumes that the decision-making rule for hunter-gatherer mobility is biased by previous deposition of material resources at particular locations within homogeneous resource distribution. In this way, the model simulates processes of environmental niche construction and adaptation, where "the intrinsic environmental properties of a given location alone may not be able to account for an observed intensity of human occupation." That is, the habitual deposition of material resources at particular places on landscapes biases the future mobility decisions of energy-optimizing foragers. The authors hypothesize that constructed properties would determine reiterated occupation and artifact density on particular habitats. In their own words, mobility is "based on the spatial locations of materials that people carried and discarded, intentionally or unintentionally." The basic assumptions of the model depart from the definition of human as "tool users," which does not include the immaterial/ideological world included in the extrasomatic use of the material. They also say that the specific characteristics of the locations where people move (i.e., water sources, raw materials, hunting prey, ease of transit) are not driving forces on migratory moving processes. Natural resource structure (biomass productivity, precipitation, temperature, and latitude) is discarded, mainly because it can only account for the largest sites but not for variations on analogous environmental contexts. In other words, the main concern of the authors is explaining long-term larger occupational sites within homogeneous landscapes.

We estimate that models of foragers' decision to move in one direction or another and to select particular locations should include the intrinsic conditions of the places and the immaterial values that people assign to them. By excluding the presence of localized resources as a cofactor in the selection of places to settle, the model missed the influence of the distribution of resources (abundance, diversity, spatial dispersion) that varies greatly according to the ecological structure of a given area. The model works well within homogeneous distribution of resources, which would not be the case in regions with patches of distribution of resources such as deserts. The authors point out that "despite the extreme site size variation observed among Late Archaic sites ... . we were unable to identify any localized natural resources in spatial association with the largest sites." Given the characteristics of the chosen study area - precisely characterized for having homogeneous resources - it is not surprising that the influence of localized resources in the size of the sites was not detected or that they have not found any localized resources in the study area. In sum, by leaving the resource variable constant, how would the model test that resources are not influential, as suggested by the second prediction? Moreover, the authors stated that "we should also expect site size variation holding such 
environmental variables constant and even in the absence of such localized resources." The authors recognize the limitation by acknowledging that "a second extension of the working niche-construction model might consider how different degrees of environmental heterogeneity might affect the strength of preferential attachment to places" and that it is undeniable the "important role that natural environments play in structuring forager mobility, especially at large, interpatch scales where forager behavior and the associated material record is well accounted for by environmental structure."

The most critical point of the model is that the places to settle are not only chosen by the presence of natural resources, an issue difficult to approach archaeologically, especially for earlier epochs such as those dealt with in the paper. Ethnographically, it is known that certain places can be reoccupied over time redundantly, not by virtue of their resources but by virtue of other attributes, both intrinsic and extrinsic, whose values are enhanced by cultural factors, such as ideological ones. These values have proven to be tremendously important in structuring the mobility and settlement of hunter-gatherers (see, e.g., McBryde 1987). These factors could explain the query raised by the authors when they ask "why some rare locations experience accumulation over extremely long time frames."

For example, a simple confluence of rivers was a common reason to locate rock art sites that were used intensely, through successive events of artistic activities, expressed in a proliferation of rock art panels over time. These locations, without significant resources, contained instead intrinsic attributes (i.e., confluence of rivers) culturally valued for their ideological significance (Briones and Mondaca 2004). These issues are also acknowledged by the authors: "we might concede that many of the social and environmental contingencies that go into settlement location and occupation intensity are largely beyond archaeological detection and satisfactory explanation."

Although it is plausible that under certain conditions reusing certain places can minimize the cost and risks of exploring new places, it is not clear how the first settlements were selected. What were the motivations behind the "founding effect"? What were the criteria or attributes to choose a particular place? It is not clear what is the theoretical basis for the "behavioral explanation for structural properties of huntergatherer settlement systems" proposed by the authors. They escape from this constraint with the following: "We begin with the premise that knowing a prehistoric forager's motivation for initially occupying a novel point within some environmental context is partially, if not wholly, unknowable. The contingencies that go into specific site selection may be quite complicated, historically contingent, and ephemeral." The model does not account for the motivations of individuals to reuse old locations, beyond the benefits that this could bring, as the authors argue. Nor does it account for the abandonment of old locations and the subsequent use of new locations over time, as is amply documented by the archaeological record in the Andean region.
To solve these constraints, the authors avoided constructing a complicated numerical ABM by excluding the wide array of endogenous and exogenous variables. This resulted in a parsimonious description exploring the structure of variation among forager site sizes within a given environment, with special attention given to the attachment to culturally constructed places, which are well described in the literature but rare for novel or founder occupation motivation.

The four predictions for the emergence of structure and settlement patterns deduced from the numerical ABM simulations fit well with the analyzed archaeological data from Lake Titicaca Basin. The model describes the behavior of foragers as a stochastic process that can be seen as a biased random walk that itself changes the structure of the landscape. This hypothesis recalls the modeling of chemotaxis in a biological context. Theoretical results show that there is a relationship between the initial mass (in this case, the number of foragers) and the chemoattractant parameter (in this case, the probability $m$ ) leading to clusters (see, e.g., Perthame 2004). We estimate that this remark should be considered for exploration in the current model. For a landscape with a low density of foragers, it should be more likely to find small excursion paths and a low rate of encounter between foragers than in large, complex settlements.

In physics, a very extended rule is that nature tends to minimize the use of energy. While this assumption can be extended directly to modern humans, it does not represent quite clear thinking, for example, in complex religious systems. Among hunter-gatherer societies, however, it makes more sense (Brantingham 2003; Kuhn 1995). The model incorporates this assumption by adding the element of planning in moving strategies, resulting in the notion that reuse, while apparently trivial, shows surprising scale structure and implications for archaeological settlement patterns.

One remarkable point is that "small differences in the initial conditions of site use and reuse can lead to radically different outcomes in overall occupation intensity of particular places on landscapes." Mathematically speaking, this implies either that steady states are not globally stable or that there is a set of steady states with different resource attraction locations. Eventually, the proposed model could be a chaotic dynamical system opening a whole set of theoretical implications. However, the nondeterministic characteristic of the working model is intrinsic to some stochastic structures and can be studied by different techniques, for example, the theory of open systems. Another possibility is to change the focus of the study to the probability of finding some particular configuration instead of studying the particular configuration itself. The authors addressed this by explicitly stating that the model can be understood as a "neutral model."

In sum, since a model is a simplification of a complex problem, variables have to be well stated and discussed. The present $\mathrm{ABM}$ is based on three main ideas: "obligate tool use, mobility, and energy optimization." If the authors consider expanding the model in the future, they might elaborate on more detailed 
descriptions, including landscape heterogeneity, despite the fact that the framework presented led to a set of testable predictions that are consistent with archaeological data. The present model is an implementation of the rule that with some probability $m$, foragers move to a new place that has been previously visited or randomly to a new location. In a scenario of a large $m$, results will depend on initial conditions of foragers depositing a unit of material culture. But even under this oversimplification, some statistical distributions can be observed and identified as predictions of the model. Alternatively, the second prediction (site size is independent of localized natural resources) could be more deeply studied to contrast it with the notion of heterogeneity on populations and self-organization patterns, which will also lead to span on homogeneous landscape scenarios. An alternative hypothesis is that the span of large and small locations could be the product of cultural differences between hunter-gatherer groups rather than revisitation of cultural settlements.

Above all, the model has the virtue of explaining the mobility and settlement of hunter-gatherers beyond the structure of resources, which has been overemphasized in huntergatherer studies. This is a relevant contribution and represents a turning point in most hunter-gatherer models.

\section{Marcela Sepulveda}

Instituto de Alta Invetigación, Universidad de Tarapacá, Antofagasta 1520, Arica, Chile (marcelaasre@gmail.com). 9 XI 18

Understanding the causes, motivations, and limitations of mobility, as well as its forms and durations, is one of the primary challenges of hunter-gatherer studies (e.g., Binford 1980; Brantingham 2006; Grove 2009; Hamilton et al. 2016; Kelly 1983). Ethnographic information available about these societies has given rise to quantitative indicators that have been useful for building models that attempt precisely to explain the reasons for such displacement. Those include environmental/ ecological causes but also social and cultural ones; yet these studies emphasize external factors more often than the group's own decision-making process. In the authors' own words, the problem with studying remote hunter-gatherer societies isas in all archaeological research-that "archaeologists cannot observe movement per se," a reality that only increases the analytical challenge. The analysis of materials - usually lithics, along with their technologies, organization, and reductive sequences, but also the raw materials used - and the characterization of settlements by site type and function, location, size, and other aspects are all strategies that can be used to address the mobility of hunter-gatherer groups. Another approach is modeling, which involves the abstraction and reduction of reality via the definition and weighting of indicators deemed most relevant.

Haas and Kuhn fall here into the latter group of studies, proposing in their article a predictive model that allows them to "explain the distribution of site sizes within a given hunter- gatherer settlement system within a given environment" and attempting to show that "forager site size variation can be surprisingly structured and entails mobility decisions with preferential attachment to culturally constructed places on landscapes." For the authors, "simply by moving, modifying, and depositing materials on landscapes, people actively construct the ecological niches to which they adapt." This is a crucial point of their proposal that is based not on the optimization of resources but on "use of a socionatural landscape." Indeed, the authors attempt precisely to comprehend the reiterated use of certain locations over time, once a space had been occupied. Relying on a mathematical (agent-based) model, the authors deduce and evaluate four predictions, contrasting them with spatial records associated with hunter-gatherers of the Late Archaic period. They confine their analysis strictly to the lithic material present in a $41-\mathrm{km}^{2}$ area near the Ilave River, in the western watershed of Lake Titicaca in Peru, situated specifically in the Altiplano at 3,800-4,000 $\mathrm{m}$ asl.

The study describes and addresses a concrete case of mobility within an ecological niche with very homogeneous conditions and in which the "habitual deposition of material resources at places on landscapes biases the future mobility decisions of energy-optimizing foragers." By understanding the reutilization of locations with a preponderance of potentially recyclable resources as a deliberate, intentional act in a culturally constructed and not only environmentally determined landscape, the authors confirm their predictions almost entirely. Nevertheless, their study has the advantage of being focused on an environment that we could consider ideal, as the altitude conditions and seriously limits the availability of resources, including water. So they can reduce indicators studied. Their analysis has the added advantage of restricting understanding of movement to a limited area, which the authors themselves justify. This prompts one of our first observations, as while we understand that these decisions were merely methodological, we know that material evidence - employed here as diagnostic types (in this case, the lithic points, types $4 \mathrm{D}$ and $3 \mathrm{~F}$ ) recorded on the surface-is common in a region that is actually much more extensive, encompassing the highlands of southern Peru, western Bolivia, and northern Chile. Osorio et al. (2017) have called this space a megapatch, recognizing the need to understand the mobility of hunter-gatherers in this great macroregion as a shared tradition that dates as far back as the Early Archaic (10,500-8,000 years BP), and so it should not be surprising that knowledge of and the construction of dynamics of the Late Archaic had their origins in previous eras. But the authors fail to mention this in their work, as they also limit their study to a limited time span, based on the discovery of a single type of diagnostic object, whose morphology and metric typology are today rather questionable. Regarding the organization of mobility (Kuhn 1995), any study should consider not a limited area alone but a broader area - although the authors expect that this should not affect the model. In effect, the mobility of huntergatherer groups in the Altiplano is part of a much more extensive settlement system or pattern, and thus in addition to 
considering the size of the sites, they should also identify concretely the activities carried out at each deposit (considering the entire assemblage of materials, instruments, and waste), which can differ from and even complement one another within a limited niche. Furthermore, they should provide details about that record-for example, the quantity and types of waste and other artifacts and the use and distribution of raw materialsthat could reveal large differences among the deposits identified in the Altiplano and their relation to the origin of the huntergatherers who used that space. In effect, it could very well be that there was not a single group that moved in the Altiplano but several entities that may have come together on specific occasions and occupied the most extensive sites, for example. Finally, basing the model on a limited area limits our view of the mobility of these groups, who transited through environments that were much more diverse than those observed in the Altiplano alone and included very different landscapes and rugged topography that displayed quite different conditions even over short distances. Added to this, given our experience in northern Chile, it seems problematic for these environments to omit taphonomic issues that affect the preservation of the deposits. The appearance of new material on the surface 18 years after the first collections were performed in the basin points to the scope of those processes.

Added to these observations related to the site configuration is that the model isolates hunter-gatherer mobility from all other processes occurring in their surroundings, when we know for a fact that during the Late Archaic, in addition to moving around and obtaining resources directly, these groups exchanged goods with other groups, some of whom were already sedentary (Castillo and Sepúlveda 2017). These social interactions thereby affected the mobility dynamics of the hunter-gatherer groups themselves, through the development of circuits that were increasingly smaller and more circumscribed along archaic sites. We have to consider that people move to establish and to keep social relations with others (Tomasso and Porraz 2016), an aspect not included by the authors. Additionally, the most extensive sites could well correspond to deposits left at meeting places or left along mobility routes that had been clearly established even thousands of years before, at particular landmarks related to the routes these groups traveled- or the specific activities they carried out - collective hunting spots, for example. Decontextualized not only from their natural but also their cultural environments, our understanding of the use of space and the reiterated use of specific places in that space can be only partial, at best.

The Late Archaic in the Andes was a space in which significant territories, cultural landscapes, places of memory, and cultural landmarks were constructed and cultural mapping took place (Tomasso and Porraz 2016), in which the role of flows of information and the transmission of knowledge were key factors in the dynamics of the different social entities that inhabited those spaces. Understanding those broader aspects is therefore particularly important for understanding huntergatherer mobility, and as such it is necessary to attempt to value and weight indicators that may refer to those aspects (to enlarge this discussion, see also Brantingham 2006, including the comments and reply).

Haas and Kuhn's work offers an interesting way of modeling and understanding decisions made by hunter-gatherers with regard to mobility, based on the material record dispersed in a particular environment with ideal conditions, without managing to go beyond a theoretical framework ruled by optimization. As they work with a model, we understand their simplification of reality, but we are persuaded of a greater complexity. At the end of their work, they also offer interesting possibilities for broadening their study, as well as acknowledging their own limitations, an apt reflection for a work still in progress and one that invites us to rethink our approach to hunter-gatherer mobility in the Andean highlands. We agree that there is a need to further develop, broaden, and renew our way of analyzing the mobility of these Archaic groups in order to better understand those entities who lived in the shadow of the Andes's highest peaks for more than 10,000 years and who were the precursors of later traditional Andean societies-societies that, as we well know, had a particular cultural geography that was far removed from paradigms of optimization.

\section{Brian A. Stewart}

Museum of Anthropological Archaeology and Department of Anthropology, University of Michigan, 1109 Geddes Avenue, Ann Arbor, Michigan 48109, USA (bastew@umich.edu). 5 XII 18

Recent years have witnessed a growing appreciation of huntergatherer niche-construction processes and their feedback effects within coupled human-natural systems (e.g., Bird et al. 2016; Bliege Bird et al. 2013; Collard et al. 2011; Laland and O'Brien 2010; Riede 2011; Riel-Salvatore 2010; Riel-Salvatore and Negrino 2018; Rowley-Conwy and Layton 2011). But while claims of hunter-gatherer niche-construction behavior pepper the archaeological literature, lacking is a cohesive body of theory and operable models with clear archaeological predictions and test implications to asses them (cf. Zeanah 2017). With this article, Haas and Kuhn take an important step toward redressing this by carefully crafting and testing a formal model concerned with understanding the extent to which an exclusively cultural variable - the reuse of discarded material culture-influences hunter-gatherer settlement behavior and emergent structure. Their contention that extant sites serve as de facto resource patches - attracting foragers by reducing provisioning costs while growing in supply in a catalytic process that leads to skewed site size distributions and occupation spans - is borne out by their agent-based model and subsequent case study.

Archaeologists, often citing Binford (1983), frequently express the view that suboptimal conditions generated by previous occupations (e.g., local resource depression or noisome waste/pests) deter mobile hunter-gatherers from reinhabiting 
the same locale. While this is in many cases true, broader ethnographic and archaeological readings reveal that campsite reoccupations - many at least partly motivated to take advantage of accumulated materials or food patches - are in fact not uncommon (e.g., Bailey and Galanidou 2009; Buenger and Goodrick 2017; Cribb 1996; Eerkens 2003; Gorecki 1991; LaBelle 2010; Nadel et al. 2004; Peterson 1968, 1973; Politis 2007; Smith and McNees 2011; Stewart, Parkington, and Fisher 2011; Vaquero et al. 2012; Wandsnider 2008). Huntergatherer settlement decisions were clearly affected by the visible material residues of previous such decisions. I applaud the authors for their analysis of how this process plays out and its predictable effects on archaeological settlement patterns. There are many other, more detailed aspects of this paper that are praiseworthy. In my remaining space, though, I wish to highlight what I suggest are several vulnerabilities of the model that may hinder its ability to gain traction. I do this not to disparage but rather in the spirit of helping broaden its applicability.

First, opportunities to recruit Haas and Kuhn's model in the interpretation of settlement structure would seem heavily contingent on local environmental structure. The landscapes under scrutiny in the study are either wholly (simulated) or largely (case study) undifferentiated with regard to natural resource distributions. Though I appreciate the need to keep things simple in order to hold constant as many variables as possible, I wonder how broadly the resulting patterns can be extrapolated to less homogeneous settings. If settlement decisions in the latter are dictated more by dietary concerns than material provisioning, it may be useful in future to model such decisions on a sliding scale of resource patchiness from homogenous/predictable (material provisioning dominated) to heterogeneous/volatile (dietary provisioning dominated). Moreover, many material resource types (flakeable rock, firewood, etc.) vary independently from one another in terms of abundance, distribution, and quality, while others (bone, horn, antler, skins, sinew, shells, plant fibers for tools, clothing, shelters, etc.) cannot be cleanly isolated from variability in the dietary resources from which they derive.

A more practical concern is with geomorphological variability. As skillfully demonstrated, Haas and Kuhn's model works well in their highly specific case study location on the Andean Plateau. But how useful is it for predicting or detecting such niche-construction behaviors in geomorphological settings more dynamic than the wet puna? Likoaeng, a southern African Later Stone Age site mentioned by the authors early in the paper, is a case in point. The layers of this repeatedly inhabited site are often separated by sterile silts and sands (Parker, Lee-Thorp, and Mitchell 2011). This is a consequence of the site's location in a deep river valley of a highly erosive landscape. These recurrent alluvial depositions would have concealed signs of previous encampments. Similarly, regions with dense forests, sandy deserts, or persistent snow cover all seem unlikely to foster regular site reoccupation on the basis of visible material residues alone.
This brings me to my final point, which is that I think Haas and Kuhn too readily brush aside alternative cultural motivations for reinhabiting specific places in hunter-gatherer landscapes. Fission-fusion cycles-fundamental to mobile lifeways and likely of considerable antiquity among Homo sapiens - are given particularly short shrift. The authors suggest that fission-fusion dynamics do not explain why certain rare locales experience long-term material accumulation, but again that seems likely to be true only for environments with evenly distributed resources. In most environments, feeding many mouths during an annual aggregation phase(s) means large gatherings around spatiotemporally redundant concentrations of key dietary resources. Returning to Likoaeng, this site's immense assemblages of fish bones, their low species diversity, and its position astride rocky rapids all point toward it having hosted large springtime aggregations of people scheduled to exploit specific taxa of spawning freshwater fish (Mitchell et al. 2011; Plug, Mitchell, and Bailey 2010; Stewart and Mitchell 2018).

But we must also acknowledge the possibility that specific places were repeatedly inhabited or used for largely or purely ideological reasons, including religious purposes and associated ritual performance. Discussing the use of such sacred places in hunter-gatherer ethnographies, Whallon (2016) emphasizes their importance as "nodes in networks of movement required by cycles of ceremonies which must be carried out in some regular and recurrent basis to fulfill the requirements of various religious, belief, and symbolic systems" (268). Iterated over hundreds or thousands of years, might the tight spatial redundancy of such gatherings produce a similar settlement pattern as that predicted by Haas and Kuhn? If so, this could be viewed for the following reasons as working complementary, rather than in opposition, to their model: Whallon (2011) and others (e.g., Minc 1986; Minc and Smith 1989; Rockman 2003) have suggested that hunter-gatherers embed ecological information within systems of belief and religious practice to enhance the spatiotemporal accuracy and transmission of such adaptive information and that this extends to ceremonial mobility and associated gatherings (Whallon 2016). The embedding of adaptive information in religious tradition is argued to be particularly pronounced in extremely patchy environments, where premiums on acquisition and storage of fresh and accurate information are high. Spatially redundant gatherings motivated by ritual and ceremony should thus be more common in heterogeneous resource settings. Though speculative, I wonder whether this represents a sort of ideological nicheconstruction behavior that - while triggered at the opposite (spatiotemporally discontinuous) end of the spectrum of resource configuration from its material reuse counterpart (spatiotemporally continuous) - might nonetheless influence settlement structure in analogous ways.

These questions and critiques notwithstanding, Haas and Kuhn's contribution provides a much-needed testable model for a specific form of hunter-gatherer niche construction with clear archaeological implications and showcases its power for 
creating a fuller and more realistic picture-given the right conditions - of emergent ancient behavioral systems. While I hope that in future work they attempt to incorporate more diverse environments and nonmaterial concerns into their explorations of persistent places, I eagerly look forward to next steps.

\section{Reply}

We thank the 10 commentators for evaluating our argument and offering their insights, which have challenged us to sharpen our thinking on the hypothesis of forager mobility in constructed environments. The comments seem to indicate general agreement that some form of systemic preferential attachment behavior - as opposed to some postdepositional process or sampling error - likely drove extreme site size variation in prehistoric hunter-gatherer settlement systems. We are furthermore reassured by Grove's, Hamilton's, and Santoro's encouraging assessments of our application of agent-based modeling for generating archaeologically testable predictions.

We will begin by discussing a concern raised by Bettinger about our theoretical starting point in ecological niche construction. We then go on to consider alternative mechanisms to account for the major empirical pattern of interest-extreme site size variation in hunter-gatherer settlement systems. Nearly all commentators identified one or more alternatives, including guided variation in site selection, environmental structure, fission-fusion dynamics, functional differentiation, and metaphysical cultural meaning. We consider each of these in turn to evaluate their explanatory merits relative to the constructed environments model that our paper puts forth. We show that while each alternative is valid and offers plausible accounts of certain predictions, each falls short of anticipating one or more of the empirical patterns under consideration. This leads us to conclude that the alternative behaviors likely contributed less than niche construction to the cultural systems under investigation. Last, we will address concerns about evaluating the model in certain ecological and sampling contexts.

\section{On Niche-Construction Theory}

Our reference to niche-construction theory (NCT) raises concern with Bettinger who argues that NCT has added little substance to archaeological research. He suggests that "just about everything humans do has longitudinal feedback effects that can be construed as niche construction, but very little of what we have learned about these varied behaviors owes much to niche-construction theory." We agree with Bettinger here (Stiner and Kuhn 2016). We note that our use of the term "constructed environments" serves to highlight endogenous drivers of human mobility in contrast to the exogenous ones that hunter-gatherer anthropologists have tended to emphasize. While our model does derive conceptual inspiration from NCT, we note that it also derives key insights from optimal foraging theory, statistical physics, complex systems theory, and neutral theory. That these diverse perspectives point to a similar theoretical end point-recursive land-use dynamics and extreme site size variation among hunter-gatherers - suggests a theoretical consilience (Wilson 1998). The name of the theoretical starting point is less important to us than the extent to which we have gained insight into the processes of human mobility and archaeological site formation.

\section{Guided Variation}

Bettinger also proposes a guided variation model as an alternative explanation for the observed forager settlement patterns. Morgan alludes to a similar mechanism. Bettinger captures the gist of the model as follows: "the place worked for them and nothing much has changed, so it ought to work for us." This mechanism posits that previously occupied places serve as analytical shortcuts to identifying high-productivity natural resource areas. He proposes that the model entails strong preferential attachment to places consistent with our prediction 1. It is easy to understand why people might identify a place with debris from previous occupations as a safe and acceptable campsite. However, it is not self-evident that the quantity of debris would be identified as proportionately safer or more acceptable. In contrast, the quantity of debris at a place does index proportionately more opportunities to find materials to reuse. So we are unconvinced that the guided variation model entails runaway material accumulation at few sites, per prediction 1 of our model. Similarly, it is unclear how such a model predicts skewed variation in site areas (our prediction 4). The guided variation model does, however, anticipate highly variable occupation spans (our prediction 3 ).

The predictions of the two models also diverge in how they articulate with environmental structure. Our cultural resource model predicts that recursive land-use practices and thus extreme site size variation should transcend environmental structure, occurring even in the most homogeneous environments because geographic heterogeneity emerges from human land use (our prediction 2). Because Bettinger's guided variation model privileges natural resources - that is, it is agnostic on the role of culturally constructed resources-we should expect the behavior to vary by environmental structure. The greatest benefit ought to arise in patchy environments, where some foraging territories are intrinsically more productive than others and foragers seek them out. In contrast, the least benefit ought to occur in uniform environments where all foraging territories are roughly equivalent. In fact, guided variation in site selection would be self-destructive in homogeneous environments because high-frequency reoccupation of a few particular locations would preferentially exhaust local natural resources while fundamentally limiting access to untapped resources at other environmentally equivalent locales. 
To be sure, such environmental degradation is to be expected in our constructed environments model as well, but those costs are offset by the time savings associated with recycling cultural materials. To salvage the guided variation model, some direct economic benefit is required to offset the costs of environmental degradation in homogeneous environments.

This critical difference between the two models leads to a related set of competing predictions. Our cultural resource model intrinsically suggests recycling of cultural materialsfor example, reuse of houses, lithics, and groundstone. The guided variation model, in contrast, is agnostic on the recycling of cultural materials. Although we did not specifically examine the extent to which recycling was observed in our Altiplano archaeological case study, we note that material recycling is well known from archaeological contexts (Barkai, Lemorini, and Vaquero 2015). Moreover, Haas, Surovell, and O'Brien (2019) recently evaluated this expectation in an ethnoarchaeological study of residentially mobile herder-foragers in the Mongolian Taiga. They directly or indirectly observed recycling of previously deposited cultural materials in five of six camp reoccupations. Again, guided variation may be at play, but an additional parameter is needed to explain recycling. The constructed environments model captures both reoccupation and recycling with a single behavior.

We therefore suspect that guided variation played a lesser role in hunter-gatherer site reoccupation. This conclusion is similar to one recently reached by Richerson (2019). In a simple thought experiment involving the value of a farm, he observes that although a naive purchaser of a farm would certainly benefit materially from land improvements made by previous owners (i.e., niche construction), the information content in such farm improvements (i.e., guided variation) would do little to enhance the new owner's farming abilities.

\section{Fission-Fusion Dynamics}

Grove, Sepulveda, and Stewart raise the possibility that social interests could be at play. Grove juxtaposes our environmental construction mechanism against a hierarchical fission-fusion mechanism that he previously put forth to account for extreme site size variation in prehistoric agricultural settlement systems (Grove 2011). This model imagines that site size variation is a function of differential population aggregation as opposed to differential reoccupation. Whereas the former is largely a synchronous process, the latter is diachronic. He proposes a simple empirical test to compare the efficacy of the two competing models. He argues that whereas our model implies a continuum of occupancy at a given site, fission-fusion entails occupational hiatuses. He then analyzes the temporal frequency distribution of ${ }^{14} \mathrm{C}$ data at Soro Mik'aya Patjxa, finding evidence in support of occupational hiatuses and thus the fission-fusion model.

In fact, our working model does not actually predict continuous occupation as Grove suggests. Figure 4 of our manuscript reveals highly variable occupation spans across a large range of site sizes, which entails long hiatuses at many sites. Such occupational hiatuses follow from the fact that there is no material degradation built into the model - a reasonable assumption for durable materials such as stone, which allows foragers to discover usable materials at sites long after their abandonment. We therefore do not see Grove's test as valid for discriminating between our diachronic model and his synchronic model.

A more fundamental deficiency of Grove's fission-fusion model, in the strict sense, is that it does include a mechanism that compels mobile foragers to reoccupy particular locations on landscapes once a fusion event is over. The model must therefore add an additional parameter, such as a localized natural or constructed resource, to ensure fusion events occur at particular locations and thus achieve the same level of explanatory power as our single-parameter model. This suggests to us that reoccupancy was a more substantial force than fission-fusion dynamics in driving site size variation in huntergatherer settlement systems. The case may be different for agricultural settlement systems, where site occupancy is relatively synchronous.

Morgan hints at an intriguing possibility that marries the guided variation and fission-fusion models. He suggests that predictable camp locations may be adaptive for increasing the probability of making social connections. Here as in the guided variation model, the material dimensions of previous occupations signal some other currency of interest - social interaction, in this case - rather than offering some intrinsic economic value to the foragers who detect them. This is an interesting and plausible model. However, if the guided variation and fission-fusion models are overengineered, as we have argued, then this three-parameter model would be even more so.

\section{Functional Differentiation}

Morgan, Santoro, and Sepulveda suggest functionalist models to account for hunter-gatherer site size variation. Sepulveda contends that it is important to carefully examine how occupation intensity covaries with assemblage type under the reasonable assumption that different activities should be associated with different rates of artifact deposition. We have opted not to pursue an explicitly functionalist interpretation of site size variation for two reasons - one theoretical and the other empirical. From the theoretical perspective, Binford (1982) observed that functional classification of hunter-gatherer sites is notoriously problematic because of the tendency of huntergatherers to use the same place for different purposes at different times. We should therefore not expect to observe clear site differentiation when places are used repeatedly.

From an empirical perspective, the Late Archaic Period lithic surface assemblages that are the subject of our study are notably uniform. Projectile points overwhelmingly dominate tool assemblages, with scrapers present but rare. We are unable to identify any readily apparent functional differentiation among sites of different sizes. We suspect that formal statistical 
analysis would be unable to rule out the possibility that small sites are merely statistical subsets of large sites in most cases. Admittedly, we have not explicitly tested this proposition.

Franco raises a related concern in our use of projectile points as a metric of site size. We assume that the problem here is that projectile points entail a specific function or set of functions. By extension, sites with projectile points served specific functions, such as hunting camps. Thus the artifact quantities we observe reflect intensity of those activities and not occupation intensity per se. We agree that our use of projectile points as demographic proxy is imperfect. Nonetheless, we believe it is appropriate for our purpose. We are assured by the fact that site size and site area are correlated. Because site area takes into account the full range of artifact types, the correlation suggests that projectile point counts are a reasonable proxy for artifact quantities more generally. From a practical standpoint, projectile points are the only artifact class that allows relatively large sample sizes from many sites with a degree of temporal control. Franco presciently suggests using obsidian artifact counts as a viable alternative metric, with hydration for temporal control. We agree that the approach could provide a check on our projectile point proxy, while recognizing that obsidian also suffers from the same functional limitation as projectile points. Moreover, obsidian was not used by Archaic populations in the Ilave Basin study region and so is not an option for this case study.

Franco also questions our exclusion of planning and geographic distance. Though we acknowledge that these would have been undeniably important in hunter-gatherer camp selection, we have chosen to set them aside because we have no theoretical reason to believe that they are directly relevant to the question at hand. Specifically, it is impossible to predict why use of specific locations would be planned to different degrees on a relatively homogeneous landscape. We could only add planning into the equation post hoc. Moreover, the small geographic extent of our study makes geographic distance a trivial variable.

Santoro raises another related possibility - that size variation reflects cultural differences. Here it is imagined that site size variation is the product of distinct cultural groups. This could be the case but only if different cultural groups who laid out their camps differently or lived in groups of different sizes also produced the same projectile point styles in the same valley. In principle, one could examine the more subtle design traits of projectile points or other material aspects of the associated sites to determine whether they covary with site size, but that would be another study.

\section{Geologic Process}

Sepulveda raises the concern that taphonomic process may be influencing our results, citing the fact that we were able to recollect large quantities of projectile points 18 years after initial investigations. In other words, the geology must be quite dynamic if so many artifacts surfaced in that time. Tapho- nomic processes have certainly affected site size variation in our study. However, the fact that we observed the same basic pattern 18 years apart suggests to us that the observed statistical patterns are remarkably stable despite such taphonomic processes. The process largely responsible for the exposure of artifacts on the surface is agricultural plowing, which tends to randomize artifact exposure and burial within sites. We furthermore note that the geologic surfaces examined have been stable throughout much of the Holocene (Rigsby, Baker, and Aldenderfer 2003), and the site boundaries rarely correspond to erosional features. We therefore have little reason to suspect that geologic processes contribute much to the patterns examined in our analysis.

Stewart raises a different question related to geology. $\mathrm{He}$ rightly notes that the burial of occupations would obscure material affordances, preventing subsequent occupants from identifying them and thus reoccupying the location per our constructed environments model. He points to Likoaeng, a multicomponent hunter-gatherer site in South Africa, as an example of thick artifact-sterile strata alternate with cultural strata, suggesting periods in which the material record would have been invisible on the surface. Indeed, such an observation would not be predicted by our environmental construction model. However, closer inspection of Likoaeng site structure suggests that it violates the assumption of ecological homogeneity. The site appears to be associated with a natural rockshelter. Mitchell, Plug, and Bailey (2008) state, "[Sediment] deposition took place against an exposed sandstone rock face that runs along the south side of the Likoaeng stream and southward parallel to the Senqu. It became apparent during excavation that a buried overhang, probably of some size, is present within this rock face. . . . We believe that this probably formed the original focus of human activity" (83). Thus a localized natural affordance, which was exposed and visible in the past, may account for reoccupations spanning periods of site burial in that particular case. Moreover, there is no reason to suspect that sediment aggradation at the larger sites was slower and more regular than at the smaller sites.

\section{Metaphysical Cultural Meaning}

Clark points out that foragers reoccupy locations for a variety of reasons that are not always economic. The "metaphysical cultural meaning" of places offers one such alternative motivation. Santoro and Stewart echo this model. Clark cites the human burials at Soro Mik'aya Patjxa (SMP) as evidence, supposing that the high concentration of burials index ideological motivations for reoccupying the site. We agree that such dynamics could have been at play in any given huntergatherer system, including the system that we examined.

It is also worth asking how particular places become meaningful. In Keith Basso's remarkable examination of Western Apache place-names, he notes that the majority of toponyms are purely descriptive. Still, some places are identified with noteworthy events, and people may take care to name places that 
they want to recall, places that are good to know about or good to avoid. However, even the purely descriptive toponyms are tightly woven into narratives of mundane and historically important events (Basso 1984). Consequently, the meaningfulness of a place may not be independent of its occupational history. The places where people spend a lot of time will be talked about a lot and will enter into the lexicon of known and meaningful places. An oft-occupied location is more likely to have been the stage for memorable events, and a place with lots of usable material left over from past occupations is good to know about.

While acknowledging the important role of cultural meaning in camp selection, we hesitate to exclude the alternative extreme that, at least in some times and places, foragers were acutely attuned to the economic calculus of camp reoccupancy. We furthermore hesitate to assume that human burial assemblages evidence ideological attractions to place, especially when those places show domestic refuse, as at SMP (Haas and Viviano Llave 2015). Natural death rates might offer a more parsimonious explanation for the burial concentration in such cases. If SMP were occupied for just 1 month per year for 1,500 years by families of four, the total occupancy would represent 180,000 person-days. Given a life expectancy of 40 years, we would expect about 12 deaths at that location by chance alone. These parameter values are well within reason, and so we cannot reject the possibility that the concentration of human burials reflects natural death rates as opposed to metaphysical attachment and preferential burial at the site. Even if we were to accept a metaphysical argument, one would still have to explain how such recursive land-use practices could offset the costs of environmental degradation discussed above (see "Guided Variation").

\section{Natural Resource Structure}

Bettinger, Morgan, Stewart, Santoro, and Franco all expressed varying degrees of skepticism about our conclusion that internal dynamics could explain extreme site size variation in forager settlement systems. Bettinger points out that highly localized resources such as springs ought to preferentially draw foragers to reoccupy specific locations. We agree, at least at a general level. Hence, our assertion that the results presented here "do not undermine the undeniably important role that natural environments play in structuring forager mobility, especially at large, interpatch scales where forager behavior and the associated material record is well accounted for by environmental structure." What does this mean for the specific example of springs that Bettinger highlights? Imagine five springs distributed across a forager territory. Each spring has similar outflow and is located in similar environmental contexts. A strictly environmental model would predict that occupation intensity at each should thus be similar. The constructed environments model, in contrast, predicts that one spring would experience far greater occupation intensity than the other four. So even when localized resources attract more occupation than other parts of the landscape, the constructed dimensions of those springs anticipates an additional level of variation in occupation intensity.

Drawing further from the hypothesis that natural environments structure site selection, Morgan takes issue with our claim that the initial impetus for camp selection may be unknowable: "[Haas and Kuhn] also claim that what conditions settlement choice is 'partially, if not wholly, unknowable.' I have to disagree." The highlighted phrase is taken out of context. We stated that "knowing a prehistoric forager's motivation for initially occupying a novel point within some environmental context is partially, if not wholly, unknowable" (emphasis in original). The point here is that when all other environmental parameters are equivalent, it may be difficult or impossible to know why a forager chose to occupy this or that particular spot for the first time. As obligate dwellers of houses, most contemporary humans occupy extremely localized spaces. One may choose to camp by a river, but why they chose to place their camp here and not $200 \mathrm{~m}$ over there along the same linear feature may be difficult to know archaeologically.

\section{On Model Complexity and Parsimony}

Our consideration of the six alternative models and their variants reveals a common thread in our responses. We perceive a lack of theoretical parsimony in the alternative models relative to the constructed environment model. The environmental and fission-fusion models do not include an explicit mechanism for drawing individuals back to highly specific locations on landscapes. The environmental models furthermore cannot account for extreme site size variation within homogeneous environments. The guided variation and metaphysical culture meaning models similarly cannot account for why such behavior should exist in homogeneous environments where the costs of reoccupancy would be high due to environmental degradation. Each of these alternatives can only be salvaged by the addition of a mechanism that adds some direct economic benefit to high-frequency reoccupation of highly localized places. The alternatives therefore require additional complexity without increasing explanatory power beyond what is achieved with the constructed environments model.

Sepulveda is "persuaded of a greater complexity." We agree. Reality is always more complex than cognitively finite humans can hope to construct. But that does not mean that simple models are not useful. Just because local road networks are more complex than what is shown on my road map does not mean I should replace it with a 1:1 scale map. If the goal were to enumerate all of the behaviors that contribute to camp selection among foragers, then we would certainly want to include all of the behaviors identified by the individuals who commented on this paper and then some. However, our goal is to understand whether attractions of constructed environments could have been a major behavioral driver of the 
extreme site size variation seen in many sets of hunter-gatherer archaeological sites. We argue that the constructed environments model offers a good first approximation, simultaneously minimizing free parameters while accounting for the most empirical variation. Finding the appropriate level of model specificity furthermore helps us understand the major drivers of key features in the evolution of hierarchy and sedentism in human societies. Overspecificity risks misidentification of underlying mechanisms. Nonetheless, more detailed exploration of this case or alternative applications may show where the model is insufficient and where other factors must be given greater weight.

\section{Application of the Model}

Clark, Stewart, and Santoro express concern about applying the model to certain environments. Clark observes that our analysis would not be possible where differential burial and preferential excavation of large sites biases samples. Even without systematic recovery at a regional scale, we feel that the constructed environments model could serve as a candidate hypothesis when trying to interpret few large sites. Occupation spans and quantitative comparisons between measures of occupation intensity and environmental productivity at a few sites of interest could lend insights in such cases. Recycling is another prediction that can be evaluated in the cases Clark mentions.

Franco proposes that the model predictions would be more difficult to evaluate in patchy environments under the premise that it would be hard to parse the relative contributions of natural and constructed resources. We agree that such application is more difficult, though, we think, not impossible. In fact, Garvey recognizes an elegant solution to this problem when she states that "our ability to identify anthropic niche construction in a heterogeneous environment hinges on the presence of two or more equally rich patches with notably unequal prehistoric use intensities." We can extend her notion to an approach that could take advantage of a larger range of environmental variation. Following an old game plan in archaeology (site-catchment analysis), one could derive estimates of environmental productivity in the foraging radii of each site in a study area. Under the assumption that environmental productivity ought to positively predict some measure of site size, the structure of variation in the residuals would suggest the presence or absence of feedback processes in the system. A residual distribution with low variance, such as one that can be approximated by a Poisson model, would suggest an absence of nonlinear feedback dynamics. A residual model with overdispersion, such as one that could be approximated by a gamma model, would suggest feedback dynamics and thus variation that is not readily predicted by the environment alone.

Garvey's analysis stands apart as the one commentary that extends our model. She explains variation in the probability of moving to lithic tools previously deposited on landscapesour $m$ term. She argues that not only is natural raw material availability important for the strength of preferential attach- ment to culturally deposited materials but also that this should interact with reliance on stone tools and the probability that discarded tools have remaining utility. She shows that there may be forces working in opposition such that the conditions where locating deposited cultural materials are the most difficult are the least likely to promote their deposition. Her rationale suggests that the degree of preferential attachment to previously discarded lithic tools - and thus the exponent of the power function - may be constant across environmental gradients. This is an intriguing observation that undermines our claim that raw material availability ought to predict the strength of preferential attachment. Garvey's extension gives us much to consider, though space does not permit further exploration here.

— Randall Haas and Steven L. Kuhn

\section{References Cited}

Aldenderfer, Mark S. 1998. Montane foragers: Asana and the south-central Andean archaic. Iowa City: University of Iowa Press.

Aldenderfer, Mark S., Edmundo De la Vega, and Cynthia J. Klink. 1996. Pedestrian and buried sites reconnaissance for early-to-late Preceramic archaeological sites in the Rio have drainage, southern Peru: a report submitted to the National Geographic Society on the 1995 field season of Proyecto Ch'amak Pacha. National Geographic Society Project No. 5245-94. Santa Barbara: University of California.

Ames, Kenneth M. 2008. The archaeology of rank. In Handbook of archaeological theories. R. Alexander Bentley and Hebert D. G. Maschner, eds. Pp. 487-513. Lanham, MD: AltaMira.

Andrews, Brian N., Jason M. LaBelle, and John D. Seebach. 2008. Spatial variability in the Folsom archaeological record: a multi-scalar approach. American Antiquity 73(3):464-490, doi:10.2307/25470500.

Bailey, G. N., and Nena Galanidou. 2009. Caves, palimpsests and dwelling spaces: examples from the Upper Palaeolithic of southeast Europe. World Archaeology 41:215-241. [BAS]

Baker, Paul A., Catherine A. Rigsby, Geoffrey O. Seltzer, Sherilyn C. Fritz, Tim K. Lowenstein, Niklas P. Bacher, and Carlos Veliz. 2001. Tropical climate changes at millennial and orbital timescales on the Bolivian Altiplano. Nature 409(6821):698-701, doi:10.1038/35055524.

Bankes, Steven C. 2002. Agent-based modeling: a revolution? Proceedings of the National Academy of Sciences of the USA 99:7199-7200.

Barkai, Ran, Cristina Lemorini, and Manuel Vaquero. 2015. The origins of recycling: a Paleolithic perspective. Quaternary International 361:1-3, doi: 10.1016/j.quaint.2014.12.044.

Basso, Keith H. 1984. "Stalking with stories": names, places, and moral narratives among the Western Apache. In Text, play, and story: the construction and reconstruction of self and society. E. M. Bruner, ed. Pp. 19-55. Washington, DC: American Ethnological Society.

. 1990. Western Apache language and culture: essays in linguistic anthropology. Tucson: University of Arizona Press. [AEC]

. 1996. Wisdom sits in places: landscape and language among the Western Apache. Albuquerque: University of New Mexico Press.

Batty, Michael. 2008. The size, scale, and shape of cities. Science 319(5864):769771, doi:10.1126/science.1151419.

Bell, Graham. 2001. Neutral macroecology. Science 293(5539):2413-2418, doi:10.1126/science.293.5539.2413.

Benfer, Robert A. 1999. Proyecto de Excavaciones en Paloma, valle de Chilca, Peru. Boletin de Arqueologia 3:213-237.

Bentley, R. Alexander, Matthew W. Hahn, and Stephen J. Shennan. 2004. Random drift and culture change. Proceedings of the Royal Society B: Biological Sciences 271(1547):1443-1450.

Bentley, R. Alexander, and Herbert D. G. Maschner. 2008. Complexity theory. In Handbook of archaeological theories. R. Alexander Bentley and Hebert D. G. Maschner, eds. Pp. 245-270. Lanham, MD: AltaMira.

Bettinger, Robert L., Raven Garvey, and Shannon Tushingham. 2015. Huntergatherers: archaeological and evolutionary theory. 2nd edition. New York: Springer. 
Binford, Lewis R. 1977. Forty-seven trips. In Stone tools as cultural markers. R. V. S. Wright, ed. Pp. 24-36. Canberra: Australian Institute of Aboriginal Studies. [NVF]

- 1980. Willow smoke and dogs' tails: hunter-gatherer settlement systems and archaeological site formation. American Antiquity 45(1):420 .

. 1982. The archaeology of place. Lournal of Anthropological Archaeology 1(1):5-31, doi:10.1016/0278-4165(82)90006-X.

1983. In pursuit of the past: decoding the archaeological record. New York: Thames \& Hudson. [BAS]

1990. Mobility, housing, and environment: a comparative study. Journal of Anthropological Research 46:119-152.

2001. Constructing frames of reference: an analytical method for ar chaeological theory building using hunter-gatherer and environmental data sets. Berkeley: University of California Press.

Bird, Douglas W., Rebecca Bliege Bird, Brian F. Codding, and Nyalangka Taylor. 2016. A landscape architecture of fire: cultural emergence and ecological pyrodiversity in Australia's Western Desert. Current Anthro pology 57(suppl.):S65-S79. [BAS]

Bird, Douglas W., and James F. O'Connell. 2006. Behavioral ecology and archaeology. Lournal of Archaeological Research 14(2):143-188.

Bliege Bird, Rebecca, Nyalangka Tayor, Brian F. Codding, and Douglas W. Bird. 2013. Niche construction and Dreaming logic: aboriginal patch mosaic burning and varanid lizards (Varanus gouldii) in Australia. Proceedings of the Royal Society B: Biological Sciences 280(1772):20132297, doi:10.1098 /rspb.2013.2297. [BAS]

Borrero, Lewis A. 1994-1995. Arqueología de la Patagonia. Palimpsesto: Revista de Arqueología y Antropología Anarquista 4:9-69. [NVF]

- 2011. The archaeology of transformation. Quaternary International 245:178-181. [NVF]

Borrero, Luis A., Ramiro Barberena, Fabiana M. Martín, and Karen Borrazzo. 2007. Collapsed rockshelters in Patagonia. In On shelter's ledge: histories, theories and methods of rockshelter research. Proceedings of the XV World Congress UISPP (Lisbon, 4-9 September 2006). M. Kornfeld, S. Vasil'ev, and L. Miotti, eds. Pp. 135-139. Oxford: Archaeopress. [NVF]

Bousman, C. Britt. 1993. Hunter-gatherer adaptations, economic risk and tool design. Lithic Technology 18(1/2):59-86. [NVF]

Boyd, R., and P. J. Richerson. 1985. Culture and the evolutionary process. Chicago: University of Chicago Press. [RLB]

Brantingham, P. Jeffrey. 2003. A neutral model of stone raw material procurement. American Antiauity 68(3):487-509.

- 2006. Measuring forager mobility. Current Anthropology 47(3):435459. [CM, MS]

Briones, Luis, and Carlos Mondaca. 2004. Conocimiento del medio ambiente, rutas de tráfico y representaciones rupestres de la quebrada de Suca: una interacción geocultural andina milenaria. Diálogo Andino 24:99-113. [CMS/CQ/DV]

Bronk Ramsey, Christopher. 2009. Bayesian analysis of radiocarbon dates. Radiocarbon 51(1):337-360. [MG]

. 2013. OxCal, version 4.2.3. Oxford: Research Lab for Archaeology, Oxford Radiocarbon Accelerator Unit. http://c14.arch.ox.ac.uk/.

Broughton, Jack M., Michael D. Cannon, and Eric J. Bartelink. 2010. Evolutionary ecology, resource depression, and niche construction theory: applications to Central California hunter-gatherers and Mimbres-Mogollon agriculturalists. Journal of Archaeological Method and Theory 17(4):371421, doi:10.1007/s10816-010-9095-7.

Brown, Clifford T., Larry S. Liebovitch, and Rachel Glendon. 2006. Lévy flights in Dobe Ju/'hoansi foraging patterns. Human Ecology 35(1):129-138, doi:10.1007/s10745-006-9083-4.

Brown, Clifford T., and Walter R. T. Witschey. 2003. The fractal geometry of ancient Maya settlement. Lournal of Archaeological Science 30(12):1619 1632, doi:10.1016/S0305-4403(03)00063-3.

Brown, Clifford T., Walter R. T. Witschey, and Larry S. Liebovitch. 2005. The broken past: fractals in archaeology. Journal of Archaeological Method and Theory 12(1):37-78, doi:10.1007/s10816-005-2396-6.

Bruno, Maria C. 2006. A morphological approach to documenting the domestication of Chenopodium in the Andes. In Documenting domestication new genetic and archaeological paradigms. Melinda A Zeder, Daniel G Bradley, Eve Emshwiller, and Bruce D Smith, eds. Pp. 32-45. Berkeley: University of California Press.

Buenger, Brent A., and Stacy R. Goodrick. 2017. Mid-Holocene hunter gatherers, housepits, and landscape reuse: Sweetwater River, Wyoming Plains Anthropologist 64:1-22, doi:10.1080/00320447.2017.1346947. [BAS]
Camilli, Eileen L., and James I. Ebert. 1992. Artifact reuse and recycling in continuous surface distributions and implications for interpreting land use patterns. In Space, time, and archaeological landscapes. Jacqueline Rossignol and LuAnn Wandsnider, eds. Pp. 113-136. New York: Plenum.

Castillo, C., and M. Sepúlveda. 2017. Objetos "miscelaneos" y dinámicas sociales en contextos cazadores recolectores de la precordillera de Arica, norte de Chile (área Centro-Sur andina). Chungara 49(2):159-174. [MS]

Christaller, Walter. 1966. Central places in southern Germany. Carlisle W. Baskin, trans. Englewood Cliffs, NJ: Prentice-Hall.

Cipolla, Lisa M. 2005. Preceramic period settlement patterns in the HuancanéPutina river valley, northern Titicaca Basin, Peru. In Advances in Titicaca Basin archaeology 1. Charles Stanish, Amanda B. Cohen, and Mark S. Aldenderfer, eds. Pp. 55-64. Los Angeles: Cotsen Institute of Archaeology at UCLA.

Clauset, Aaron, Cosma Rohilla Shalizi, and M. E. J Newman. 2009. Power-law distributions in empirical data. SIAM Review 51:1-43, doi:10.1137/070710111.

Codding, Brian F., and Terry L. Jones. 2013. Environmental productivity predicts migration, demographic, and linguistic patterns in prehistoric California. Proceedings of the National Academy of Sciences of the USA 110(36):14569-14573. [CM]

Collard, Mark, Briggs Buchanan, April Ruttle, and Michael J. O’Brien. 2011. Niche construction and the toolkit of hunter-gatherers and food producers. Biological Theory 6:251-259. [BAS]

Colombo, Mariano, and Nora Flegenheimer. 2013. La elección de rocas de colores por los pobladores tempranos de la región pampeana (Buenos Aires, Argentina). Nuevas consideraciones desde las canteras. Boletín del Museo Chileno de Arte Precolombino 18(1):125-137. [NVF]

Craig, Nathan M. 2011. Cultural dynamics, climate, and landscape in the south-central Andes during the Mid-Late Holocene: a consideration of two socio-natural perspectives. Chungará 43:367-391, doi:10.4067/S0717 $-73562011000300004$

Craig, Nathan M., Mark S. Aldenderfer, Paul Baker, and Catherine A. Rigsby. 2010. Terminal archaic settlement pattern and land cover change in the Rio Ilave, southwestern Lake Titicaca Basin, Peru. In The archaeology of anthropogenic environments. Rebecca M. Dean, ed. Center for Archaeological Investigations, Occasional Paper no. 37. Carbondale: Southern Illinois University Center for Archaeological Investigations.

Cribb, Roger. 1996. Shell mounds, ecosystem manipulation and domiculture on Western Cape York Peninsula. Tempus 4:150-174. [BAS]

Culkin, John M. 1967. A schoolman's guide to Marshall McLuhan. Saturday Review, March 18.

Drennan, Robert D., and Christian E. Peterson. 2004. Comparing archaeological settlement systems with rank-size graphs: a measure of shape and statistical confidence. Journal of Archaeological Science 31(5):533-549, doi: 10.1016/j.jas.2003.10.002.

Dunbar, R. I. M. 1998. The social brain hypothesis. Evolutionary Anthropology 6(5):178-190. [MG]

Edwards, Andrew M., Richard A. Phillips, Nicholas W. Watkins, Mervyn P. Freeman, Eugene J. Murphy, Vsevolod Afanasyev, Sergey V. Buldyrev, et al. 2007. Revisiting Lévy flight search patterns of wandering albatrosses, bumblebees and deer. Nature 449(7165):1044-1048, doi:10.1038/nature06199.

Eerkens, Jelmer W. 1999. Common pool resources, buffer zones, and jointly owned territories: hunter-gatherer land and resource tenure in Fort Irwin, southeastern California. Human Ecology 27(2):297-318. [CM]

. 2003. Residential mobility and pottery use in the Western Great Basin. Current Anthropology 44:728-738. [BAS]

Ellis, Christopher. 2011. Measuring Paleoindian range mobility and land-use in the Great Lakes/Northeast. Journal of Anthropological Archaeology 30:385-401. [NVF]

Elston, R. G., D. W. Zeanah, and B. F. Codding. 2014. Living outside the box: an updated perspective on diet breadth and sexual division of labor in the Prearchaic Great Basin. Quaternary International 352:200-211, doi:10.1016 /j.quaint.2014.09.064.

Favier Dubois, M. Cristian, and Luis A. Borrero. 2005. Playas de acreción: cronología y procesos de formación del registro arqueológico en la costa central de la bahía San Sebastián, Tierra del Fuego, Argentina. Magallania 33(2):93-108. [NVF]

Flannery, Kent V. 1998. The ground plans of archaic states. In Archaic states. Gary M. Feinman and Joyce Marcus, eds. Pp. 15-57. Santa Fe, NM: School of American Research Press.

Franco, Nora V., Luis A. Borrero, George A. Brook, and María Virginia Mancini. 2017. Changes in technological organization and human use of the space in the south of Patagonia (Argentina) during the Late Holocene. In Lithic technological organization and paleoenvironmental change: global 
and diachronic perspectives. E. Robinson and F. Sellet, eds. Pp. 301-320. New York: Springer. [NVF]

Fretwell, Stephen DeWitt, and Henry L. Lucas. 1969. On territorial behavior and other factors influencing habitat distribution in birds. Acta Biotheoretica 19:16-36. [CM]

Garvey, Raven, and Robert Bettinger. 2018. A regional approach to prehistoric landscape use in west-central Argentina. Journal of Archaeological Science 19:846-855. [RG]

Gorecki, Paul P. 1991. Horticulturalists as hunter gatherers: rock shelter usage in Papua New Guinea. In Ethnoarchaeological approaches to mobile campsites: hunter-gatherer case studies. Clive S. Gamble and William A. Boismier, eds. Pp. 237-262. Ann Arbor, MI: International Monographs in Prehistory. [BAS]

Griffin, Arthur F. 2011. Emergence of fusion/fission cycling and selforganized criticality from a simulation model of early complex polities. $\underline{\text { Jour- }}$ nal of Archaeological Science 38(4):873-883, doi:10.1016/j.jas.2010.11.017.

Griffin, Arthur F., and Charles Stanish. 2007. An agent-based model of prehistoric settlement patterns and political consolidation in the Lake Titicaca Basin of Peru and Bolivia. Structure and Dynamics: eJournal of Anthropological and Related Sciences 2(2):1-47.

Grøn, Ole. 2012. Our grandfather sent the elk: some problems for huntergatherer predictive modelling. Quartär 59:175-188.

Grove, Matt. 2009. Hunter-gatherer movement patterns: causes and constraints. Journal of Anthropological Archaeology 28(2):222-233, doi:10.1016/j.jaa.2009 .01 .003 .

- 2010. Logistical mobility reduces subsistence risk in hunting economies. Journal of Archaeological Science 37(8):1913-1921, doi:10.1016/j.jas .2010 .02 .017 .

- 2011. An archaeological signature of multi-level social systems: the case of the Irish Bronze Age. Iournal of Anthropological Archaeology 30(1):44-61, doi:10.1016/j.jaa.2010.12.002.

Haas, Randall, Cynthia J. Klink, Greg J. Maggard, and Mark S. Aldenderfer. 2015. Settlement-size scaling among prehistoric hunter-gatherer settlement systems in the New World. PLoS ONE 10(11):e0140127, doi:10.1371/journal.pone .0140127 .

Haas, Randall, Todd A. Surovell, and Matthew J. O'Brien. 2019. Dukha mobility in a constructed environment: prior camp use biases future use in the Mongolian Taiga. American Antiquity 84:215-233.

Haas, Randall, and Carlos Viviano Llave. 2015. Hunter-gatherers on the eve of agriculture: investigations at Soro Mik'aya Patjxa, Lake Titicaca Basin, Peru, 8000-6700 BP. Antiquity 89(348):1297-1312, doi:10.15184/aqy.2015.100.

Hahn, Matthew W., and R. Alexander Bentley. 2003. Drift as a mechanism for cultural change: an example from baby names. Proceedings of the Royal Society B: Biological Sciences 270(suppl.):S120-S123.

Hamilton, Marcus J., J. Lobo, E. Rupley, H. Youn and G. B. West. 2016. The ecological and evolutionary energetics of hunter-gatherer residential mobility. Evolutionary Anthropology 25:124-132. [MS]

Hamilton, Marcus J., Bruce T. Milne, Robert S. Walker, and James H. Brown. 2007. Nonlinear scaling of space use in human hunter-gatherers. Proceedings of the National Academy of Sciences of the USA 104(11):4765-4769, doi:10 $.1073 /$ pnas.0611197104.

Hamilton, Marcus J., Bruce T. Milne, Robert S. Walker, Oskar Burger, and James H. Brown. 2007. The complex structure of hunter-gatherer social networks. Proceedings of the Royal Society B: Biological Sciences 274(1622) 2195-2202.

Hevly, Richard H. 1983. High-altitude biotic resources, paleoenvironments, and demographic patterns: southern Colorado plateaus, A.D. 500-1400. In Cultural resource management: high altitude adaptations in the Southwest. J. C. Winter, ed. Pp. 22-40. Cultural Resource Management Report no. 2. Albuquerque, NM: United States Department of Agriculture, Forest Service, Southwestern Region. [CM]

Hietala, Harold J., and Dominique S. Stevens. 1977. Spatial analysis: multiple procedures in pattern recognition. American Antiquity 42:539-559. [NVF]

Hill, R. A., and R. I. M. Dunbar. 2003. Social network size in humans. Human Nature 14(1):53-72. [MG]

Holdaway, Simon J., LuAnn Wandsnider, and Ed Rhodes. 2008. Assemblage accumulation as a time-dependent process in the arid zone of New South Wales, Australia. In Time in archaeology: time perspectivism revisited. Simon J. Holdaway and LuAnn Wandsnider, eds. Pp. 110-132. Salt Lake City: University of Utah Press.

Holdaway, Simon J., Dan Witter, Patricia C. Fanning, Robert Musgrave, Grant Cochrane, Trudy Doelman, Simon Greenwood, Dan Pigdon, and Jamie Reeves. 1998. New approaches to open site spatial archaeology in
Sturt National Park, New South Wales, Australia. Archaeology in Oceania 33:1-19. [NVF]

Inomata, Takeshi, and Kazuo Aoyama. 1996. Central-place analyses in the La Entrada region, Honduras: implications for understanding the classic Maya political and economic systems. Latin American Antiquity 7(4):291-312, doi:10.2307/972261.

Jochim, Michael. 1976. Hunter-gatherer subsistence and settlement: a predictive model. New York: Academic Press.

. 1981. Strategies for survival: cultural behavior in an ecological context. New York: Academic Press.

Johnson, Gregory A. 1980. Rank-size convexity and system integration: a view from archaeology. Economic Geography 56(3):234-247.

Kelly, Robert L. 1983. Hunter-gatherer mobility strategies. Journal of Anthropological Research 39:277-306.

. 1995. The foraging spectrum: diversity in hunter-gatherer lifeways. Washington, DC: Smithsonian Institution Press. [NVF]

. 2013. The lifeways of hunter-gatherers: the foraging spectrum. Cambridge: Cambridge University Press.

Kelly, Robert L., Todd A. Surovell, Bryan N. Shuman, and Geoffrey M. Smith. 2013. A continuous climatic impact on Holocene human population in the Rocky Mountains. Proceedings of the National Academy of Sciences of the USA 110(2):443-447, doi:10.1073/pnas.1201341110.

Kendal, Jeremy, Jamshid J. Tehrani, and John Odling-Smee. 2011. Human niche construction in interdisciplinary focus. Philosophical Transactions of the Royal Society B: Biological Sciences 366(1566):785-792, doi:10.1098 /rstb.2010.0306.

Kimura, Motoo. 1985. The neutral theory of molecular evolution. Cambridge: Cambridge University Press.

Klink, Cynthia J. 2005. Archaic Period research in the Río Huenque Valley, Peru. In Advances in Titicaca Basin archaeology 1. Charles Stanish, Amanda B. Cohen, and Mark S. Aldenderfer, eds. Pp. 13-24. Los Angeles: Cotsen Institute of Archaeology at UCLA.

Klink, Cynthia J., and Mark S. Aldenderfer. 2005. A projectile point chronology for the south-central Andean Highlands. In Advances in Titicaca Basin archaeology 1. Charles Stanish, Amanda B. Cohen, and Mark S. Aldenderfer, eds. Pp. 25-54. Los Angeles: Cotsen Institute of Archaeology at UCLA.

Krugman, Paul. 1996. The self-organizing economy. Cambridge: Blackwell.

Kuhn, Steven L. 1995. Mousterian lithic technology: an ecological perspective. 1st edition. Princeton, NJ: Princeton University Press.

Kuhn, Steven L., David A. Raichlen, and Amy E. Clark. 2016. What moves us? how mobility and movement are at the center of human evolution. Evolutionary Anthropology 25(3):86-97, doi:10.1002/evan.21480.

LaBelle, Jason M. 2010. Reoccupation of place: Late Paleoindian land use strategies in the Central Plains. In Exploring variability in early Holocene hunter-gatherer lifeways. Stance Hurst and Jack L. Hofman, eds. Pp. 37-72. University of Kansas Publications in Anthropology no. 25. Lawrence: University of Kansas.

Laland, Kevin N., and Michael J. O’Brien. 2010. Niche construction theory and archaeology. Lournal of Archaeological Method and Theory 17(4):303322 .

Langlie, BrieAnna S., Natalie G. Mueller, Robert N. Spengler, and Gayle J. Fritz. 2014. Agricultural origins from the ground up: archaeological approaches to plant domestication. American Journal of Botany 101(10):1601-1617, doi:10 .3732/ajb.1400145.

Lansing, J. Stephen. 2003. Complex adaptive systems. Annual Review of Anthropology 32:183-204.

Lansing, J. Stephen, and Sean S. Downey. 2011. Complexity and anthropology. In Philosophy of complex systems, vol. 10 of Handbook of the philosophy of science. Cliff Hooker, ed. Pp. 569-601. Amsterdam: North-Holland.

Larson, Mary Lou, Marcel Kornfeld, and George C. Frison. 2009. Hell gap: a stratified Paleoindian campsite at the edge of the Rockies. Salt Lake City: University of Utah Press.

Lehmann, J., P. C. Lee, and R. I. M. Dunbar. 2014. Unravelling the evolutionary function of communities. In Lucy to language: the benchmark papers. R. I. M. Dunbar, C. S. Gamble, and J. A. J. Gowlett, eds. Oxford: Oxford University Press. [MG]

Lewontin, Richard. 1983. Gene, organism and environment. In Evolution from molecules to men. D. S. Bendall, ed. Pp. 273-286. Cambridge: Cambridge University Press. [RG]

Lyman, R. Lee. 2004. The concept of equifinality in taphonomy. Journal of Taphonomy 2(1):15-26.

Martínez, Gustavo, and Gustavo A. Martínez. 2011. Late Holocene environmental dynamics in fluvial and eolian depositional settings: archaeological 
record variability at the lower basin of the Colorado River (Argentina). Quaternary International 245(1):89-102. [NVF]

Martínez-Tagüeña, Natalia, and Luz Alicia Torres Cubillas. 2018. Walking the desert, paddling the sea: Comcaac mobility in time. Journal of Anthropological Archaeology 49:146-160. [AEC]

McBryde, Isabel. 1987. Goods from another country: exchange networks and the people of the Lake Eyre Basin. In Australians to 1788. D. J. Mulvaney and J. P. White, eds. Pp. 252-273. Broadway, NSW: Fairfax, Syme \& Weldon. $[\mathrm{CMS} / \mathrm{CQ} / \mathrm{DV}]$

Mena, Francisco, Víctor Lucero, Omar Reyes, Valentina Trejo, and Héctor Velásquez. 2000. Cazadores tempranos y tardíos en la cueva Baño Nuevo 1 margen occidental de la estepa centropatagónica (XI Región de Aisén, Chile). Anales del Instituto de la Patagonia (Serie Ciencias Humanas) 28:173-196. [NVF]

Meltzer, David J. 1989. Was stone exchanged among eastern North American Paleoindians? In Eastern Paleoindian lithic resource use. C. J. Ellis and J. Lothrop, eds. Pp. 11-39. Boulder, CO: Westview. [NVF]

Méndez, César, Donald Jackson, Roxana Seguel, and Amalia Nuevo Delaunay. 2010. Early high-quality lithic procurement in the semiarid north of Chile. Current Research in the Pleistocene 27:19-21. [NVF]

Minc, Leah D. 1986. Scarcity and survival: the role of oral tradition in mediating subsistence crises. Journal of Anthropological Archaeology 5:39-113. [BAS]

Minc, Leah D., and Kevin P. Smith. 1989. The spirit of survival: cultural responses to resource variability in north Alaska. In Bad year economics: cultural responses to risk and uncertainty. Paul Halstead and John O'Shea, eds. Pp. 8-39. Cambridge: Cambridge University Press. [BAS]

Mitchell, Peter, Ina Plug, and Geoff Bailey. 2008. Spatial patterning and site occupation at Likoaeng, an open-air hunter-gatherer campsite in the Lesotho Highlands, southern Africa. Archeological Papers of the American Anthropological Association 16(1):81-94, doi:10.1525/ap3a.2006.16.1.81.

Mitchell, Peter, Ina Plug, Geoff Bailey, Ruth Charles, Amanda Esterhuysen, Julia Lee Thorp, Adrian Parker, and Stephan Woodborne. 2011. Beyond the drip-line: a high-resolution open-air Holocene hunter-gatherer sequence from highland Lesotho. Antiquity 85(330):1225-1242.

Mitzenmacher, Michael. 2001. A brief history of generative models for power law and lognormal distributions. Proceedings of the Annual Allerton Conference on Communication Control and Computing 39:182-191.

Morgan, Christopher. 2009a. Climate change, uncertainty and prehistoric hunter-gatherer mobility. Journal of Anthropological Archaeology 28(4):382396, doi:10.1016/j.jaa.2009.07.004.

2009b. Optimal foraging patterns in the southern Sierra Nevada. California Archaeology 1(2):205-226. [CM]

Morgan, Christopher, Dallin Webb, Kari Sprengeler, Marielle Black, an Nicole D. George. 2018. Experimental construction of hunter-gathere residential features and the costs of occupying "persistent places." Iournal of Archaeological Science 91:65-76. [CM]

Murdock, G. P. 1949. Social structure. New York: Macmillan. [MG]

Nadel, Dani, Ehud Weiss, Orit Simchoni, Alexander Tsatskin, Avinoam Danin, and Mordechai Kislev. 2004. Stone Age hut in Israel yields world's oldest evidence of bedding. Proceedings of the National Academy of Sciences of the USA 101(17):6821-6826. [BAS]

Nelson, Margaret C. 1991. The study of technological organization. In Ar chaeological method and theory, vol. 3. Michael Schiffer, ed. Pp. 57-100. Tucson: University of Arizona Press. [NVF]

Newman, M. E. J. 2005. Power laws, Pareto distributions and Zipf's law. Contemporary Physics 46(5):323-351, doi:10.1080/00107510500052444.

Odling-Smee, F. John. 1988. Niche constructing phenotypes. In The role of behavior in evolution. H. C. Plotkin, ed. Pp. 73-132. Cambridge, MA: MIT Press. [RG]

Odling-Smee, F. John, Kevin N. Laland, and Marcus W. Feldman. 2003. Niche construction. the neglected process in evolution. Princeton, NJ: Princeton University Press. [NVF]

Oetelaar, Gerald A., and D. Joy Oetelaar. 2011. The structured world of the Niitsitapi: the landscape as historical archive among hunter-gatherers of the Northern Plains. In Structured worlds: the archaeology of hunter-gatherer thought and action. Aubrey Cannon, ed. Pp. 69-94. London: Routledge. [AEC]

Ortmann, Anthony L. 2010. Placing the poverty point mounds in their temporal context. American Antiauity 75(3):657-678.

Osorio, D., J. Steele, M. Sepúlveda, J. Capriles, E. Gayó, K. Herrera, P. Ugalde, R. De Pol-Holz, C. Latorre, and C. Santoro. 2017. The Dry Puna as an ecological megapatch and the peopling of South America: technology, mobility, and the development of a Late Pleistocene/early Holocene Andean hunter-gatherer tradition in northern Chile. Quaternary International 461:41-53. [MS]

Parker, Adrian G., Julia Lee-Thorp, and Peter J. Mitchell. 2011. Late Holocene Neoglacial conditions from the Lesotho highlands, southern Africa: phytolith and stable carbon isotope evidence from the archaeological site of Likoaeng. Proceedings of the Geologists' Association 122:201-211. [BAS]

Paynter, Robert. 1982. Models of spatial inequality: settlement patterns in historical archeology. New York: Academic Press.

Perthame, Benoit. 2004. PDE models for chemotactic movements: parabolic, hyperbolic and kinetic. Applications of Mathematics 49(6):539-564. [CMS/ $\mathrm{CQ} / \mathrm{DV}]$

Peterson, Nicolas. 1968. The pestle and mortar: an ethnographic analogy for archaeology in Arnhem Land. Mankind 6:567-570. [BAS]

. 1973. Camp site location amongst Australian hunter-gatherers: archaeological and ethnographic evidence for a key determinant. Archaeology and Physical Anthropology in Oceania 6:173-193. [BAS]

Plug, Ina, Peter Mitchell, and Geoff Bailey. 2010. Late Holocene fishing strategies in southern Africa as seen from Likoaeng, highland Lesotho. Journal of Archaeological Science 37:3111-3123. [BAS]

Politis, Gustavo. 2007. Nukak: ethnoarchaeology of an Amazonian people. Walnut Creek, CA: Left Coast Press. [BAS]

Premo, Luke S. 2006. Agent-based models as behavioral laboratories for evolutionary anthropological research. Arizona Anthropologist 17:91-113.

R Core Team. 2013. R: a language and environment for statistical computing. Vienna: R Foundation for Statistical Computing. http://www.R-project.org/.

Reimer, Paula. 2013. Intcal13 and Marine13 radiocarbon age calibration curves 0-50,000 years cal BP. Radiocarbon 55(4):1869-1887, doi:10.2458 /azu_js_rc.55.16947.

Richerson, Peter J. 2019. An integrated Bayesian theory of phenotypic flexibility. Behavioural Processes 161:54-64.

Richerson, Peter J., and Robert Boyd. 1992. Cultural inheritance and evolutionary ecology. In Evolutionary ecology and human behavior. E. A. Smith and B. Winterhalder, eds. Pp. 61-92. New York: Aldine de Gruyter. $[\mathrm{CM}]$

2005. Not by genes alone: how culture transformed human evolution. Chicago: University of Chicago Press. [RLB]

Riede, Felix. 2011. Adaptation and niche construction in human prehistory: a case study from the southern Scandinavian Late Glacial. Philosophical Transactions of the Royal Society B: Biological Sciences 366(1566):793-808. [BAS]

Riel-Salvatore, Julien. 2010. A niche construction perspective on the MiddleUpper Paleolithic transition in Italy. Journal of Archaeological Method and Theory 17:323-355. [BAS]

Riel-Salvatore, Julien, and Fabio Negrino. 2018. Proto-Aurignacian lithic technology, mobility, and human niche construction: a case study from Riparo Bombrini, Italy. In Lithic technological organization and paleoenvironmental change: global and diachronic perspectives. Erich Robinson and Frédéric Sellet, eds. Pp. 163-188. Cham, Switzerland: Springer. [BAS]

Rigsby, Catherine A., Paul A. Baker, and Mark S. Aldenderfer. 2003. Fluvial history of the Rio Ilave Valley, Peru, and its relationship to climate and human history. Palaeogeography, Palaeoclimatology, Palaeoecology 194(1-3):165-185.

Rindos, David. 1983. The origins of agriculture: an evolutionary perspective. New York: Academic Press.

Rockman, Marcy. 2003. Knowledge and learning in the archaeology of colonization. In Colonization of unfamiliar landscapes: the archaeology of adaptation. Marcy Rockman and James Steele, eds. Pp. 3-24. London: Routledge. [BAS]

Rowley-Conwy, Peter, and Robert Layton. 2011. Foraging and farming as niche construction: stable and unstable adaptations. Philosophical Transactions of the Royal Society B: Biological Sciences 366(1566):849-862. [BAS]

Salazar, Noel B., and Alan Smart. 2011. Anthropological takes on (im)mobility. Identities 18(6): i-ix, doi:10.1080/1070289X.2012.683674.

Saunders, Joe W., Rolfe D. Mandel, C. Garth Sampson, Charles M. Allen, E. Thurman Allen, Daniel A. Bush, James K. Feathers, et al. 2005. Watson Brake, a Middle Archaic mound complex in northeast Louisiana. American Antiauity 70(4):631-668, doi:10.2307/40035868.

Saunders, Joe W., Rolfe D. Mandel, Roger T. Saucier, E. Thurman Allen, C. T. Hallmark, Jay K. Johnson, Edwin H. Jackson, et al. 1997. A mound complex in Louisiana at 5400-5000 years before the present. Science 277(5333): 1796-1799, doi:10.1126/science.277.5333.1796.

Schiffer, Michael B. 1975. An alternative to Morse's Dalton Settlement pattern hypothesis. Plains Anthropologist 20(70):253-266.

1987. Formation processes of the archaeological record. 1st ed. Albuquerque: University of New Mexico Press. 
Schlanger, Sarah H. 1992. Recognizing persistent places in Anasazi Settlement systems. In Space, time, and archaeological landscapes. Jacqueline Rossignol and LuAnn Wandsnider, eds. Pp. 91-112. New York: Plenum.

Smith, Bruce D. 2001. Low-level food production. Lournal of Archaeological Research 9(1):1-43.

. 2015. A comparison of niche construction theory and diet breadth models as explanatory frameworks for the initial domestication of plants and animals. Journal of Archaeological Research 23:215-262. [NVF]

Smith, Craig S., and Lance M. McNees. 2011. Persistent land use patterns and the mid-Holocene housepits of Wyoming. Journal of Field Archaeology 36:298 311. [BAS]

Smith, Eric Alden. 1981. The relationship between northern Athabaskan Settlement patterns and resource distribution: an application of Horn's model. In Hunter-gatherer foraging strategies: ethnographic and archeological analyses. Bruce Winterhalder and Eric Alden Smith, eds. Pp. 126-147. Chicago: University of Chicago Press.

Stanish, Charles. 2003. Ancient Titicaca: the evolution of complex society in southern Peru and northern Bolivia. Berkeley: University of California Press.

Stewart, Brian A., and Peter J. Mitchell. 2018. Beyond the shadow of a desert: aquatic resource intensification on the roof of southern Africa. In Foraging in the past: archaeological studies of hunter-gatherer diversity. Ashley $\mathrm{K}$. Lemke, ed. Pp. 159-208. Boulder: University Press of Colorado. [BAS]

Stewart, Brian A., John Parkington, and John W. Fisher Jr. 2011. The tortoise and the ostrich egg: projecting the home base hypothesis into the 21st century. In Casting the net wide: papers in honor of Glynn Isaac and his approach to human origins research. Jeanne Sept and David Pilbeam, eds. Pp. 254-278. Cambridge, MA: American School of Prehistoric Research. [BAS]

Stiger, Mark. 2001. Hunter-gatherer archaeology of the Colorado high country. Boulder: University Press of Colorado.

Stiner, Mary C., and Steven L. Kuhn. 2016. Are we missing the "sweet spot" between optimality theory and niche construction theory in archaeology? Lournal of Anthropological Archaeology 44:177-184.

Surovell, Todd A., and Matthew O'Brien. 2016. Mobility at the scale of meters. Evolutionary Anthropology: Issues, News, and Reviews 25(3):142-152, doi 10.1002/evan.21487.

Thomas, David Hurst. 1972. A computer simulation model of Great Basin Shoshonean subsistence and settlement patterns. In Models in archaeology. David L. Clarke, ed. Pp. 671-704. London: Methuen.

. 1973. An empirical test for Steward's model of Great Basin settlement patterns. American Antiquity 38(2):155-176, doi:10.2307/279362.

Tindale, Norman. 1972. Hunters and gatherers today: a socioeconomic study of eleven such cultures in the twentieth century. In Hunters and gatherers today: a socioeconomic study of eleven such cultures in the twentieth century. Marco G. Bicchieri, ed. Pp. 217-268. New York: Holt, Rinehart \& Winston

Tomasso, A., and G. Porraz. 2016. Hunter-gatherer mobility and embedded raw-material procurement strategies in the Mediterranean Upper Paleolithic. Evolutionary Anthropology 25:164-174. [MS]

Turnbull, Colin M. 1968. The importance of flux in two hunting societies. In Man the hunter. Richard B Lee and Irven DeVore, eds. Pp. 132-137. Chicago: Aldine.
Vaquero, Manuel, Susana Alonso, Sergio García-Catalán, Angélica GarcíaHernández, Bruno Gómez de Soler, David Rettig, and Maria Soto. 2012. Temporal nature and recycling of Upper Paleolithic artifacts: the burned tools from the Molí del Salt site (Vimbodí i Poblet, northeastern Spain). Journal of Archaeological Science 39:2785-2796. [BAS]

Wandsnider, LuAnn. 1992. The spatial dimension of time. In Space, time, and archaeological landscapes. Jacqueline Rossignol and LuAnn Wandsnider, eds. Pp. 257-282. New York: Plenum.

2008. Time averaged deposits and multitemporal processes in the Wyoming Basin, intermontane North America: a preliminary consideration of land tenure in terms of occupation frequency and integration. In Time in archaeology: time perspectivism revisited. Simon J. Holdaway and LuAnn Wandsnider, eds. Pp. 61-93. Salt Lake City: University of Utah Press. [BAS]

Whallon, Robert. 2011. An introduction to Information and its role in huntergatherer bands. In Information and its role in hunter-gatherer bands. Robert Whallon, William A. Lovis, and Robert K. Hitchcock, eds. Pp. 1-27. Los Angeles: Cotsen Institute of Archaeology Press. [BAS]

. 2016. Marked sacred places of hunter-gatherer bands. In Marking the land: hunter-gatherer creation of meaning in their environment. William A. Lovis and Robert Whallon, eds. Pp. 263-275. New York: Routledge. [BAS]

Wilensky, U. 1999. NetLogo, ver. 4.1. Evanston, IL: Center for Connected Learning and Computer-Based Modeling, Northwestern University. http:// ccl.northwestern.edu/netlogo/.

Williams, L., R. L. Bettinger, and D. H. Thomas. 1973. Notions to numbers: Great Basin settlements as polythetic sets. In Research and theory in current archaeology. C. Redman, ed. Pp. 215-237. New York: J. Wiley. [RLB]

Wilson, E. O. 1998. Consilience: the unity of knowledge. New York: Knopf.

Winterhalder, Bruce, Douglas J. Kennett, Mark N. Grote, and Jacob Bartruff. 2010. Ideal free settlement of California's Northern Channel Islands. Iournal of Anthropological Archaeology 29(4):469-490, doi:10.1016/j.jaa.2010.07 .001 .

Winterhalder, Bruce, and R. Brooke Thomas. 1978. Geoecology of Southern Highland Peru: a human adaptation perspective. Boulder: Institute of Arctic and Alpine Research, University of Colorado.

Woodburn, James. 1968. Stability and flexibility in Hadza residential groupings. In Man the hunter. Richard B Lee and Irven DeVore, eds. Pp. 103-117. Chicago: Aldine.

Yellen, John. 1977. Archaeological approaches to the present: models for reconstructing the past. New York: Academic Press.

Zeanah, David W. 2002. Central place foraging and prehistoric pinyon utilization in the Great Basin. In Beyond foraging and collecting: evolutionary change in hunter-gatherer settlement systems. Ben Fitzhugh, ed. Pp. 231256. New York: Kluwer Academic/Plenum.

- 2004. Sexual division of labor and central place foraging: a model for the Carson Desert of Western Nevada. Journal of Anthropological Archaeology 23(1):1-32, doi:10.1016/S0278-4165(03)00061-8.

. 2017. Foraging models, niche construction, and the eastern agricultural complex. American Antiauity 82:3-24. [BAS]

Zipf, George Kingsley. 1949. Human behavior and the principle of least effort: an introduction to human ecology. Cambridge: Addison-Wesley. 